\title{
CARACTERIZAÇÃO SILVICULTURAL, BOTÂNICA E TECNOLÓGICA DO Eucalyptus urophylla S. T. BLAKE E DE SEU POTENCIAL PARA UTILIZAÇÃO EM SERRARIA.
}

\section{LAERTE SCANAVACA JUNIOR}

\author{
Dissertação apresentada à Escola \\ Superior de Agricultura "Luiz de \\ Queiroz", da Universidade de São \\ Paulo, para obtenção do título de Mestre \\ em Ciências, Área de Concentração: \\ Ciências Florestais
}

PIRACICABA

Estado de São Paulo - Brasil

Dezembro-2001 


\title{
CARACTERIZAÇÃO SILVICULTURAL, BOTÂNICA E TECNOLÓGICA DO Eucalyptus urophylla S. T. BLAKE E DE SEU POTENCIAL PARA UTILIZAÇÃO EM SERRARIA.
}

\author{
LAERTE SCANAVACA JUNIOR \\ Engenheiro Florestal
}

Orientador: Prof. Dr. JOSÉ NIVALDO GARCIA

Dissertação apresentada à Escola Superior de Agricultura "Luiz de Queiroz", da Universidade de São Paulo, para obtenção do título de Mestre em Ciências, Área de Concentração: Ciências Florestais

PIRACICABA

Estado de São Paulo - Brasil

Dezembro - 2001 
Dados Internacionais de Catalogação na Publicação (CIP) DIVISÃO DE BIBLIOTECA E DOCUMENTAÇÃO - ESALQ/USP

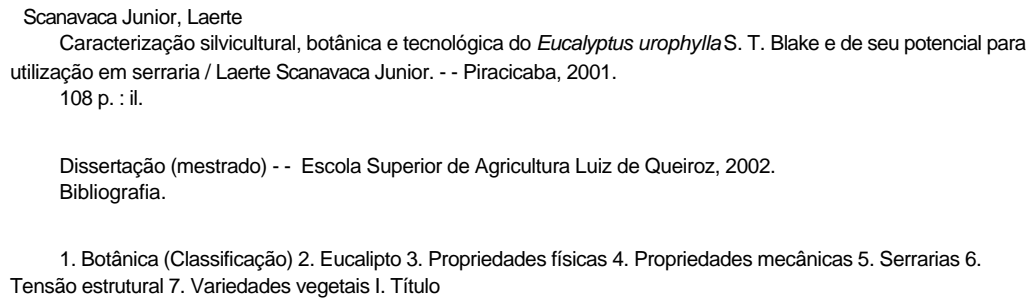

"Permitida a cópia total ou parcial deste documento, desde que citada a fonte - $\mathrm{O}$ autor" 


\section{AGRADECIMENTOS}

Aos meus pais pelo incentivo carinho e compreensão e pela formação pessoal.

Ao Prof. Dr. José Nivaldo Garcia, pela orientação e confiança.

Ao Prof. Dr. Mario Ferreira pelas sugestões, colaboração, amizade e acima de tudo pela exemplo de vida.

Ao Prof. Dr. Antonio Augusto Franco Garcia, amigo e colaborador, pelas sugestões e criticas construtivas.

Ao amigo Luiz Eduardo Facco, pela inestimável colaboração.

Ao técnico de laboratório e amigo Udemilson Luiz Ceribeli, pelas análises.

Ao amigo Paulo Sérgio Beraldo, pela colaboração.

Ao Setor de Sementes do IPEF, em especial ao amigo Israel Gomes Vieira.

Aos colegas e amigos de turma em especial à Maria de Fatima Christe Adorno, pelas criticas, sugestões e estimulo.

A FAPESP (Fundação de Amparo à Pesquisa do Estado de São Paulo).

A todos que direta e indiretamente colaboraram com a realização deste trabalho. 


\section{SUMÁRIO}

Página

LISTA DE FIGURAS..................................................................... vi

LISTA DE TABELAS........................................................................... viii

LISTA DE SIGLAS, ABREVIATURAS E SÍMBOLOS................................ xii

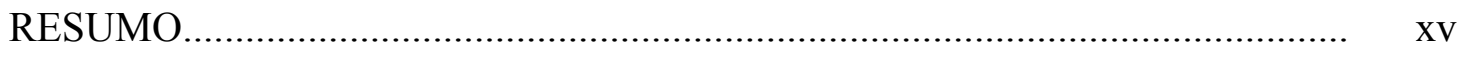

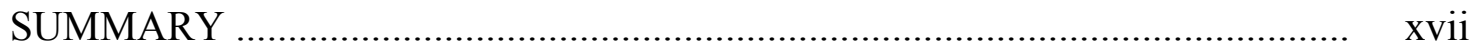

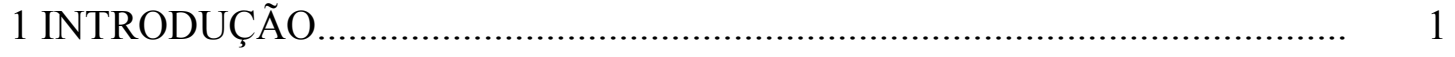

2 REVISÃO DE LITERATURA............................................................... 3

2.1 Descrição da espécie.............................................................................. 3

2.2 Centro de origem ........................................................................... 3

2.3 Comportamento ecológico, silvicultural e botânico....................................... 6

2.4 Teste de procedências/progênies............................................................... 8

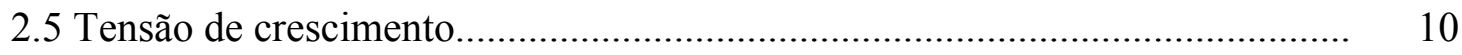

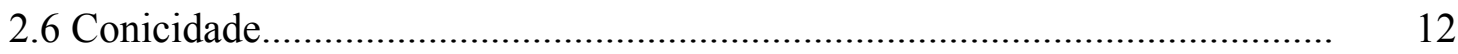

2.7 Rendimento em madeira serrada.......................................................... 12

2.8 Propriedades físicas e mecânicas da madeira............................................... 13

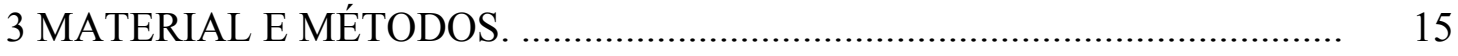

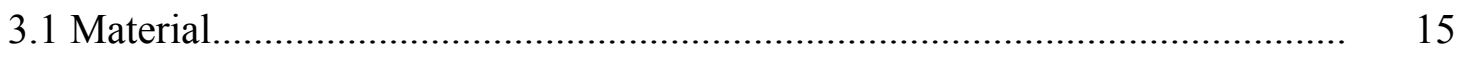

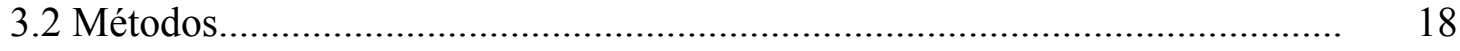

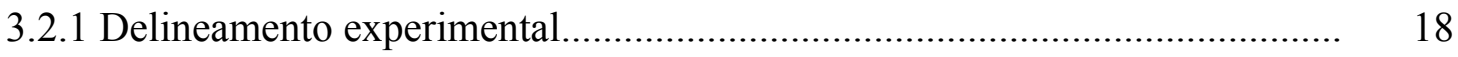

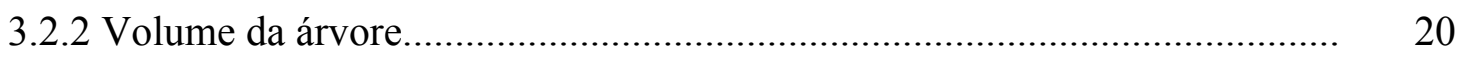

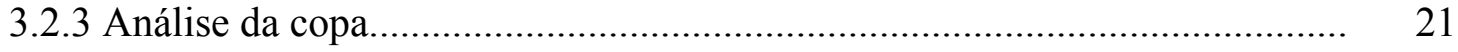

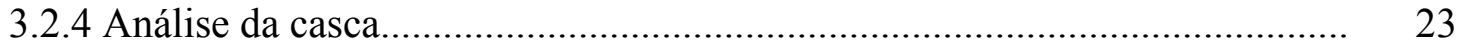


3.2.5 Análises da Folha.................................................................................. 25

3.2.6 Análises do Fruto................................................................................... 26

3.2.7 Rachaduras de extremidades de tora........................................................ 30

3.2.8 Desdobro das toras ............................................................................... 31

3.2.9 Rachaduras das tábuas e da prancha central ............................................... 33

3.2.10 Volume da tora................................................................................

3.2.11 Volume das tábuas e perdas em rendimento ............................................... 34

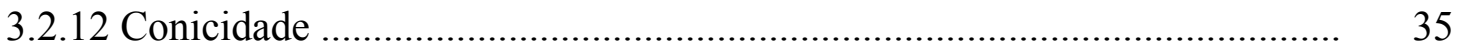

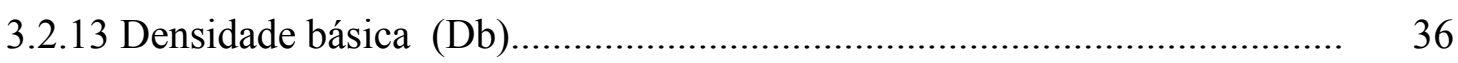

3.2.14 Retratibilidade ………………………………............................... 36

3.2.15 Resistência ao Cisalhamento tangencial aos anéis de crescimento (Fs)

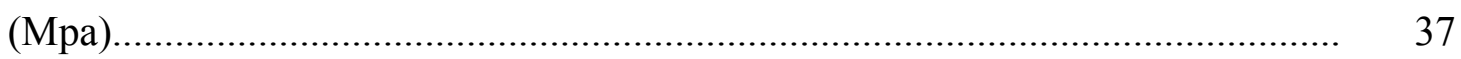

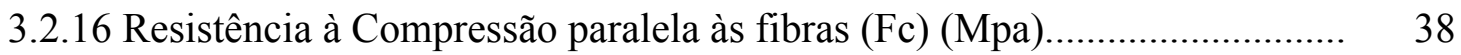

3.2.17 Resistência à Flexão estática $(\mathrm{Ff})(\mathrm{Mpa})$ e módulo de elasticiadade na flexão estática (Ef) (Mpa)............................................................................... 38

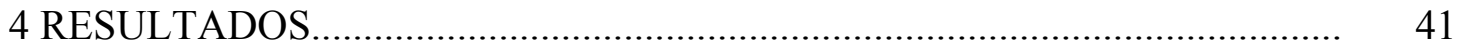

4.1 Análise silvicultural do ensaio ................................................................... 41

4.2 Análise silvicultural das progênies selecionadas ............................................ 45

4.3 Análise da folha..................................................................................... 48

4.4 Análise do fruto..................................................................................... 55

4.5 Rachaduras de extremidades de tora e conicidade ........................................... 63

4.6 Rachaduras de extremidades da tábua.............................................................. 65

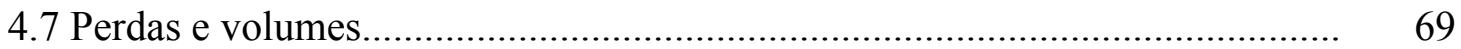

4.8 Propriedades físicas da madeira ……………………………………........ 72

4.9 Propriedades mecânicas da madeira............................................................... $\quad 76$

4.10 Correlações entre as características Quantitativas analisadas......................... 77

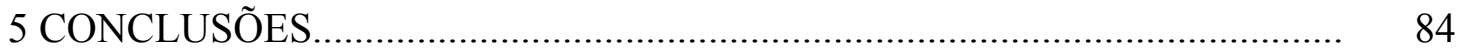

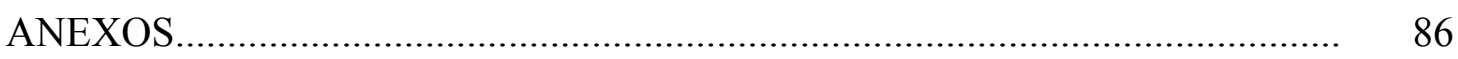

REFERÊNCIAS BIBIOGRÁFICAS ………………………………………….... 96 


\section{LISTA DE FIGURAS}

Página

1 Localização da Indonésia............................................................. 5

$2 \quad$ Ilha Flores. .................................................................................. 6

3 Visão microscópica de uma célula vegetal, mostrando a orientação das microfibrilas nas várias camadas da parede celular.............................. 11

$4 \quad$ Copa aberta de E. urophylla ......................................................... 21

$5 \quad$ Copa fechada de E. urophylla ...................................................... 22

$6 \quad$ Casca lisa (A) e rugosa (B) de E. urophylla ...................................... 23

$7 \quad$ Árvore tipo meia casca de E. urophylla ............................................ 24

8 Variáveis da folha do E. urophylla (Pryor et al., 1995), em que: $\mathrm{L} 1$ = Comprimento da folha; $\mathrm{L} 2$ = Comprimento do pecíolo; L3 = Comprimento da cauda ou expansão da nervura e do limbo; $\mathrm{W}=$ Maior largura da folha.

9 Forma da folha, baseado em Penfold \& Willis (1961) e Brooker e Kleinig (1983), em que: $\mathrm{A}=$ Linear; $\mathrm{B}=$ Lanceolada estreita; $\mathrm{C}=$ Lanceolada; $\mathrm{D}=$ Lanceolada estreita oblonga; $\mathrm{E}=$ Lanceolada larga; $\mathrm{F}=$ Lanceolada ovóide; $\mathrm{G}=$ Ovóide; $\mathrm{H}=$ Elíptica; $\mathrm{I}=$ Orbicular; $\mathrm{J}=$ Oblonga; $\mathrm{K}=$ Margem crenada; $\mathrm{L}=$ Falcada; $\mathrm{M}=$ Obliqua; $\mathrm{N}=$ Cordiforme....................................................... 26

10 Componentes do fruto, baseado em Goes (1985).............................. 27

11 Variáveis quantitativas do fruto, baseado em Pryor et al., (1995), em que: $\mathrm{L} 1$ = Comprimento do fruto; L2 = Comprimento do pedicelo e $\mathrm{W}=$ Diâmetro do fruto. 
12 Posição do disco do anel estaminal, baseado em Brooker \& Kleinig (1983), em que: $\mathrm{A}=$ Rasante ou nivelado; $\mathrm{B}=$ Saliente $\mathrm{e}$ $\mathrm{C}=$ Incluso.

13 Posição das valvas, baseado em Brooker \& Kleinig (1983), em que: $\mathrm{A}=$ Incluso $; \mathrm{B}=$ Rasante ou nivelado e $\mathrm{C}=$ Saliente..

14 Forma do fruto (receptáculo), baseado em Penfold \& Willis (1961) e Brooker \& Kleinig (1983), em que: A = Oblongo; B = Cilíndrico; $\mathrm{C}=$ Barril $; \mathrm{D}=$ Urceolado $\mathrm{E}=$ Ovóide $; \mathrm{F}=$ Ovóide truncado; $\mathrm{G}=$ Globular; $\mathrm{H}=$ Globular truncado; $\mathrm{I}=$ Hemisférico; $\mathrm{J}$ e $\mathrm{K}=$ Amplamente cônico; $\mathrm{L}$ = Campanulado; $\mathrm{M}$ = Periforme; $\mathrm{N}$ e $\mathrm{O}=$ Cônico e $\mathrm{P}=$ Quadrangular.

15 Rachaduras de extremidades de tora..................................................... 30

16 Desdobro da tora em serra de fita simples............................................ 32

17 Rachadura de extremidade de tábua........................................................ 33

18 Corpo de prova do ensaio de cisalhamento. .......................................... 37

19 Tipo de casca dentro de procedência. ..................................................... 42

20 Tipo de copa dentro de procedência. ...................................................... 46

21 Variação radial da abertura da rachaduras de extremidade de tábua...... 68

22 Variação radial do comprimento da rachadura de extremidade de tábua $\quad 69$ 


\section{LISTA DE TABELAS}

Página

1 Caracterização das Procedências......................................................... 16

2 Caracterização do material selecionado................................................. 17

3 Esquema de análise de variância para as progênies selecionadas........... 20

4 Pesos atribuídos as diferentes classes de comprimento das rachaduras.. $\quad 30$

5 Resumo da análise de variância para a raiz quadrada do DAP $(\sqrt{D A P})$, raiz quadrada da altura $(\sqrt{\text { Altura }})$ e raiz quadrada do

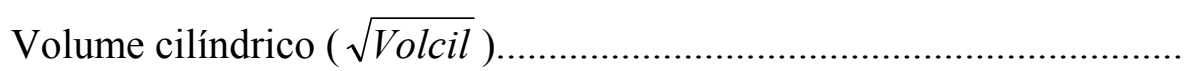

6 Tipo de casca, número de observações em porcentagem (N\%), DAP (m), altura $(\mathrm{m})$ e volume cilíndrico $\left(\mathrm{m}^{3}\right)$, com os respectivos coeficientes de variação em porcentagem $(\mathrm{CV} \%)$...............................

7 Tipo de copa, número de observações em porcentagem (N\%), DAP $(\mathrm{m})$, altura $(\mathrm{m})$ e volume cilíndrico $\left(\mathrm{m}^{3}\right)$, com os respectivos coeficientes de variação em porcentagem $(\mathrm{CV} \%)$................................

8 Resumo da análise de variância do DAP (m), altura (m) e volume cilíndrico $\left(\mathrm{m}^{3}\right)$ das progênies selecionadas........................................... 46

9 Tipo de casca, número de observações em porcentagem (N\%), DAP $(\mathrm{m})$, altura $(\mathrm{m})$ e volume cilíndrico $\left(\mathrm{m}^{3}\right)$, com os respectivos coeficientes de variação em porcentagem (CV \%)..............................

10 Tipo de copa, número de observações em porcentagem (N\%), DAP $(\mathrm{m})$, altura $(\mathrm{m})$ e volume cilíndrico $\left(\mathrm{m}^{3}\right)$, com os respectivos coeficientes de variação em porcentagem $(\mathrm{CV} \%)$ 
11 Tratamento (Trat), freqüência da forma da folha (Letras de acordo com a Figura 9), razão entre o comprimento (L1) e a largura (W) da folha e sua amplitude de variação

12 Tratamento (Trat), média e amplitude de variação do comprimento do pecíolo (Comp pecíolo), comprimento da folha, largura da folha e comprimento da cauda (Comp cauda).

13 Resumo da análise de variância para o comprimento do pecíolo (Comp pecíolo), logaritmo (base 10) do comprimento da folha (Log comp folha), raiz quadrada da largura da folha $(\sqrt{\text { Larfolha }})$, raiz quadrada do comprimento da cauda $(\sqrt{\text { Compcaulda }})$ e o inverso da raiz quadrada da razão $\mathrm{L} 1 / \mathrm{W}(1 / \sqrt{L 1 / w})$

14 Média do tratamentos (Trat) para o comprimento do pecíolo (Comp pecíolo), logaritmo (base 10) do comprimento da folha (Log comp folha), raiz quadrada da largura da folha $(\sqrt{\text { Larfolha }})$ e raiz quadrada do comprimento da cauda $(\sqrt{\text { Compcaulda }})$.

15 Número de frutos por infrutescência (\%)

16 Freqüência da posição do disco (\%) (A = Rasante ou nivelado; $\mathrm{B}=$ Saliente e $\mathrm{C}=$ Incluso), número de valvas por fruto (\%) e freqüência da posição da valva (\%) (A = Incluso; $\mathrm{B}=$ Rasante ou nivelado e $\mathrm{C}=$ Saliente)

17 Freqüência da forma do fruto (\%).

18 Médias e amplitudes de variação do diâmetro e comprimento do fruto $(\mathrm{mm})$ e comprimento do pedicelo $(\mathrm{mm})$.

19 Resumo da análise de variância do diâmetro e comprimento do fruto (mm) e raiz quadrada do comprimento do pedicelo (mm) ( $\sqrt{\text { Comppedicelo }})$.

20 Média dos tratamentos (Trat) para o diâmetro, comprimento do fruto (mm) e raiz quadrada do comprimento do pedicelo ( $\mathrm{mm}$ )..... 
21 Resumo da análise de variância do inverso da raiz quadrada da porcentagem estimada de rachadura de extremidade de tora com 1 dia ( $1 / \sqrt{P E R 1})$ e 7 dias $(1 / \sqrt{P E R 7})$, raiz quadrada da porcentagem estimada de rachadura de extremidade de tora 60 dias após o abate das árvores $(\sqrt{P E R 60})$, raiz quadrada da conicidade da tora com casca $(\sqrt{\text { Conic1 }})$ e sem casca $(\sqrt{\text { Conic } 2})$.

22 Resumo da análise de variância para a raiz quadrada da abertura da rachadura na base da tábua $(\sqrt{\text { Aberbas }})$, raiz quadrada do comprimento da rachadura na base da tábua $(\sqrt{\text { Compbas }})$, raiz quadrada da abertura da rachadura no topo da tábua $(\sqrt{\text { Abertop }})$, raiz quadrada dos comprimento da rachadura no topo da tábua ( $\sqrt{\text { Comptop }}$ ), raiz quadrada do número de peças por tora (tábuas e prancha central) $(\sqrt{\text { Npeças }})$ e comprimento da rachadura (base + topo) (Comprach)

23 Resumo da análise de variância da espessura média da tábua (Espess), largura média da tábua (Larg), comprimento da tora (Comptor) e comprimento útil da tora (livre das rachaduras) (Computil).

24 Teste $t$ pareado para a rachadura da tábua..................................................

25 Resumo da análise de variância da perda no desdobro (Perda1) (\%), raiz quadrada das perdas devido as tensão de crescimento longitudinal $(\sqrt{P e r d a 2})(\%)$ e perdas totais (desdobro e tensão de crescimento

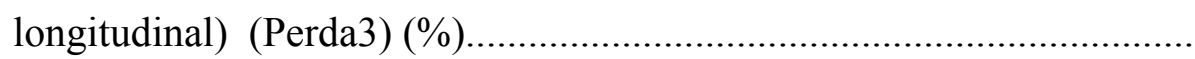


26 Resumo da análise de variância do inverso da raiz quadrada do volume da tora com casca $(1 / \sqrt{\text { Voltorcc }})$ e sem casca ( $1 / \sqrt{\text { Voltorsc }})$, raiz quadrada do volume da casca $(\sqrt{\text { Volcasc }})$, raiz quadrada do volume das tábuas $(\sqrt{\text { Volpri }})$, raiz quadrada do volume das tábuas livre da tensão de crescimento longitudinal $(\sqrt{V o l s e c})$ e raiz quadrada

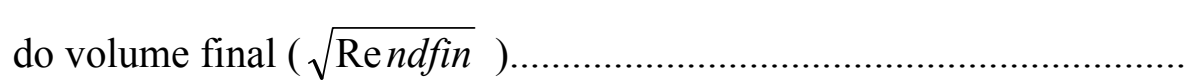

27 Resumo da análise de variância para a densidade básica $(\mathrm{Db})\left(\mathrm{g} / \mathrm{cm}^{3}\right)$, umidade $(\%)$, raiz quadrada da retração longitudinal $(\sqrt{R L})(\%)$, retração radial (RR) (\%), retração tangencial (RT) (\%), retração volumétrica (RV) (\%) e índice de retração anisotrópico (IR) (\%)......... 73

28 Teste Duncan para a retração volumétrica (RV) (\%) dos tratamentos....

29 Estimativas das variâncias, coeficientes de variação, herdabilidades e estimativas dos erros destas estimativas para a retração volumétrica (RV)

30 Resumo da análise de variância para o módulo da ruptura à flexão estática (Ff) (MPa), do módulo da elasticidade (Ef) (MPa), cisalhamento paralelo às fibras $(\mathrm{Fs})(\mathrm{MPa})$ e compressão paralela às fibras (Fc) (MPa)

31 Correlações ente as variáveis das rachaduras de extremidades de tábua 79

32 Correlações entre as propriedades físicas e mecânicas da madeira..........

33 Valores de A e B obtidos através da equação 13 para as estimativas das propriedades mecânicas da madeira em função da densidade básica com os respectivos coeficientes de determinação $\left(\mathrm{R}^{2}\right)$. 


\title{
LISTA DE SIGLAS, ABREVIATURAS E SÍMBOLOS
}

\author{
Conic1 Conicidade da tora com casca $(\mathrm{cm} / \mathrm{m})$. \\ Conic2 Conicidade da tora sem casca $(\mathrm{cm} / \mathrm{m})$. \\ Cva Coeficiente de variação da variância aditiva. \\ CVd Coeficiente de variação dentro de parcelas. \\ Cve Coeficiente de variação entre parcelas. \\ CVf Coeficiente de variação fenotípico. \\ CVg Coeficiente de variação genético. \\ DAP Diâmetro à Altura do Peito. \\ $\mathrm{Db} \quad$ Densidade básica $\left(\mathrm{g} / \mathrm{cm}^{3}\right)$. \\ $\mathrm{D}_{\text {base }} \quad$ Diâmetro da base da tora. \\ $\mathrm{D}_{\text {médio }} \quad$ Diâmetro do meio da tora. \\ $\mathrm{D}_{\text {topo }} \quad$ Diâmetro do topo da tora. \\ Ef Módulo de elasticidade na flexão estática (MPa). \\ Fc Resistência à Compressão paralela às fibras ( $\mathrm{MPa})$. \\ Ff Resistência à flexão estática (MPa). \\ FRD Florestas Rio Doce S. A.. \\ Fs Resistência ao Cisalhamento tangencial aos anéis de crescimento (MPa). \\ $\mathrm{H} \quad$ Altura da árvore $(\mathrm{m})$. \\ $\mathrm{H} \quad$ Altura (comprimento da tora) (m). \\ IPEF Instituto de Pesquisas e Estudos Florestais. \\ IR Índice de Rachadura da tora. \\ IRA Índice de Retração Anisotrópico (IRA = RT/RR). \\ PER1 Porcentagem Estimada de Rachadura 1 dia após o abate da árvore.
}


PER7 Porcentagem Estimada de Rachadura 7 dias após o abate da árvore.

PER60 Porcentagem Estimada de Rachadura 60 dias após o abate da árvore.

R Coeficiente de Correlação.

$\mathrm{R}^{2} \quad$ Coeficiente de Determinação.

RENDFIN Rendimento final em madeira serrada $\left(\mathrm{m}^{3}\right)$.

RL Retração Longitudinal (\%).

RR Retração Radial (\%).

RT Retração Tangencial (\%).

RV Retração Volumétrica (\%).

U Umidade (\%).

Volcasc Volume de casca $\left(\mathrm{m}^{3}\right)$.

Volcil Volume cilíndrico da árvore $\left(\mathrm{m}^{3}\right)$.

Voltor Volume da tora $\left(\mathrm{m}^{3}\right)$.

Voltorce Volume da tora com casca $\left(\mathrm{m}^{3}\right)$.

Voltorsc Volume da tora sem casca $\left(\mathrm{m}^{3}\right)$.

VOLPRI Volume das tábuas e prancha central $\left(\mathrm{m}^{3}\right)$.

VOLSEC Volume das tábuas e prancha central descontadas as rachaduras das duas extremidades das peças serradas $\left(\mathrm{m}^{3}\right)$.

$\sigma_{\mathrm{p}}^{2} \quad$ Variância genética entre progênies.

$\sigma_{\mathrm{e}}^{2} \quad$ Variância ambiental entre parcelas.

$\sigma_{\mathrm{d}}^{2} \quad$ Variância ambiental dentro de parcelas.

$\sigma_{F}^{2} \quad$ Variância fenotípica.

$\sigma_{\mathrm{A}}^{2} \quad$ Variância genética aditiva.

$\hat{\mathrm{h}}_{\mathrm{d}}^{2} \quad$ Coeficiente de herdabilidade no sentido restrito a nível de plantas dentro de progênies.

$\hat{\mathrm{h}}_{\mathrm{i}}^{2} \quad$ Coeficiente de herdabilidade no sentido restrito a nível de plantas individuais.

$\hat{\mathrm{h}}_{\mathrm{m}}^{2} \quad$ Coeficiente de herdabilidade no sentido restrito a nível de média de progênies. 
$\mathrm{Gs}_{\mathrm{d}} \%\left(\mathrm{i} \hat{\mathrm{h}}_{\mathrm{d}}^{2}\right) \quad$ Ganho de seleção para intensidade (i) de seleção de 20\% (i $\left.=1,40\right)$

$\hat{b}$

Vâr $\left(\sigma_{p}^{2}\right) \quad$ Estimativa do erro da variância entre progênie.

Vâr $\left(\sigma_{\mathrm{e}}^{2}\right) \quad$ Estimativa do erro da variância ambiental entre parcelas.

Vâr $\left(\sigma_{d}^{2}\right) \quad$ Estimativa do erro da variância ambiental dentro de parcelas.

Vâr $\left(\hat{\mathrm{h}}_{\mathrm{d}}^{2}\right) \quad$ Estimativa do erro da herdabilidade no sentido restrito a nível de plantas dentro de progênies.

Vâr $\left(\hat{\mathrm{h}}^{2} \mathrm{~m}\right) \quad$ Estimativa do erro da herdabilidade no sentido restrito a nível de plantas individuais.

Vâr $\left(\hat{\mathrm{h}}^{2}{ }_{\mathrm{i}}\right) \quad$ Estimativa do erro da herdabilidade no sentido restrito a nível de plantas individuais. 


\section{CARACTERIZAÇÃO SILVICULTURAL, BOTÂNICA E TECNOLÓGICA DO Eucalyptus urophylla S. T. BLAKE E DE SEU POTENCIAL PARA UTILIZAÇÃO EM SERRARIA.}

Autor: Laerte Scanavaca Junior Orientador: Prof. Dr. José Nivaldo Garcia

\section{RESUMO}

Os eucaliptos por serem de rápido crescimento, grande abundância de madeira, facilidade e baixo custo na exploração, madeira relativamente homogênea, proximidade do mercado consumidor e barata, é um gênero que deve ser mais utilizado em serrarias no Brasil. O Eucalyptus urophylla é uma espécie de alto potencial para as zonas tropicais úmidas por ser tolerante ao cancro do eucalipto (Cryphonectria cubensis) e sua grande plasticidade de adaptação e de utilização para os mais diversos fins. Por isto, é uma das espécies mais plantadas no Brasil e com grande potencial para ser utilizada em serraria. O objetivo deste trabalho foi estudar as características botânicas, silviculturais e as propriedades físicas e mecânicas da madeira de procedências/progênies de Eucalyptus urophylla da ilha Flores com 19 anos de idade. Foram selecionadas 6 arvores de 20 progênies, totalizando 120 árvores. Com base nos resultados conclui-se que não houve diferença estatística entre as procedências ou progênies para a produtividade (DAP, altura e volume cilíndrico das árvores). Houve diferença estatística entre as características das folhas e dos frutos, mas as amplitudes de 
variação apresentaram-se dentro dos limites definidos para a espécie. Não houve diferença estatística entre as progênies para as propriedades físicas e mecânicas, exceto para a retratibilidade volumétrica. Os resultados apresentados permitiram classificar a espécie como de alta resistência mecânica, exceto para a compressão que foi de média resistência, alta retratibilidade e moderadamente pesada. Houve boa correlação entre a densidade básica, que é de fácil determinação, com as propriedades mecânicas da madeira, desta forma concluiu-se que é possível prever a resistência à flexão estática através da densidade básica. Não houve correlação das rachaduras de extremidades de tora com as rachaduras de extremidades de peça serrada. Não houve correlação da tensão de crescimento longitudinal com o diâmetro. A conicidade não influenciou no rendimento em madeira serrada. O rendimento em madeira serrada médio foi de 42,54\%. 


\section{SILVICULTURAL, BOTANICAL AND TECHNOLOGICAL CHARACTERIZATION OF THE Eucalyptus urophylla S. T. BLAKE AND ITS POTENTIAL USE IN SAWMILL.}

Author: Laerte Scanavaca Junior Adviser: Prof. Dr. José Nivaldo Garcia

\section{SUMMARY}

The eucalypts is a gender that should be more used at sawmills in Brazil, due to its fast growth, great wooden abundance, easiness and low cost in the exploration, wood relatively homogeneous, proximity to the consumer market and cheap price. The Eucalyptus urophylla is a species of high potential for the humid tropical zones, because of its tolerance to the eucalypts canker (Cryphonectria cubensis) and due to its great plasticity of adaptation for the most diverse uses. It is one of the most planted species in Brazil, with great potential to be used in sawmill. The objective of this work is to study the botanical and silvicultural features, and the physical and mechanical properties of the wood of provenances/progenies of Eucalyptus urophylla from the Flores island with 19 years of age. Six trees of 20 progenies had been selected, totaling 120 trees. There was not statistical differences among the origins or progenies for the productivity ( $\mathrm{DBH}$, height and cylindrical volume of the trees). It had statistic difference between progenies for the morphological features, like the leaves and the fruits, but the amplitude of variation presented was inside the limits defined for the species. About the study of the 
physical and mechanical properties, there was no statistic differences among the progenies, except for the volumetric shrinkage. The progenies were classified like the high mechanical resistance, except for the compression, that was of average resistance, high shrinkage and moderately weighed. There was good correlation between the basic density, that is easy to determination, and the mechanical properties of the wood, what allow to conclude that it is possible to predict the resistance to static flexion through the basic density. There was no correlation between end splitting log with end splitting board. There also were no correlations between the growth tensions and the diameter of the logs. The taper didn't influence the income in sawed wood. The medium income in sawed wood was of $42,54 \%$ 


\section{INTRODUÇÃO}

O clima no Brasil é favorável ao reflorestamento e os eucaliptos apresentam uma das maiores produtividades. A área reflorestada com Eucalyptus spp. é de aproximadamente 3.000.000 hectares, o que corresponde a 22\% do reflorestamento mundial com este gênero (Flynn \& Shield, 1999).

O E. urophylla possui duas variedades distintas, sendo uma de casca fibrosa, folhas lanceoladas com uma cauda bastante pronunciada, procedente da ilha Timor, de altitudes elevadas (acima de $1000 \mathrm{~m}$ ), esta foi a variedade utilizada por Blake para descrever e classificar a espécie, e outra de casca lisa em diferentes proporções do fuste e folhas com forma e tamanho variáveis (Martin \& Cossalter, 1975a; Vieira \& Bucsan, 1980).

Dentre as espécies de eucaliptos plantadas no Brasil, o Eucalyptus urophylla além de ser uma das mais plantadas, com aproximadamente 600.000 hectares (Ferreira, 1999), é a espécie que tem o maior potencial de crescimento em termos de área plantada em função da tolerância ao fungo causador do cancro do eucalipto (Cryphonectria cubensis), de sua boa produtividade e de seu potencial de utilização para os mais diversos fins (fabricação de celulose e papel, chapas duras, serraria e produção de carvão, entre outros).

Em função das pressões ecológicas e da distância do mercado consumidor das madeiras nativas, os eucaliptos apresentam-se como uma das melhores opções para suprir este mercado no Brasil. 
A madeira sólida representa um consumo anual de aproximadamente $22.300 .000 \mathrm{~m}^{3}$, e a participação da madeira de reflorestamento (Pinus spp e Eucalyptus spp) tem aumentado consideravelmente (Mora \& Garcia, 2000). Para que estas madeiras tenham melhor aceitação, principalmente no mercado interno, é necessário um maior conhecimento das propriedades físicas e mecânicas desta madeira.

$\mathrm{O}$ rendimento em madeira serrada de eucalipto é afetado por diversos fatores sendo as tensões de crescimento um dos mais importantes.

Baseado na importância que a espécie representa para o reflorestamento, o presente trabalho teve por objetivos:

- A caracterização botânica da espécie através das folhas e dos frutos.

- A avaliação da produtividade da espécie.

- Estudar a tensão de crescimento através das rachaduras de extremidades de toras e de peças serradas.

- Quantificar o rendimento em madeira serrada.

- Estudar algumas propriedades físicas e mecânicas da espécie.

- Verificar a possibilidade de melhoramento genético para estas propriedades. 


\section{REVISÃO DE LITERATURA}

\subsection{Classificação da espécie}

O Eucalyptus urophylla é uma espécie do Subgênero Symphyomyrthus, Secção Transversaria, Série Salignae, Sub-série Resiniferinae (Pryor \& Johnson, 1971). A facilidade de cruzamento com espécies da Sub-série Saligninae, fizeram com que Martin \& Cossalter (1975b) sugerissem que a espécie pudesse ser classificada dentro desta Sub-série.

\subsection{Centro de Origem}

O Eucalyptus urophylla é uma das poucas espécies de eucaliptos que ocorrem naturalmente fora da Austrália, no Arquipélago Sonda e é também uma das poucas espécies de eucaliptos que ocorrem em latitudes inferiores à $10^{\circ} \mathrm{S}$ (Figura 1). A zona de ocorrência varia de $7^{\circ} 30^{\prime}$ a $10^{\circ} \mathrm{S}$ de Latitude e 122 a $127^{\circ} \mathrm{E}$ de Longitude. As altitudes variam do nível do mar até $2960 \mathrm{~m}$, correspondendo a uma faixa de aproximadamente $500 \mathrm{~km}$ (Martin \& Cossalter, 1976a), sendo que as populações mais produtivas estão entre 500 e $2.200 \mathrm{~m}$ de altitude. Nestas áreas formam florestas altas, ecologicamente similares a "Wet Sclerophyll Eucalypt Forest" (Floresta Aberta Alta) do nordeste da Austrália (Pryor et al., 1995) ou "Rain Forest" (Semelhante à Floresta Amazônica) (Martin \& Cossalter, 1976a). Em muitas destas áreas ocorrem em florestas 
puras, com árvores atingindo alturas superiores a $50 \mathrm{~m}$ (Martin \& Cossalter, 1975a; Turnbull \& Brooker, 1978; FAO, 1979; Pryor et al., 1995).

A temperatura varia de $24,2^{\circ} \mathrm{C}$ a $420 \mathrm{~m}$ de altitude a $20^{\circ} \mathrm{C}$ a $1449 \mathrm{~m}$ de altitude (variação de $1^{\circ} 30^{\prime}$ na Latitude). Nesta região, a precipitação influenciada pelos ventos das Monções e pela cadeia montanhosa de Timor, varia de 600 a $2500 \mathrm{~mm}$, sendo a média de $1300 \mathrm{~mm}$ por ano. Em Timor tem-se de 2 a 4 meses com menos de $50 \mathrm{~mm}$ de precipitação e no Sul da ilha Wetar, região mais a Leste na zona de ocorrência, a precipitação é de 700 a $800 \mathrm{~mm}$ com 7 a 8 meses com precipitação inferior a $60 \mathrm{~mm}$ (Martin \& Cossalter, 1976a). A temperatura média varia de 20 a $30^{\circ} \mathrm{C}$, sendo que nos meses mais frios chega à $15^{\circ} \mathrm{C}$. O clima varia de subtropical seco a tropical úmido, tornando-se mais seco de Oeste para Leste (Vieira \& Bucsan, 1980).

$\mathrm{Na}$ ilha Flores a espécie ocorre em áreas naturais apenas na parte oriental, a partir de Maumere até a extremidade Leste, extensão de aproximadamente $80 \mathrm{~km}$. As altitudes variam de 300 a 1100 m e a precipitação varia de 1200 a 1500 mm, com 4 a 6 meses de precipitação inferior a 60 mm (Martin \& Cossalter, 1976b; Vieira \& Bucsan, 1980; Eldridge et al., 1994). O clima é predominantemente tropical seco, sendo que o déficit hídrico aumenta de Oeste para Leste. As principais procedências são encontradas nos montes Egon, Wukoh, Lewotobi e Ilimandiri (Figura 2). Os solos são de origem basáltica e pouco desenvolvidos. Há uma grande variação nas características dos frutos e folhas, não sendo possível distinguir os indivíduos puros dos híbridos. A maioria dos indivíduos apresentam casca lisa na parte superior do tronco e rugosa na parte inferior. Em altitudes superiores, a casca rugosa recobre todo o fuste e os galhos das árvores. Ocorre contato do E. urophylla com o E. alba entre as altitude de 450 e $550 \mathrm{~m}$ e em altitudes superiores, o E. urophylla ocorre em povoamentos puros. A época de frutificação é simultânea nas duas espécies (Vieira \& Bucsan, 1980). A grande variabilidade das características fenotípicas poderia ser a expressão da hibridação entre o E. urophylla com o E. alba (Martin \& Cossalter, 1976b; Vieira \& Bucsan, 1980). 


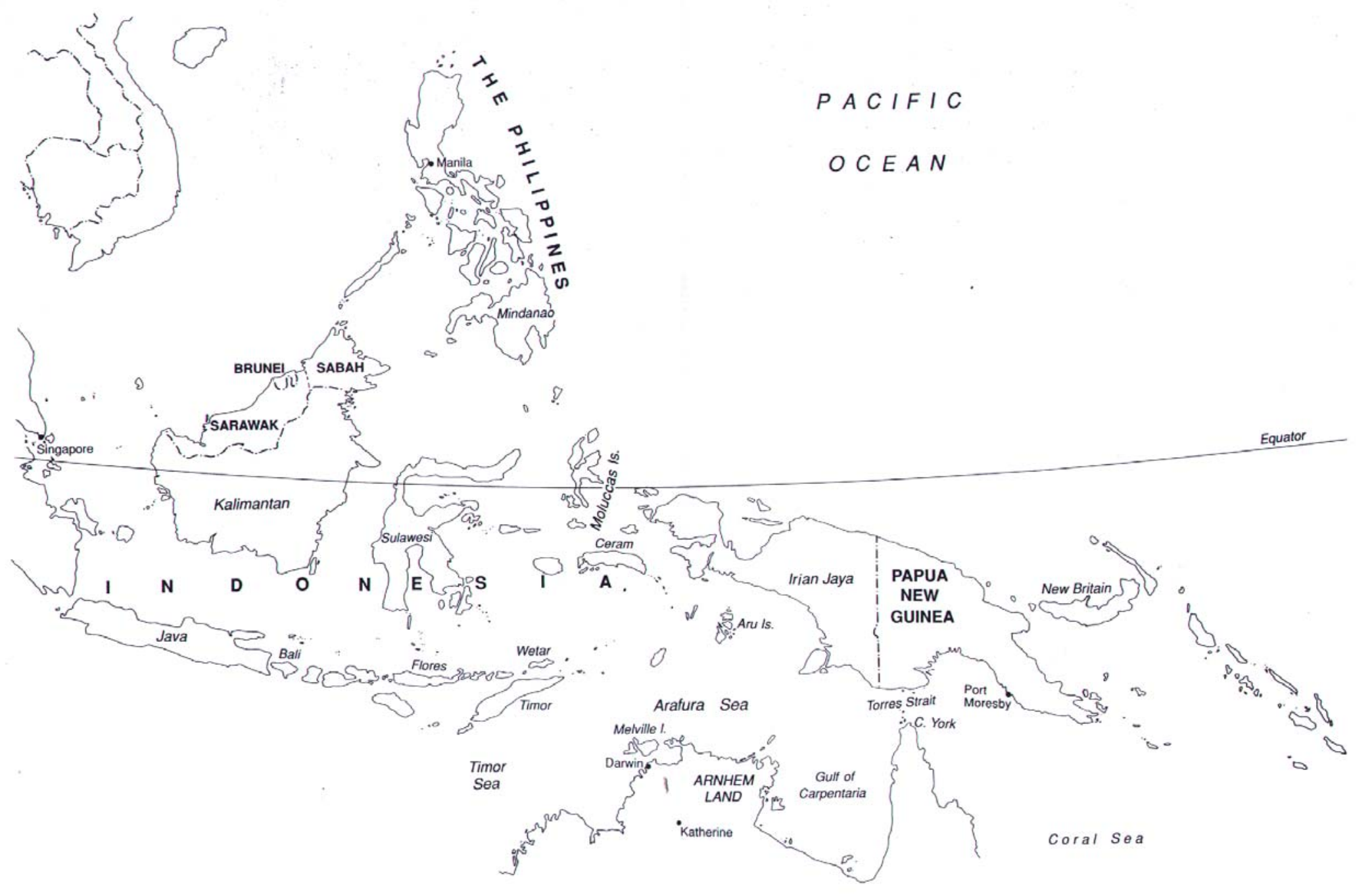

Figura 1 - Localização da Indonésia (Fonte Eldridge et al., 1994). 


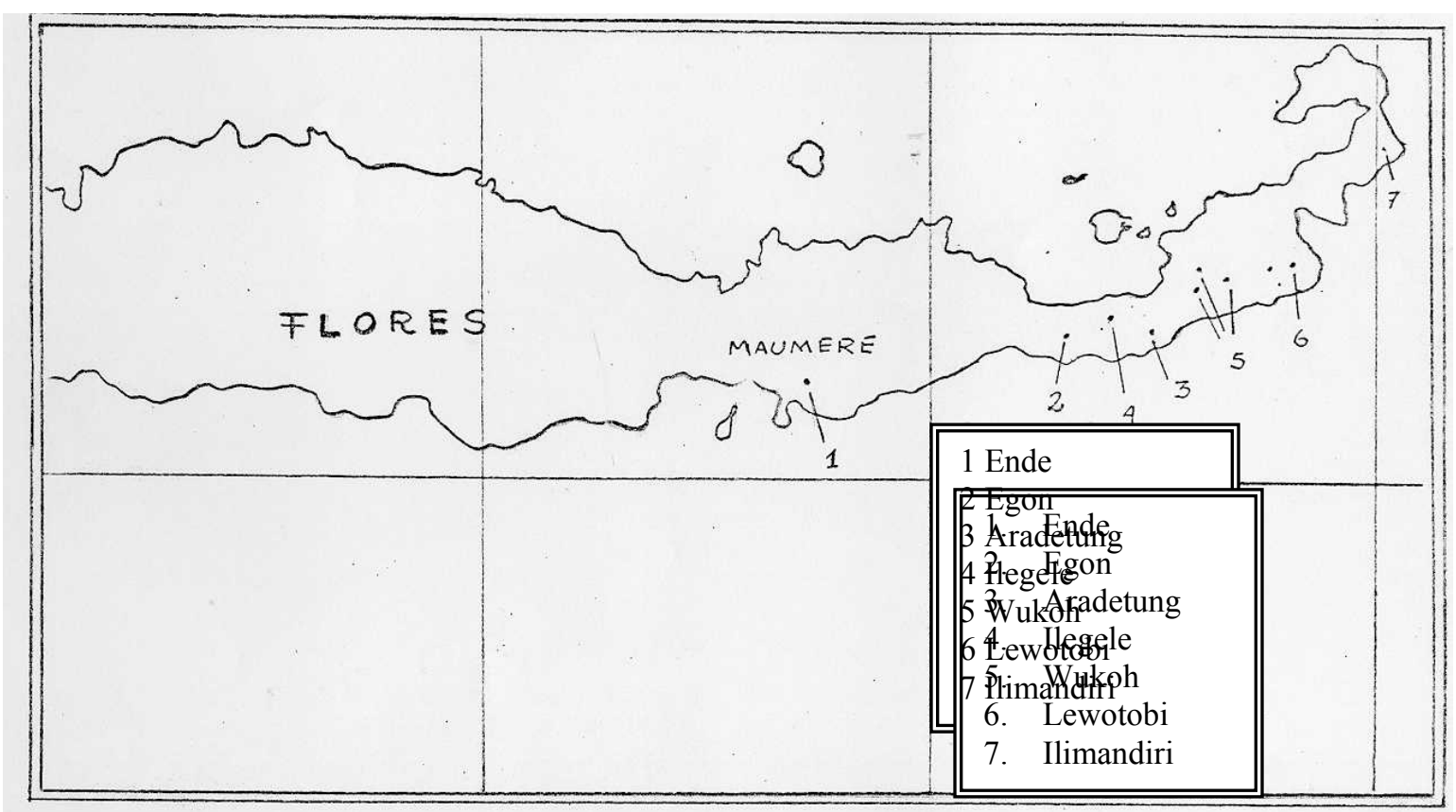

Figura 2 - Ilha Flores (Fonte Pinto Junior, 1984).

\subsection{Comportamento ecológico, silvicultural e botânico}

O E. urophylla é de floresta aberta alta com casca lisa ("smooth bark", no Brasil também é chamada de "gum") e/ou fibrosa ("rough bark"). As árvores têm de 30 a $60 \mathrm{~m}$ de altura e a penetração de luz permite a formação de subbosque. A espécie apresenta fuste com boa forma, densidade básica ao redor de $0,5 \mathrm{~g} / \mathrm{cm}^{3}$ e lignotubérculo que é responsável pela sua boa brotação. Responde ao espaçamento e à adubação, apresenta bom desenvolvimento na segunda rotação, possui resistência ao déficit hídrico, é susceptível à geada e apresenta variações clinais e ecotípicas importantíssimas para o melhoramento genético da espécie (Ferreira, 1992).

O E. urophylla é uma espécie de grande interesse para as zonas tropicais úmidas e as procedências mais produtivas são as mais tropicais. Os diversos ensaios de procedências instalados em diferentes países tropicais úmidos revelaram uma grande 
estabilidade de resposta das procedências. Resumidamente, têm-se: 1) A procedência aceitável da ilha Timor é proveniente de Dili, Região de Remexio, situada a uma altitude média de $800 \mathrm{~m}$. As demais procedências de Timor, situadas em altitudes superiores, não estão bem adaptadas; 2) As melhores procedências são originárias das baixas altitudes da ilha Flores, como Monte Egon (315 - 515 m) e Monte Lewotobi (325 - 500 m); 3) Existem igualmente boas procedências na ilha Alor (Ulanu), com excelente forma de tronco; 4) As procedências das ilhas Adonara e Lomblen são vigorosas mas as árvores apresentam o tronco com forma muito ruim e 5) As procedências das ilhas Wetar e Pantar apresentam pequena adaptação e fraco desempenho (Ferreira, 1999).

Ferreira \& Souza (1997) estudaram várias características de material juvenil e adulto de 20 clones de origem hibridógena. Com base nos resultados, os autores agruparam os clones em 3 grupos, sendo um o E. urophylla de altitude (casca rugosa/fibrosa), outro o E. urophylla var platyphylla (casca lisa) e o terceiro grupo o híbrido E. grandis x E. urophylla.

Ferreira (1999) estudou características botânicas das folhas e dos frutos de 108 árvores de E. urophylla, selecionadas em Anhembi, em função da produtividade ( 8 de Timor, 83 de Flores e 17 de Outras Ilhas). Os resultados permitiram ao autor classificar as árvores em 5 grupos. $\mathrm{O}$ autor afirmou que o tipo de casca é independente do tipo botânico e os tipos botânicos são independentes das procedências. As progênies com maior capacidade produtiva e adaptativa se concentraram em 2 grupos. Dentro da macroprocedência Outras Ilhas o autor encontrou algumas árvores que não se encaixavam em nenhum dos 5 grupos.

Diversos pesquisadores estudaram características quantitativas e qualitativas das folhas e dos frutos do E. urophylla para identificá-los e/ou reclassificalos em novas espécies ou variedades (Martin \& Cossalter, 1975a,b; Turnbull \& Brooker, 1978; FAO, 1979; Goes, 1985; López, 1992; Pryor et al., 1995; Ferreira \& Souza, 1997; Ferreira, 1999). Os resultados destes trabalhos estão no Anexo A. 
Pinyopusarerk et al. (1993) estudaram 11 características quantitativas de folhas de mudas de 22 procedências de E. urophylla. Os autores concluíram que as procedências de Wetar (Arnau, Telemar, Carbubu e Old Uhak) eram distintas das demais procedências, inclusive de outras de Wetar, para todas as características estudadas. Os autores sugeriram que isto poderia ser uma adaptação visto que estas procedências eram originárias de montanhas com alta declividade, solos bastante rasos e clima bastante seco. House \& Bell (1994) estudaram este material através de marcadores moleculares e chegaram à mesma conclusão.

Doran et al. (1995) estudaram a quantidade e os tipos de óleos de folhas de várias procedências de E. urophylla. Não houve diferença entre os tipos de óleos, mas nas quantidades sim. As procedências de Wetar tiveram um baixo rendimento quando comparadas com as procedências de Alor, Pantar e Adonara, Flores e Timor. A procedência Mt. Tatamailau de Timor de $2740 \mathrm{~m}$ de altitude apresentou o rendimento mais baixo, enquanto que a procedência Maubisse-Turiscai também de Timor de $1610 \mathrm{~m}$ de altitude, apresentou um dos melhores rendimentos.

Estes trabalhos inspiraram Pryor et al. (1995) a estudarem mais

detalhadamente as procedências do E. urophylla. Os autores reclassificaram as procedências de Wetar (região mais seca) em E. wetarensis, e as procedências de Timor, de altitude superior a $2100 \mathrm{~m}$ em E. orophila, confirmando o resultado encontrado por outros pesquisadores (Anexo B).

\subsection{Teste de procedências/progênies}

Depois da reclassificação do Eucalyptus urophylla, feita por Blake em 1973 (oficializada em 1977) e dos bons resultados das populações hibridógenas originárias do E. urophylla de Camaquã, algumas empresas reintroduziram novos 
materiais da espécie, um vez que era evidente a falta de base genética no material existente no Brasil.

A Companhia Vale do Rio Doce, através da subsidiária Florestas Rio Doce (FRD) S. A. fez uma coleta bastante abrangente e representativa da espécie. Através de um convênio específico entre a FRD, IPEF (Instituto de Pesquisas e Estudos Florestais) e o Departamento de Ciências Florestais da ESALQ-USP, as sementes colhidas na Indonésia foram testadas, através de testes de procedências/progênies, em diversas regiões bioclimáticas do Brasil. As procedências/progênies foram agrupadas e testadas em três macroprocedências, sendo uma da ilha Flores, outra da ilha Timor e a terceira das Outras Ilhas (Adonara, Alor, Lomblen, Pantar e Wetar). No Brasil, a macroprocedência Flores foi melhor que as demais macroprocedências, em todas regiões testadas. Os resultados destas pesquisas para a macroprocedência Flores são descritos a seguir.

Brasil (1983) avaliou dois experimentos aos 4 anos de idade, um em Belo Oriente - MG e outro em Linhares - ES. Nos dois locais as melhores procedências para a produtividade foram em ordem decrescente Egon e Ilegele, respectivamente.

Replicas deste experimento foram avaliadas por Pinto Junior (1984) em quatro locais (Anhembi-SP, Aracruz-ES, Bom Despacho-MG e Planaltina-DF) aos 0,5; 1; 2 e 3 anos de idade. A análise conjunta aos 3 anos de idade mostrou que as procedências Egon e Ilegele, respectivamente, como as melhores em produtividade.

Capitani et al. (1987) avaliaram uma replica deste teste em Belo OrienteMG, aos 3,5 anos de idade e também constataram que as melhores procedências em produtividade foram Egon e Ilegele.

Mori et al. (1988) avaliaram replicas deste teste em quatro locais (Aracruz-ES, Belo Oriente-MG, Bom Despacho-MG e Grão Mogol-MG), aos 7 anos de idade. A análise conjunta mostrou que melhor procedência em produtividade foi Ilegele.

Santos et al. (1990) avaliaram cópias deste ensaio em dois locais, Grão Mogol-MG e Linhares-ES, aos 8 anos de idade. Em Grão Mogol as melhores 
procedências, em produtividade, foram Ende e Aradetung e em Linhares as melhores precedências foram Lewotobi e Ilegele.

O IPEF (1990) avaliou este teste em Anhembi-SP, aos 10 anos de idade. As melhores procedências em produtividade foram Egon II e Aradetung.

A avaliação conjunta destes ensaios permitiram concluir que existe interação das procedências com os locais e da idade com o local (Anexo C).

Darrow \& Roeder (1983) avaliaram procedências de E. urophylla em dois locais na África do Sul. A produtividade das árvores com casca fibrosa foram superiores no sítios temperado e no sítio tropical, as árvores com casca lisa foram mais produtivas.

Com relação à produtividade, diversos trabalhos com E. urophylla em países tropicais, em diferentes idades, mostraram que as procedências de baixa altitude na origem (300 a $1200 \mathrm{~m}$ ) estão bem adaptadas em países tropicais e subtropicais, independente da macroprocedência (Moura, 1981; Corbasson \& Cossalter, 1983; Darrow \& Roeder, 1983; Wencelius, 1983; Capitani et al., 1987; Pasztor et al., 1990; Scanavaca Junior et al., 1990¹, 1993; Ferreira, 1999; Gouma, 1998).

\subsection{Tensões de crescimento}

As tensões de crescimento são geradas dentro dos tecidos da madeira, nas formação de novas camadas de células a partir do câmbio, durante o desenvolvimento da árvore. São iniciadas durante o desenvolvimento da parede secundária das fibras, na camada S2 (Figura 3). Ocorrem em três direções: longitudinal, radial e transversal. As tensões de crescimento transversais aparecem na periferia da árvore (câmbio) com o crescimento de novas camadas de células. As tensões de crescimento radiais, surgem como reação as tensões de crescimento transversais. As tensões longitudinais acontecem pelo encurtamento das fibras na periferia da árvore (que originam as tensões de tração) e pelo alongamento das fibras em direção à medula (tensões de compressão) (Boyd, 1950a,b).

1 = SCANAVACA JUNIOR, L.; FERREIRA, M.; SANTOS, P. E. T. Relatório de estágio na FRDSA, sistema Norte: MA e PA. Piracicaba, 1990. 61p. (Não publicado). 


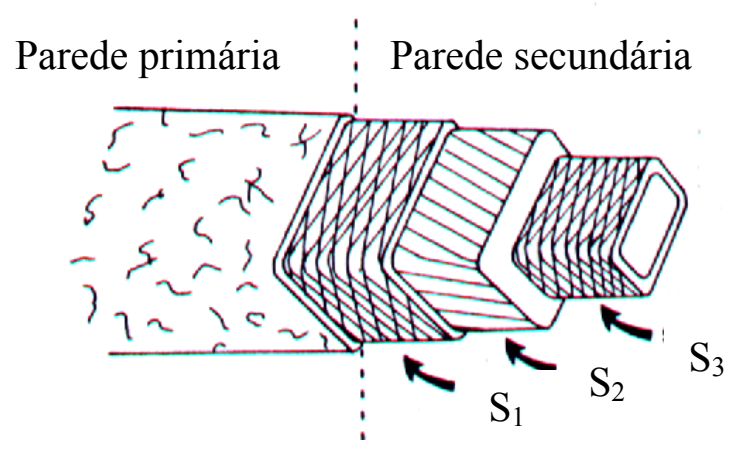

Figura 3 - Visão microscópica de uma célula vegetal, mostrando a orientação das microfibrilas nas várias camadas da parede celular (Wilkins, 1986).

Nicholson (1973) sugeriu que uma árvore não pode alterar sua orientação vertical sem primeiro mudar a tensão dentro de seu tronco. Nicholson et al. (1975) estudaram árvores de E. regnans com 32 anos de idade, com a copa inclinada e distribuída em diferentes intensidades. Os autores concluíram que a inclinação e a distribuição da copa influenciavam as tensões de crescimento, mas não estavam correlacionadas ente si. Também encontraram fortes correlações entre as tensões de crescimento e algumas propriedades físicas e mecânicas da madeira.

Boyd (1980) fez um estudo bastante minucioso com árvores adultas retas e inclinadas de Pinus sp. e Eucalyptus spp. O autor checou todas as teorias propostas a respeito das tensões de crescimento. A única teoria que funcionou para todas as árvores (retas ou inclinadas de Angiospermas e Gimnospermas) foi a da madeira de reação (ângulo de inclinação das microfibrilas da camada S2, proposta por Boyd 1950a,b) na tentativa de manter a copa centralizada, que foi proposta por Nicholson (1973).

Kubler (1959) fez uma analogia das matrizes de lignina e celulose com um prédio. A celulose funcionaria como o aço que suporta as forças de tração e a lignina como o concreto que suporta as forças de compressão. O problema desta teoria é que as árvores suportam forças de tração maiores que o aço e o concreto forças de compressão maiores que a madeira (Wilkins, 1986). 


\subsection{Conicidade}

A conicidade é a diminuição do diâmetro do tronco, da base para a copa da árvore. A árvore é considerada cônica quando apresentar diminuição de mais de 1 $\mathrm{cm} / \mathrm{m}$ no diâmetro ou $3 \mathrm{~cm} / \mathrm{m}$ na circunferência do tronco. A conicidade é uma característica que sofre influência ambiental, principalmente do espaçamento e pode influenciar no rendimento em madeira serrada (Grosser, 1980).

A conicidade varia de espécie para espécie, diminui com a idade da planta, é maior na primeira tora, isto é, na base da árvore (Anexo D).

\subsection{Rendimento em Madeira Serrada}

$\mathrm{O}$ rendimento em madeira serrada ou porcentagem de aproveitamento é a relação entre o volume de madeira serrada produzido e o volume da tora antes do desdobro.

O rendimento em madeira serrada é afetado pela interação de diversos fatores, sendo os mais importantes o diâmetro, o comprimento, a conicidade, a qualidade das toras, espessura do corte da serra e o número alternativo de produtos (Steele, 1984).

O rendimento em madeira serrada varia de uma espécie para outra em função das inerentes distinções entre as mesmas. Entre estas características pode-se citar a densidade básica, disposição dos elementos estruturais, componentes químicos, teor de umidade etc (Steele, 1984) (Anexo E).

$\mathrm{O}$ rendimento em madeira serrada aumenta com o aumento do diâmetro das toras porque o volume de toras perdido com costaneiras e aparas são menores em porcentagem em relação ao volume das toras (Wade et al., 1992). 


\subsection{Propriedades físicas e mecânicas da madeira}

A densidade é uma das propriedades físicas mais importantes na caracterização tecnológica da madeira para os mais diversos fins, visto que sua variação afeta a resistência mecânica e a variação dimensional da madeira (variação física). Em termos químicos reflete a porcentagem dos diferentes constituintes que são celulose, hemiceluloses, lignina e extrativos. Reflete também a anatomia da madeira uma vez que é reflexo das dimensões das fibras ou traqueídeos (comprimento, largura, espessura da parede e diâmetro do lúmen) (Panshin \& Zeeuw, 1970; Arganbriht, 1971; U S Forest Products Laboratory, 1974).

A densidade refere-se à quantidade de substância madeira existente num determinado volume a uma determinada umidade. Geralmente, utiliza-se a densidade básica, que é a massa de madeira seca em relação ao seu volume saturado, ou seja, a uma umidade superior ao ponto de saturação das fibras. Por ser de fácil determinação e de possuir boa correlação com as propriedades mecânicas de resistência da madeira, a densidade básica é uma das propriedade físicas mais estudas no mundo.

A retratibilidade é a movimentação da madeira (inchamento e encolhimento) pela perda de água abaixo do ponto de saturação das fibras. Verifica-se que a retratibilidade tangencial é maior que a radial, enquanto que a retratibilidade longitudinal é praticamente desprezível. Outro parâmetro importante é o Índice de Retração Anisotrópica, razão entre as retrações tangencial (RT) e radial (RR). De uma maneira geral, quanto mais baixa esta razão, isto é, quanto mais próximo de um, melhor é a espécie para marcenaria. Para Hillis (1978) a retratibilidade excessivamente alta da madeira dos eucaliptos é um dos principais problemas para a sua utilização como madeira sólida 
Os efeitos combinados das retrações tangencial e radial ocasionam mudanças na forma das peças de madeira por causa das diferenças nas retrações e na curvatura dos anéis de crescimento. Deste modo, a retração e a deformação variam conforme a posição radial de onde a peça de madeira foi retirada (U. S. Forest Products Laboratory, 1974).

Para Kollman \& Côté (1968), a retração da madeira aumenta com o aumento de sua massa específica. Chafe (1986 e 1987) afirma que esta relação não é valida para os eucaliptos devido a excessiva quantidade de extrativos encontrada neste gênero.

As propriedade mecânicas são divididas em dois grupos, um de resistência, em que estão incluídas as propriedades de compressão paralela e perpendicular a fibra, flexão estática e dinâmica e cisalhamento entre outras. Outro grupo são as propriedades de elasticidade da madeira, neste grupo temos o módulo da elasticidade à flexão estática, que determinam a rigidez da madeira.

As madeiras são caracterizadas em função de suas propriedades físicas e mecânicas. Com base nesta caracterização são classificadas e com base nesta classificação e em normas, são definidos os usos que estas madeiras podem ter. 


\section{MATERIAL E MÉTODOS}

\subsection{Material}

O presente trabalho foi desenvolvido a partir de um teste de 9 procedências e 63 progênies de meios - irmãos oriundos de populações naturais de Eucalyptus urophylla da ilha Flores introduzidas no Brasil pela Florestas Rio Doce S.A., e faz parte de uma grande rede de experimentação em diversas regiões bioclimáticas do país. Como testemunhas foram usados os melhores materiais comerciais da época e duas progênies de E. alba. A Testemunha Camaquã é de área de coleta de sementes (ACS), F1 de Rio Claro, a Testemunha Salesópolis é de área de produção de sementes (APS), cuja procedência original era Timor de $1100 \mathrm{~m}$ de altitude e a Testemunha Casa Branca é de Banco Clonal (BC), proveniente de Rio Claro. A testemunha E. alba foi totalmente excluída, devido a competição e ou desbaste, não restando nenhuma árvore quando este trabalho foi realizado, portanto, foi excluída desta avaliação.

O presente teste foi instalado na Estação Experimental de Ciências Florestais de Anhembi do Departamento de Ciências Florestais da ESALQ/USP, que está situada a $22^{\circ} 47^{\prime}$ de Latitude Sul, $48^{\circ} 09^{\prime}$ de Longitude Oeste e a 500 metros de altitude, em terreno suavemente ondulado e solo podzólico arenoso e profundo. $\mathrm{O}$ clima é Cwa (segundo Koppen), com verões quentes e chuvosos e invernos moderadamente frios e secos. A ocorrência de geadas é rara. A temperatura média anual é de $21^{\circ} \mathrm{C}$ e a temperatura média dos meses mais frios e quentes são respectivamente, $17,1^{\circ} \mathrm{C}$ e $23,7^{\circ}$ C. A precipitação média anual é de $1350 \mathrm{~mm}$ e a deficiência hídrica anual é de $20 \mathrm{~mm}$. 
O delineamento experimental utilizado foi o de parcelas subdivididas, tendo nas parcelas as procedências e nas subparcelas as progênies dentro das procedências. As parcelas eram retangulares de tamanhos variados em função do número de progênies (3 a 14). As subparcelas eram lineares com 10 plantas mensuráveis. $\mathrm{O}$ espaçamento inicial foi 3 × $2 \mathrm{~m}$ ( $3 \mathrm{~m}$ entre progênies e $2 \mathrm{~m}$ entre plantas da mesma progênie). As parcelas foram separadas por uma bordadura simples e o ensaio todo envolvido por uma bordadura dupla. $\mathrm{O}$ ensaio foi composto por 3 repetições (Tabela 1).

Tabela 1. Caracterização das Procedências.

\begin{tabular}{lcccc}
\hline Procedência & $^{\circ}$ p progênies & Latitude Sul Longitude & Altitude (m) \\
\hline Aradetung & 3 & $08^{\circ} 35^{\prime}$ & $122^{\circ} 30^{\prime} \mathrm{E}$ & 700 a 720 \\
Egon & 5 & $08^{\circ} 40^{\prime}$ & $122^{\circ} 26^{\prime} \mathrm{E}$ & 750 a 780 \\
Egon II & 4 & $08^{\circ} 40^{\prime}$ & $122^{\circ} 26^{\prime} \mathrm{E}$ & 690 a 790 \\
Ilegele & 8 & $08^{\circ} 40^{\prime}$ & $122^{\circ} 20^{\prime} \mathrm{E}$ & 720 a 870 \\
Ilimandiri & 12 & $08^{\circ} 18^{\prime}$ & $122^{\circ} 58^{\prime} \mathrm{E}$ & 400 a 650 \\
Lewotobi & 14 & $08^{\circ} 31^{\prime}$ & $122^{\circ} 46^{\prime} \mathrm{E}$ & 480 a 700 \\
Londangwuang & 9 & $08^{\circ} 40$ & $122^{\circ} 20^{\prime} \mathrm{E}$ & 890 a 940 \\
Saler Wukoh & 4 & $08^{\circ} 23^{\prime}$ & $122^{\circ} 40^{\prime} \mathrm{E}$ & 940 \\
Wukoh & 4 & $08^{\circ} 23^{\prime}$ & $122^{\circ} 40^{\prime} \mathrm{E}$ & 800 \\
Camaquã (ACS) (Testemunha 1) & & $22^{\circ} 20^{\prime}$ & $48^{\circ} 59^{\prime} \mathrm{W}$ & 517 \\
Casa Branca (BC) (Testemunha 2) & & $21^{\circ} 46^{\prime}$ & $47^{\circ} 04^{\prime} \mathrm{W}$ & 670 \\
Salesópolis (APS) (Testemunha 3) & & $23^{\circ} 32^{\prime}$ & $45^{\circ} 51^{\prime} \mathrm{W}$ & 880 \\
Linhares (Testemunha 4) & & $19^{\circ} 22^{\prime}$ & $40^{\circ} 04^{\prime} \mathrm{W}$ & 50 \\
E alba T46a Tautuka Timor & 1 & $10^{\circ} 08^{\prime}$ & $123^{\circ} 50^{\prime} \mathrm{E}$ & 80 \\
E alba T49Tautuka Timor & 1 & $10^{\circ} 08^{\prime}$ & $123^{\circ} 50^{\prime} \mathrm{E}$ & 80 \\
\hline
\end{tabular}


Com base no resultado silvicultural e procurando abranger o maior número possível de procedências, foram selecionadas 20 progênies. A seleção fenotípica foi feita em progênies que apresentavam produtividade próxima da média do ensaio (Tabela 2).

Tabela 2. Caracterização do material selecionado.

\begin{tabular}{|c|c|c|c|c|c|c|}
\hline Procedência & Progênie & Tratamento & Localidade & $\begin{array}{c}\text { Latitude } \\
\text { Sul }\end{array}$ & $\begin{array}{c}\text { Longitude } \\
\text { Oeste }\end{array}$ & $\begin{array}{l}\text { Altitude } \\
\text { (m) }\end{array}$ \\
\hline 1 & 1 & 1 & Wukoh & $8^{\circ} 32^{\prime}$ & $122^{\circ} 40^{\prime}$ & 800 \\
\hline 2 & 5 & 2 & Ilegele & $8^{\circ} 40^{\prime}$ & $122^{\circ} 20^{\prime}$ & 720 \\
\hline 2 & 6 & 3 & Ilegele & $8^{\circ} 40^{\prime}$ & $122^{\circ} 20^{\prime}$ & 720 \\
\hline 2 & 9 & 4 & Ilegele & $8^{\circ} 40^{\prime}$ & $122^{\circ} 20^{\prime}$ & 750 \\
\hline 3 & 13 & 5 & Londangwuang & $8^{\circ} 00^{\prime}$ & $122^{\circ} 00^{\prime}$ & 890 \\
\hline 3 & 14 & 6 & Londangwuang & $8^{\circ} 00^{\prime}$ & $122^{\circ} 00^{\prime}$ & 890 \\
\hline 3 & 17 & 7 & Londangwuang & $8^{\circ} 00^{\prime}$ & $122^{\circ} 00^{\prime}$ & 910 \\
\hline 3 & 20 & 8 & Londangwuang & $8^{\circ} 00^{\prime}$ & $122^{\circ} 00^{\prime}$ & 940 \\
\hline 4 & 23 & 9 & Egon II & $8^{\circ} 40^{\prime}$ & $122^{\circ} 26^{\prime}$ & 750 \\
\hline 5 & 27 & 10 & Aradetung & $8^{\circ} 35^{\prime}$ & $122^{\circ} 30^{\prime}$ & 720 \\
\hline 6 & 29 & 11 & Saler Wukok & $8^{\circ} 23^{\prime}$ & $122^{\circ} 40^{\prime}$ & 940 \\
\hline 7 & 36 & 12 & Lewotobi & $8^{\circ} 31^{\prime}$ & $122^{\circ} 46^{\prime}$ & 500 \\
\hline 7 & 39 & 13 & Lewotobi & $8^{\circ} 31^{\prime}$ & $122^{\circ} 46^{\prime}$ & 660 \\
\hline 7 & 42 & 14 & Lewotobi & $8^{\circ} 31$ & $122^{\circ} 46^{\prime}$ & 650 \\
\hline 7 & 45 & 15 & Lewotobi & $8^{\circ} 31^{\prime}$ & $122^{\circ} 46^{\prime}$ & 700 \\
\hline 7 & 46 & 16 & Lewotobi & $8^{\circ} 31^{\prime}$ & $122^{\circ} 46^{\prime}$ & 700 \\
\hline 8 & 48 & 17 & Ilimandiri & $8^{\circ} 18^{\prime}$ & $122^{\circ} 58^{\prime}$ & 650 \\
\hline 8 & 51 & 18 & Ilimandiri & $8^{\circ} 18^{\prime}$ & $122^{\circ} 58^{\prime}$ & 400 \\
\hline 8 & 54 & 19 & Ilimandiri & $8^{\circ} 18^{\prime}$ & $122^{\circ} 58^{\prime}$ & 420 \\
\hline 9 & 60 & 20 & Egon & $8^{\circ} 40^{\prime}$ & $122^{\circ} 26^{\prime}$ & 780 \\
\hline
\end{tabular}




\subsection{Métodos}

\subsubsection{Análises estatísticas}

Foram utilizados dois modelos matemáticos, um para a análise do ensaio, que foi instalado como parcela subdividida e outro para a análise das progênies selecionadas, de acordo com o delineamento de blocos casualizados porque em cinco procedências, apenas uma progênie foi selecionada, prejudicando a análise como parcela subdividida.

Nas análises estatísticas do ensaio (DAP, altura e volume cilíndrico) considerou-se o seguinte modelo matemático expresso na equação 1 .

$Y_{i j k l}=m+t_{i}+b_{j}+e_{k(j)}+p_{k}+e_{i j k} 1$,

Em que:

$\mathrm{Y}_{\mathrm{ijkl}}$ : valor observado na 1-ésima planta da subparcela da k-ésima progênie, dentro da parcela que recebeu a i-ésima procedência, no j-ésimo bloco;

m: média geral;

$t_{\mathrm{i}}$ : efeito da i-ésima procedência i $(\mathrm{i}=1,2, \ldots 13)$, aleatório;

$\mathrm{b}_{\mathrm{j}}$ : efeito do j-ésimo bloco $(\mathrm{j}=1,2,3)$, aleatório;

$e_{k}(\mathrm{ij})$ : erro atribuído dentro da parcela que recebeu a i-ésima procedência, no j-ésimo bloco, (Erro a), aleatório;

$\mathrm{p}(\mathrm{t})_{\mathrm{k}(\mathrm{i})}$ : efeito da k-ésima progênie $(\mathrm{k}=1,2,3, \ldots 67)$ dentro da i-ésima procedência, aleatório;

$\mathrm{e}_{\mathrm{ijk}}$ 1: erro atribuído a l-ésima planta $(1=1,2,3, \ldots 10)$ da subparcela da k-ésima progênie, dentro da parcela que recebeu a i-ésima procedência, no j-ésimo bloco, aleatório, (Erro b). 
Realizou-se um inventário florestal neste ensaio e com base nos resultados silviculturais e procurando abranger o maior número de procedências possíveis foram selecionadas 20 progênies. A seleção fenotípica foi feita em progênies que apresentavam mais de 2 plantas por parcela, evitando-se desta forma a eliminação da progênie na repetição, e que apresentavam produtividade próxima da média do ensaio.

Para a análise das progênies selecionadas, considerou-se o seguinte modelo matemático expresso na equação 2 .

$Y_{i j k}=m+t_{i}+b_{j}+e_{i j k}$

Em que:

$\mathrm{Y}_{\mathrm{ijk}}$ : valor observado na k-ésima planta, no j-ésimo bloco, que recebeu a i-ésima progênie;

m: média geral;

$\mathrm{t}_{\mathrm{i}}$ : efeito da i-ésima progênie $\mathrm{i}(\mathrm{i}=1,2, \ldots 20)$, aleatório;

$b_{j}$ : efeito do j-ésimo bloco $(j=1,2,3)$, aleatório;

e $\mathrm{e}_{\mathrm{j} \mathrm{k}}$ : erro atribuído a $\mathrm{k}$-ésima planta $(\mathrm{k}=1,2)$, dentro do j-ésimo bloco, que recebeu a iésima progênie, aleatório, (Erro).

As análises estatísticas foram feitas através do procedimento estatístico PROC GLM, utilizando a soma de quadrados do tipo III, do SAS. Foram verificadas todas as pressuposições para a realização da análise de variância e quando necessário, os dados foram transformados visando a normalidade dos mesmos.

As estimativas dos componentes de variância foram obtidas pelo método dos momentos, da análise de variância (Tabela 3). 
Tabela 3. Esquema de análise de variância para as progênies selecionadas.

\begin{tabular}{lllll}
\hline Fonte de Variação & $\mathrm{GL}$ & $\mathrm{QM}$ & $\mathrm{E}(\mathrm{QM})$ & $\mathrm{F}$ \\
\hline Bloco & $\mathrm{J}-1$ & $\mathrm{Q}_{4}$ & $\sigma_{\mathrm{d}}^{2}+\mathrm{K} \sigma_{\mathrm{e}}^{2}+\mathrm{IK} \sigma_{\mathrm{b}}^{2}$ & $\mathrm{Q}_{4} / \mathrm{Q}_{2}$ \\
Tratamento & $\mathrm{I}-1$ & $\mathrm{Q}_{3}$ & $\sigma_{{ }_{d}}+\mathrm{K} \sigma_{\mathrm{e}}^{2}+\mathrm{JK} \sigma^{2}{ }_{\mathrm{t}}$ & $\mathrm{Q}_{3} / \mathrm{Q}_{2}$ \\
Erro & $(\mathrm{J}-1)(\mathrm{I}-1)$ & $\mathrm{Q}_{2}$ & $\sigma_{{ }_{\mathrm{d}}}+\mathrm{K} \sigma_{\mathrm{e}}^{2}$ & $\mathrm{Q}_{2} / \mathrm{Q}_{1}$ \\
Dentro & $\mathrm{IJ}(\mathrm{K}-1)$ & $\mathrm{Q}_{1}$ & $\sigma_{\mathrm{d}}^{2}$ & ---- \\
Total & $\mathrm{IJK}-1$ & & & \\
\hline
\end{tabular}

\subsubsection{Volume da árvore}

O ensaio foi inventariado antes do abate das árvores. Os instrumentos utilizados foram o hipsômetro Blume Leiss, para a medição da altura da árvore e o compasso dendrométrico de alumínio (suta) para a medição do seu diâmetro à altura do peito (DAP).

O volume cilíndrico das árvores foi calculado pela equação 3 .

Volcil $\left(\mathrm{m}^{3}\right)=(\pi / 4) * \mathrm{DAP}^{2} * \mathrm{H}$

Em que:

Volcil $=$ Volume cilíndrico da árvore $\left(\mathrm{m}^{3}\right)$;

$\mathrm{DAP}=$ Diâmetro a altura do peito $(\mathrm{m})$;

$\mathrm{H}=$ Altura da árvore $(\mathrm{m})$;

$\pi=$ Constante $=3,1416$. 


\subsubsection{Análise da arquitetura da copa}

A arquitetura da copa das árvores foi avaliada de maneira subjetiva, em 3 níveis (Figuras 4 e 5):

$$
\begin{aligned}
& 1=\text { Aberta; } \\
& 2=\text { Intermediária; } \\
& 3=\text { Fechada } .
\end{aligned}
$$

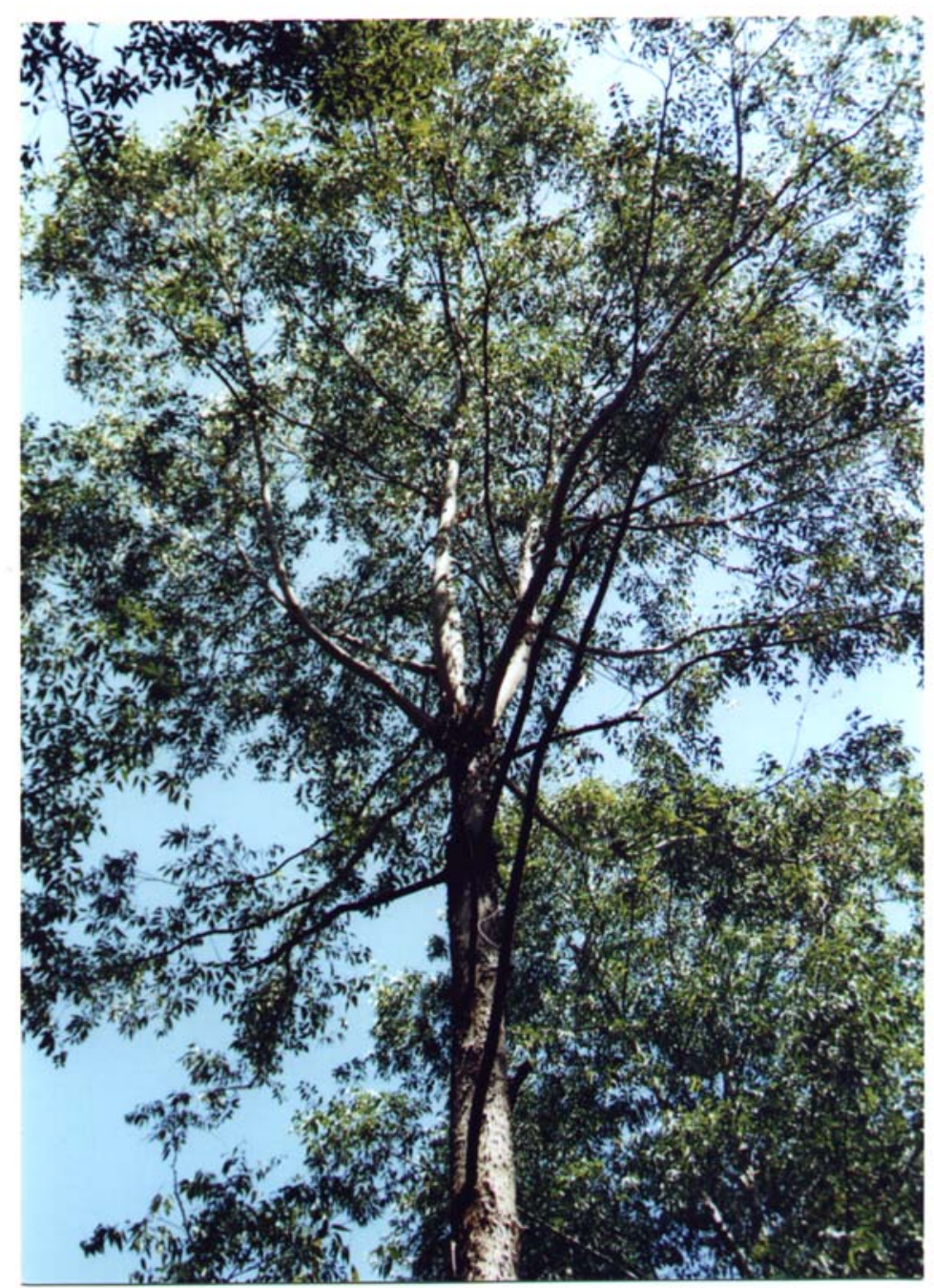

Figura 4 - Copa aberta de E. urophylla. 


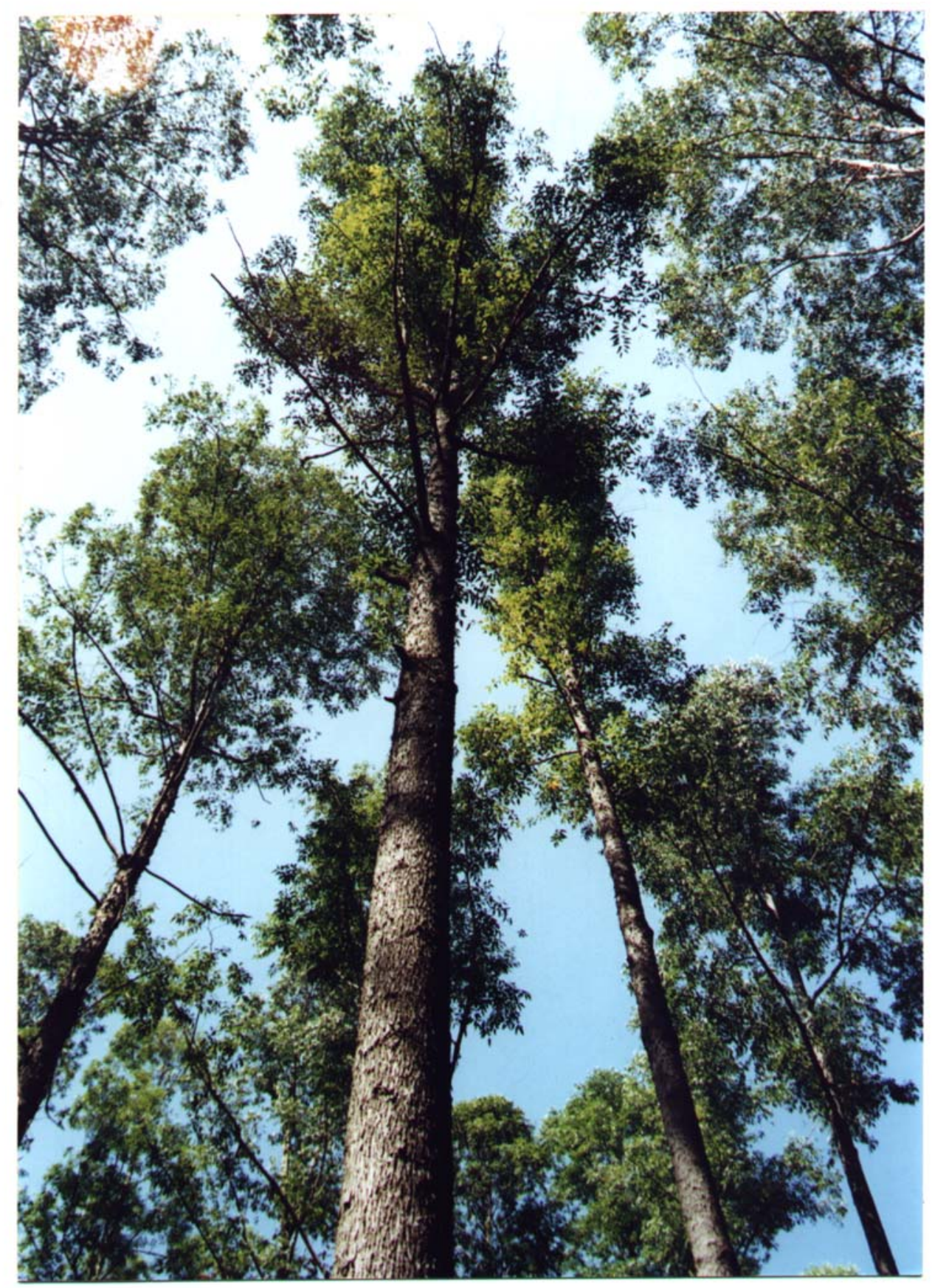

Figura 5 - Copa fechada de E. urophylla. 


\subsubsection{Análise da casca}

A casca da árvore foi avaliada de maneira subjetiva, em 3 níveis (Figuras 6 e 7):

$1=$ Lisa;

2 = Rugosa até meia altura do fuste (meia casca);

3 = Rugosa em toda a extensão do fuste.

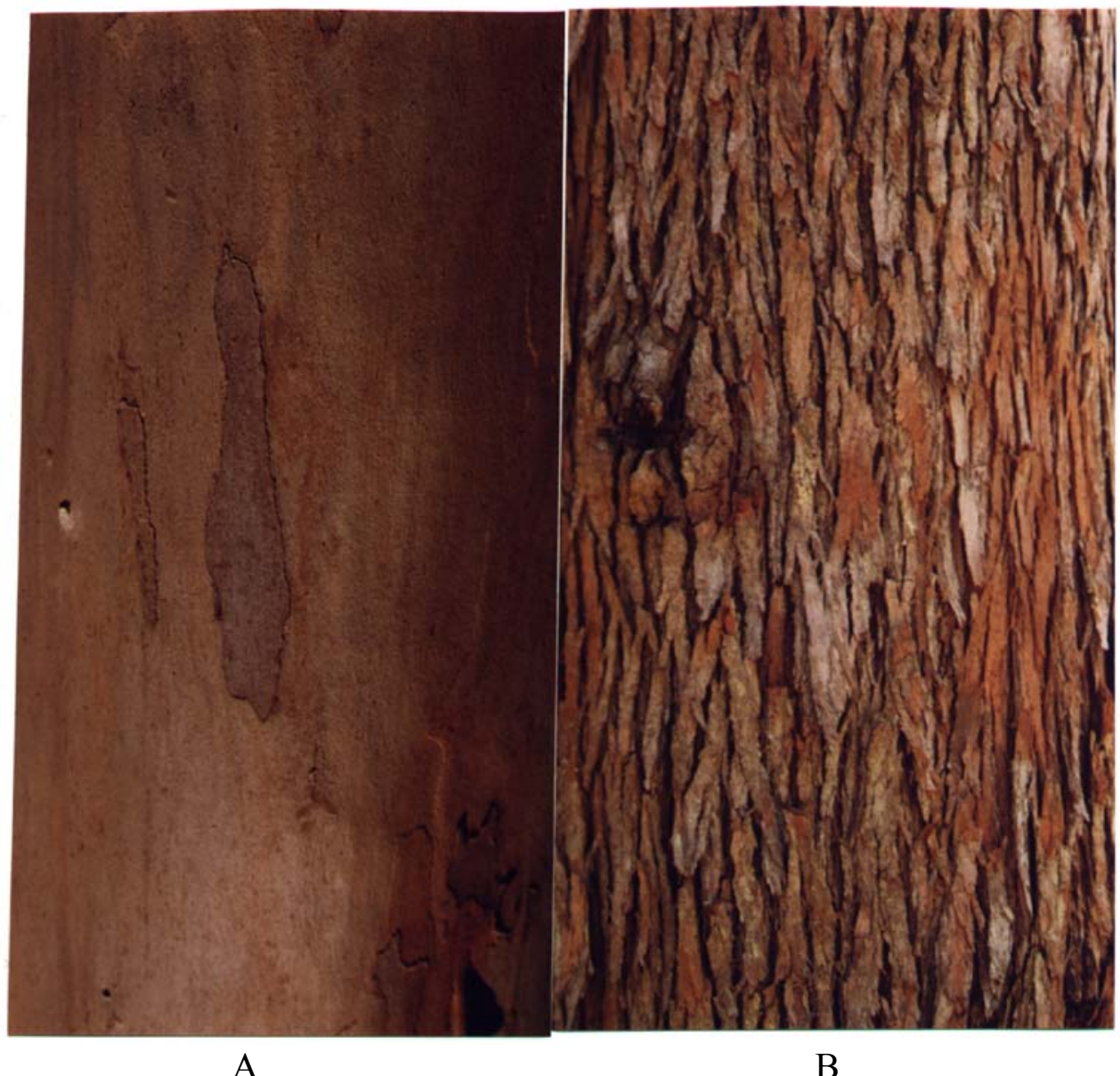

Foto 6 - Casca lisa (A) e rugosa (B) do E. urophylla. 


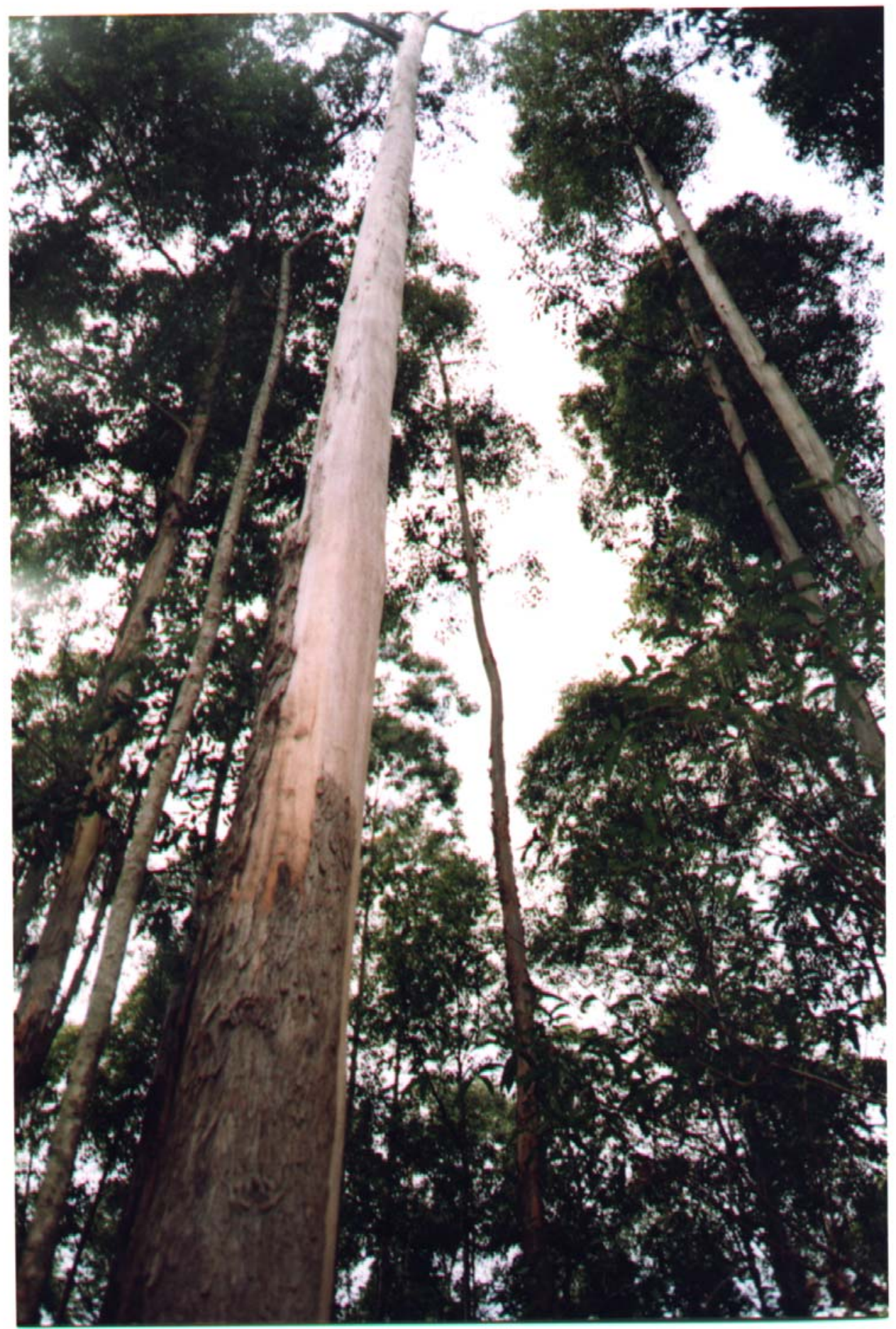

Foto 7 - Árvore tipo meia casca do E. urophylla. 


\subsubsection{Análise da Folha}

De cada árvore selecionada foram colhidas folhas adultas (coriáceas) e não senescentes da porção mediana da copa. Estas folhas foram herbarizadas e depois de secas foram selecionadas 10 folhas por progênie e avaliadas para as seguintes características quantitativas: comprimento do pecíolo, comprimento e largura da folha, comprimento da cauda e a razão entre o comprimento e a largura da folha (L1/W). Estes parâmetros foram obtidos com o auxílio de um paquímetro digital com $0,01 \mathrm{~mm}$ de precisão (Figura 8).

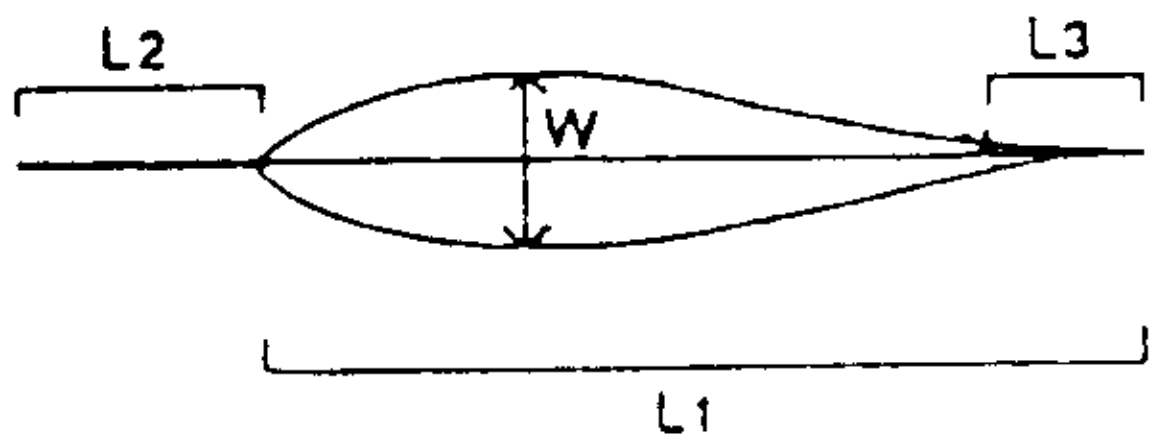

Figura 8 - Variáveis da folha do E. urophylla (Pryor et al., 1995), em que: L1 = Comprimento da folha; L2 = Comprimento do pecíolo; L3 = Comprimento da cauda ou expansão da nervura e do limbo; W = Maior largura da folha.

Também foi analisada a forma das folhas (característica qualitativa), baseado em Penfold \& Willis (1961) e Brooker \& Kleinig (1983) (Figura 9). 

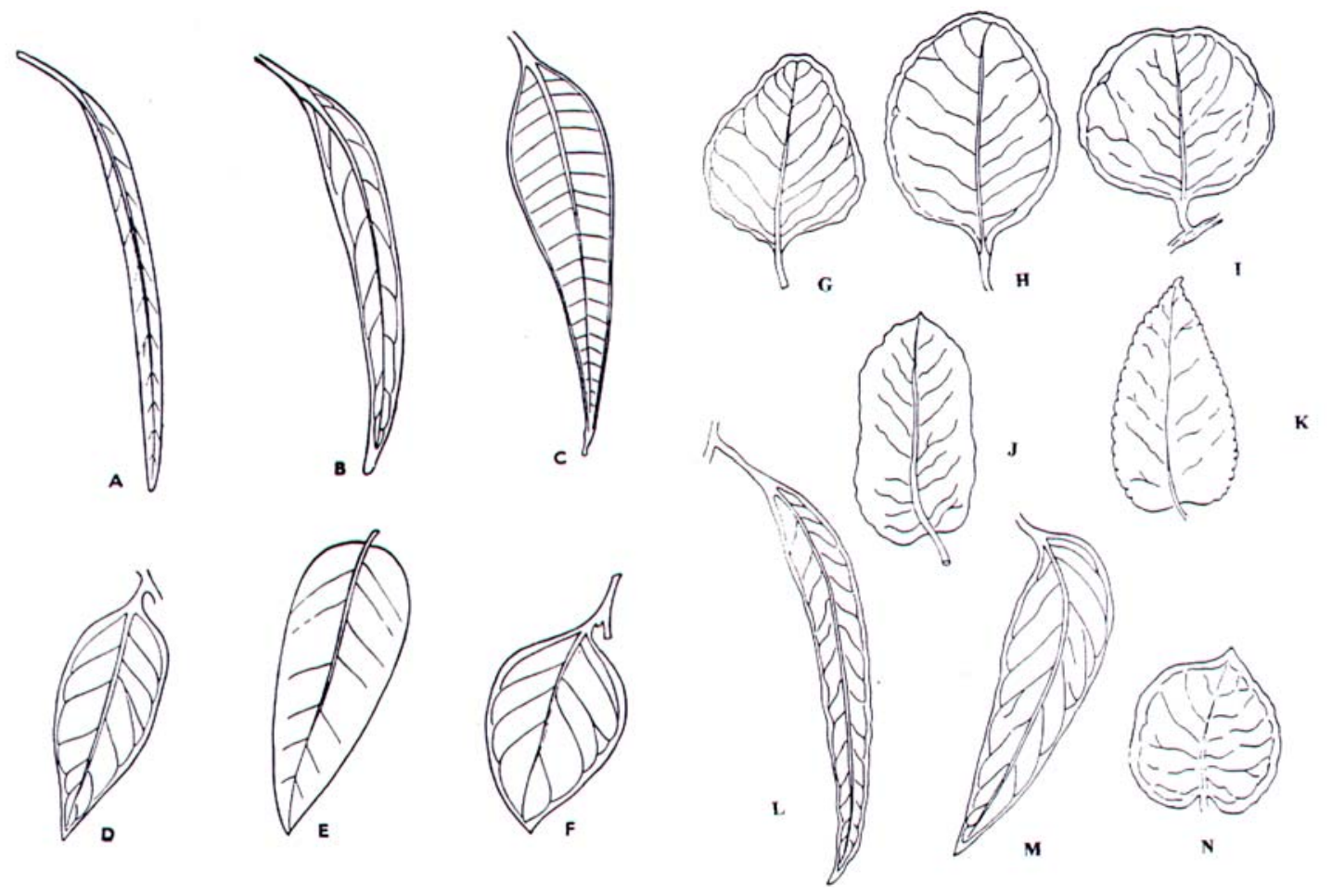

Figura 9 - Forma da folha, baseado em Penfold \& Willis (1961) e Brooker \& Kleinig (1983), em que: $\mathrm{A}=$ Linear; $\mathrm{B}=$ Lanceolada estreita; $\mathrm{C}=$ Lanceolada; $\mathrm{D}=$ Lanceolada oblonga; $\mathrm{E}=$ Lanceolada larga; $\mathrm{F}=$ Lanceolada ovóide; $\mathrm{G}=$ Ovóide; $\mathrm{H}=$ Elíptica; $\mathrm{I}=$ Orbicular; $\mathrm{J}=$ Oblonga; $\mathrm{K}=$ Margem crenada; $\mathrm{L}=$ Falcada; $\mathrm{M}=$ Oblíqua; $\mathrm{N}=$ Cordiforme.

\subsubsection{Análise do Fruto}

De cada árvore selecionada foram colhidos frutos maduros. Os frutos foram postos para secar e depois de secos foram selecionados 10 frutos por progênie, quando existiam em número abundante. Quando o número de frutos era inferior a 10, todos os frutos foram selecionados. Somente 87 das 120 progênies produziram frutos, deste modo, o número total de frutos obtidos foi de 728, quando o ideal seria de 1200 frutos. As partes que compõem o fruto estão esquematizadas na Figura 10. 


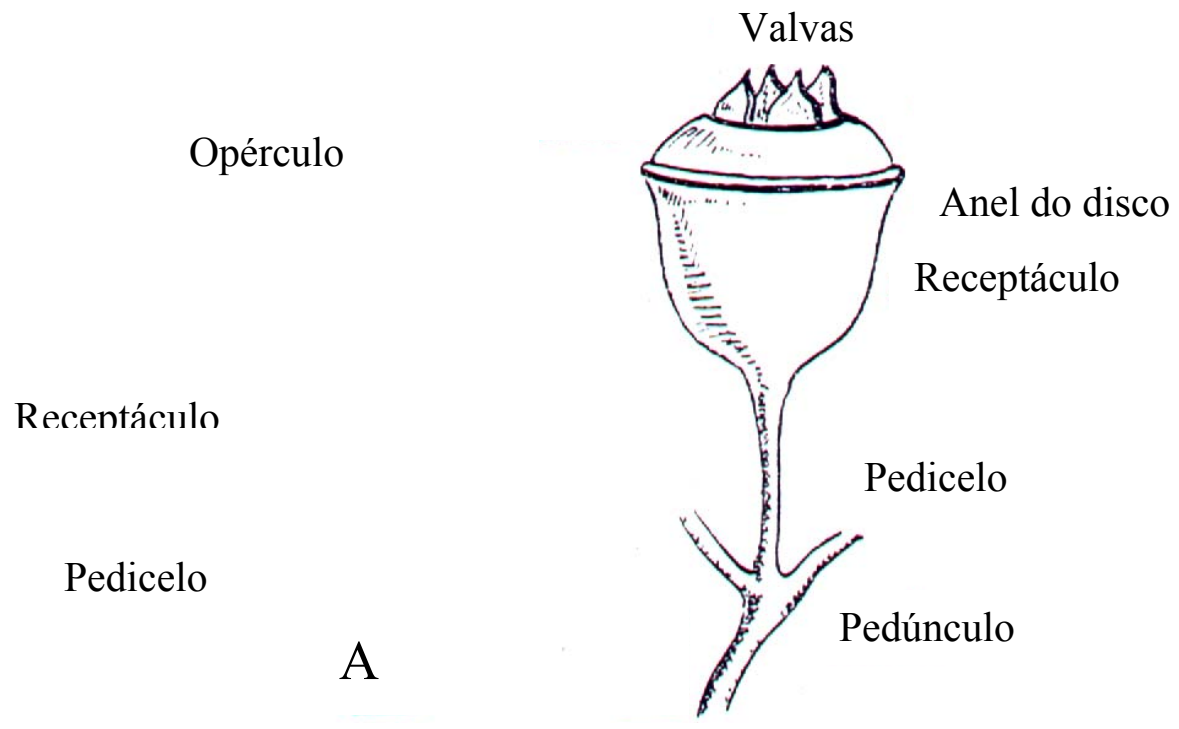

Figura 10 - Componentes do fruto, baseado em Goes (1985).

Os frutos foram avaliados nas seguintes características quantitativas: diâmetro e comprimento do fruto (receptáculo) e comprimento do pedicelo, obtidos com o auxílio de um paquímetro digital com $0,01 \mathrm{~mm}$ de precisão (Figura 11). As características qualitativas analisadas foram: posição do disco estaminal (Figura 12), posição das valvas (Figura 13), forma do fruto (Figura 14), número de valvas por fruto e número de fruto (receptáculo) por infrutescência. Estas características foram baseadas em Penfold \& Willis (1961) e Brooker \& Kleinig (1983). 


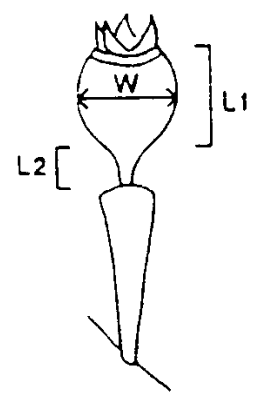

Figura 11 - Variáveis quantitativas do fruto, baseado em Pryor et al. (1995), em que: $\mathrm{L} 1$ = Comprimento do fruto; L2 = Comprimento do pedicelo e $\mathrm{W}=$ Diâmetro do fruto.

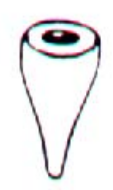

A

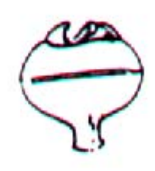

B

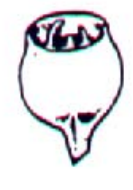

C

Figura 12 - Posição do disco do anel estaminal, baseado em Brooker \& Kleinig, (1983), em que: $\mathrm{A}=$ Rasante ou nivelado; $\mathrm{B}=$ Saliente e $\mathrm{C}=$ Incluso.

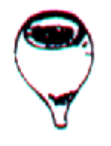

A

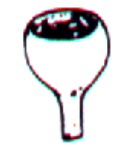

B

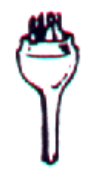

$\mathrm{C}$

Figura 13 - Posição das valvas, baseado em Brooker \& Kleinig, (1983), em que: $\mathrm{A}=$ Inclusas; $\mathrm{B}=$ Rasante ou niveladas e $\mathrm{C}=$ Salientes. 

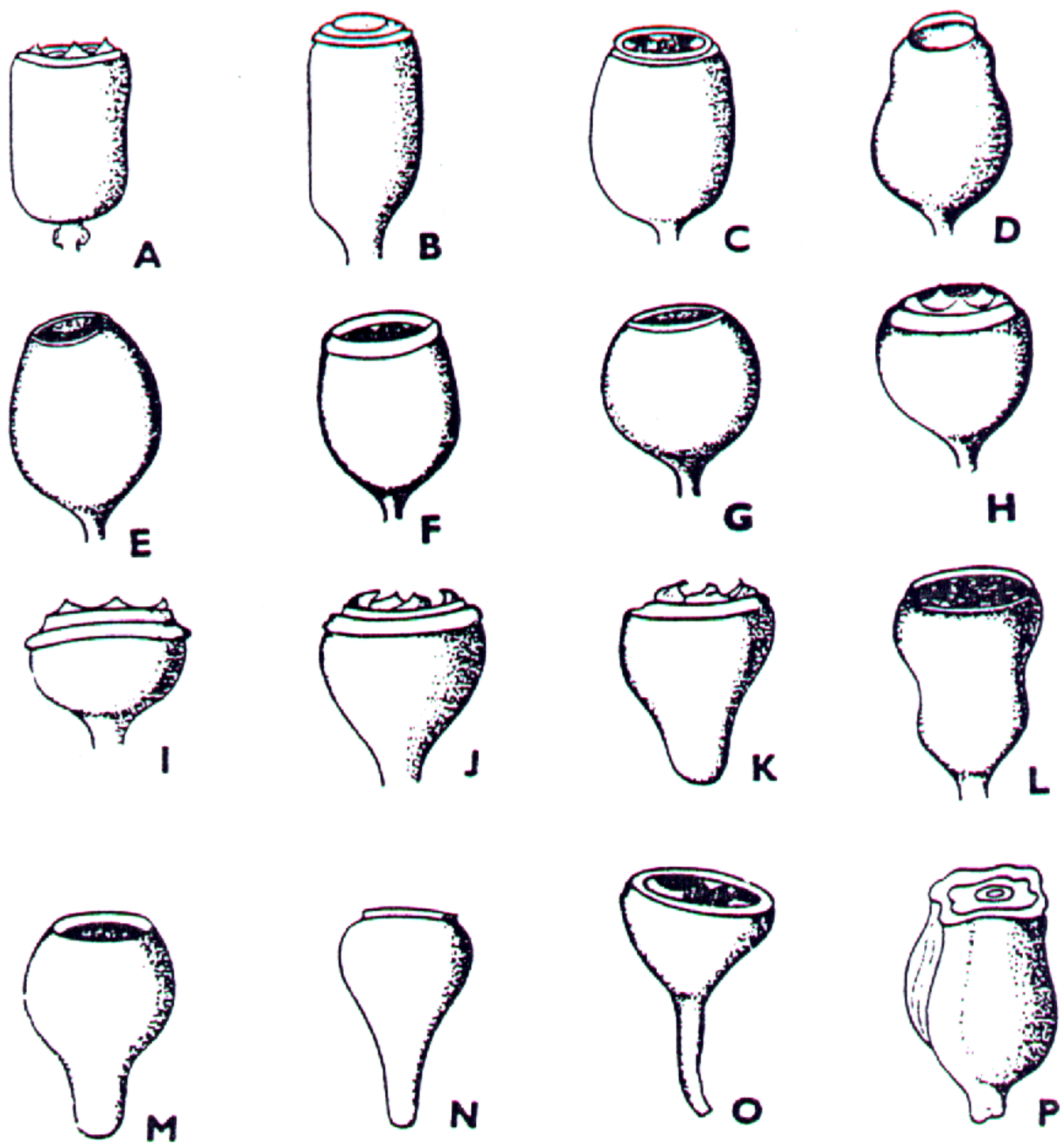

Figura 14 - Forma do fruto (receptáculo), segundo Penfold \& Willis (1961) e Brooker \& Kleinig (1983), em que: $\mathrm{A}=$ Oblongo; $\mathrm{B}=$ Cilíndrico; $\mathrm{C}=$ Barril; $\mathrm{D}=$ Urceolado; $\mathrm{E}=$ Ovóide; $\mathrm{F}=$ Ovóide truncado; $\mathrm{G}=$ Globular; $\mathrm{H}=$ Globular truncado; $\mathrm{I}=$ Hemisférico; $\mathrm{J}$ e $\mathrm{K}=$ Amplamente cônico; $\mathrm{L}=$ Campanulado; $\mathrm{M}=$ Piriforme; $\mathrm{N}$ e $\mathrm{O}=$ Cônico e $\mathrm{P}=$ Quadrangular.

\subsubsection{Rachaduras des extremidade de tora}


O método utilizado foi desenvolvido por Wilson (1985) adaptado por Schacht (1998). Esta metodologia consiste em escolher a face da tora (geralmente topo) que apresentar a maior rachadura (abertura e comprimento) e classificar esta rachadura em classes, deste modo, as rachaduras são expressas em um índice de rachadura (IR) (Tabela 4), (Figura 15).

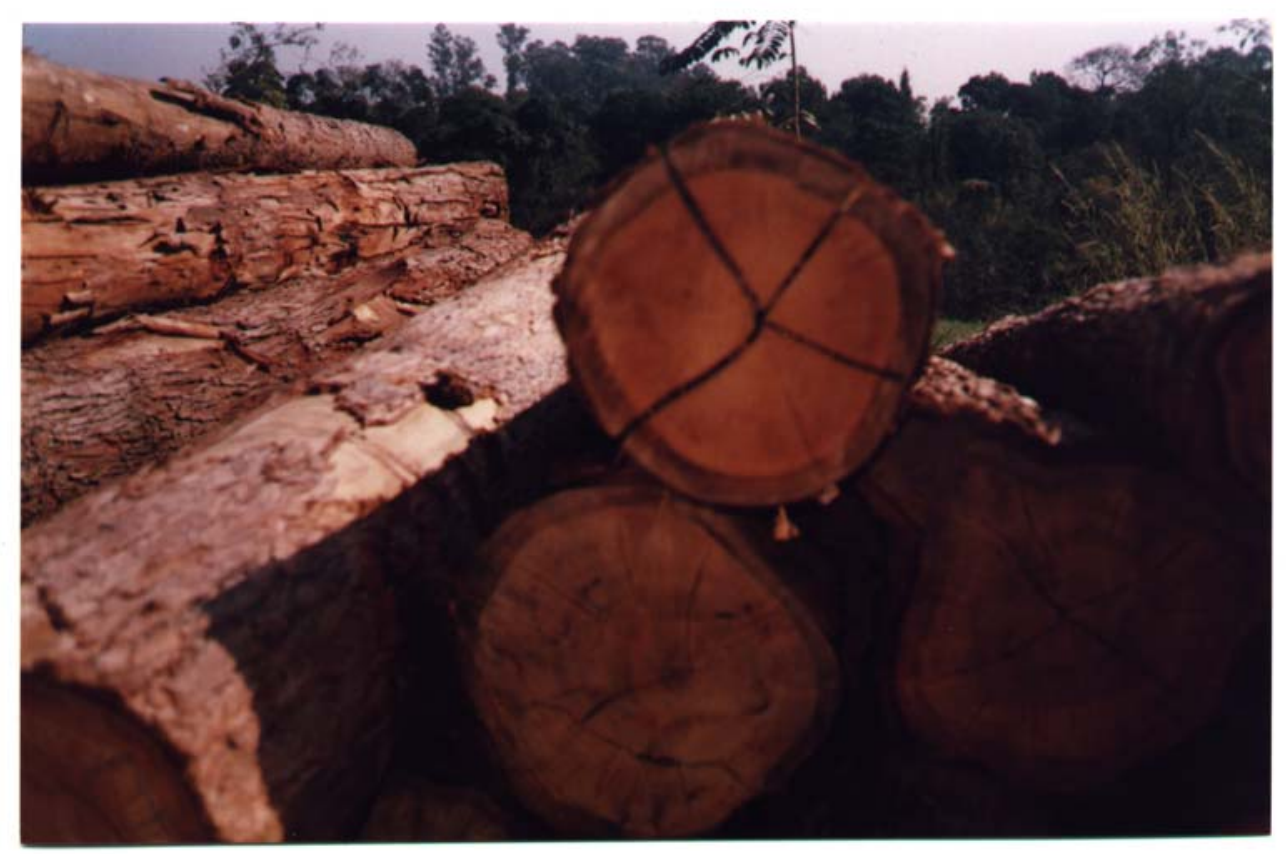

Figura 15 - Rachaduras de extremidade de tora.

Tabela 4. Pesos atribuídos as diferentes classes de comprimentos das rachaduras.

\begin{tabular}{cc}
\hline Classe de comprimento da rachadura & Peso \\
\hline Comprimento do raio da seção & 1,00 \\
Maior que $3 / 4$ e menor que o raio da seção & 0,75 \\
Maior que $1 / 2$ e menor que $3 / 4$ da seção & 0,50 \\
Maior que $1 / 4$ e menor que a $1 / 2$ do raio da seção & 0,25 \\
\hline O Índice de rachadura ( IR) foi calculado pela equação 4: \\
IR $=\frac{\left(\sum A i P i\right) \times 100}{\pi D}$
\end{tabular}


$\mathrm{Ai}=$ Abertura máxima da rachadura $(\mathrm{cm})$ (feita com um paquímetro digital de $1 \mathrm{~mm}$ de precisão, pertencente à classe de comprimento i $(i=1,2,3$ ou 4);

$\mathrm{Pi}=$ Peso da rachadura da classe $\mathrm{i}(\mathrm{cm})$;

$\mathrm{D}=$ Diâmetro médio da seção de corte $(\mathrm{cm})$.

As rachaduras de extremidades de toras foram avaliada nos tempos de 1, 7 e 60 dias após o abate das árvores.

\subsubsection{Desdobro das toras}

As toras foram desdobradas em serra de fita simples, com volante de $1,10 \mathrm{~m}$ e serra com de $3 \mathrm{~mm}$ de espessura. Os cortes foram feitos paralelos a casca, começando de um lado até atingir a medula da tora, com posterior giro de $180^{\circ}$ para que o processo fosse repetido do outro lado da tora. Foi deixado um bloco central (prancha) contendo a medula, com espessura variável, sendo que a média da espessura desta prancha foi de $62,02 \mathrm{~mm}$ com amplitude de 25,60 a $130 \mathrm{~mm}$. As tábuas retiradas tinham aproximadamente uma polegada de espessura $(2,54 \mathrm{~cm})$ (figura 16). 


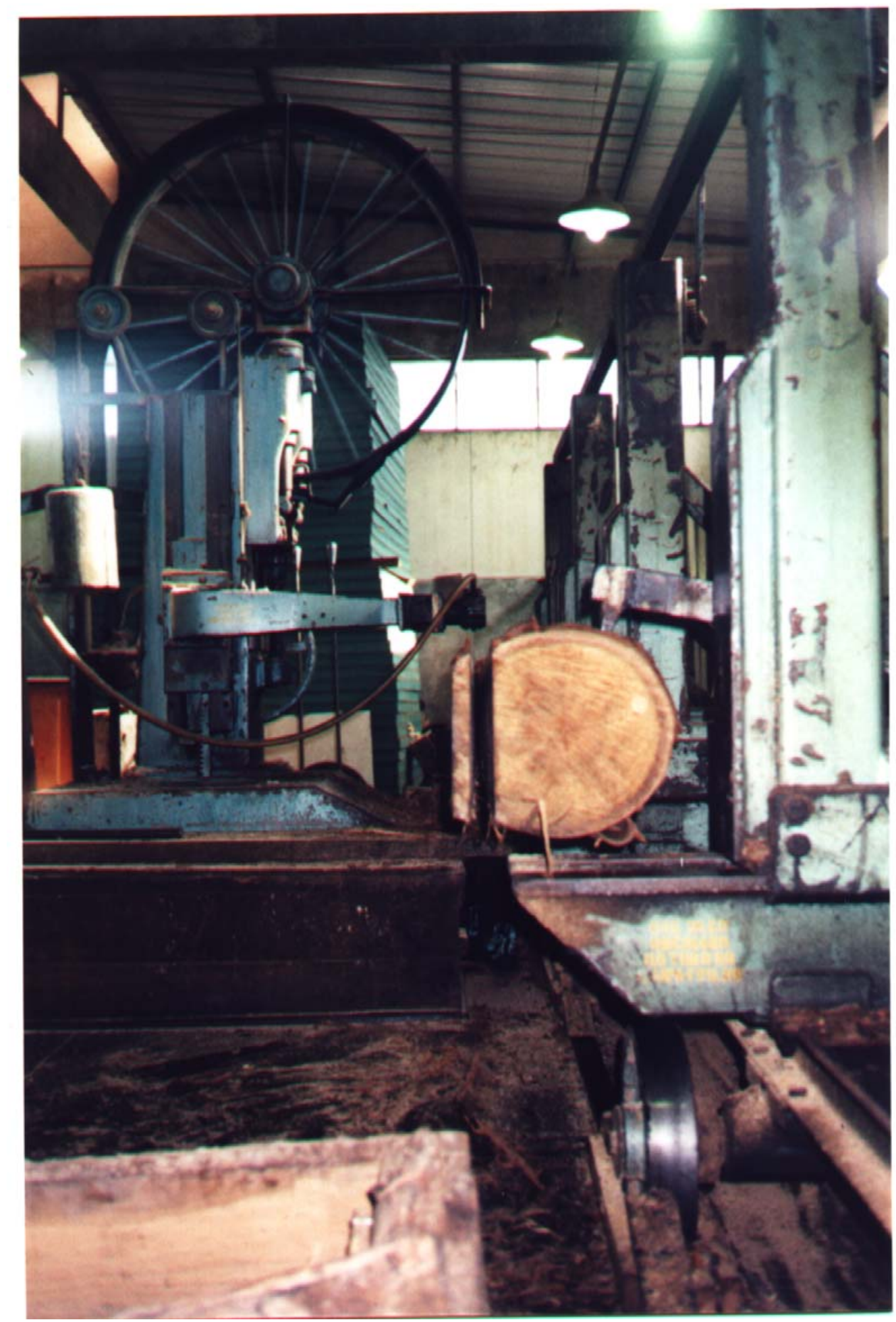

Figura 16 - Desdobro da tora em serra de fita simples. 


\subsubsection{Rachaduras das tábuas e da prancha central}

As rachaduras das tábuas e da prancha central foram mensuradas 24 horas após o desdobro das toras. Foram mensuradas a abertura e o comprimento das maiores rachaduras, na base e no topo de cada tábua, a espessura, a largura e o comprimento de cada tábua. Estas medidas foram tomadas com auxílio de uma régua com precisão de 1 mm (figura 17).

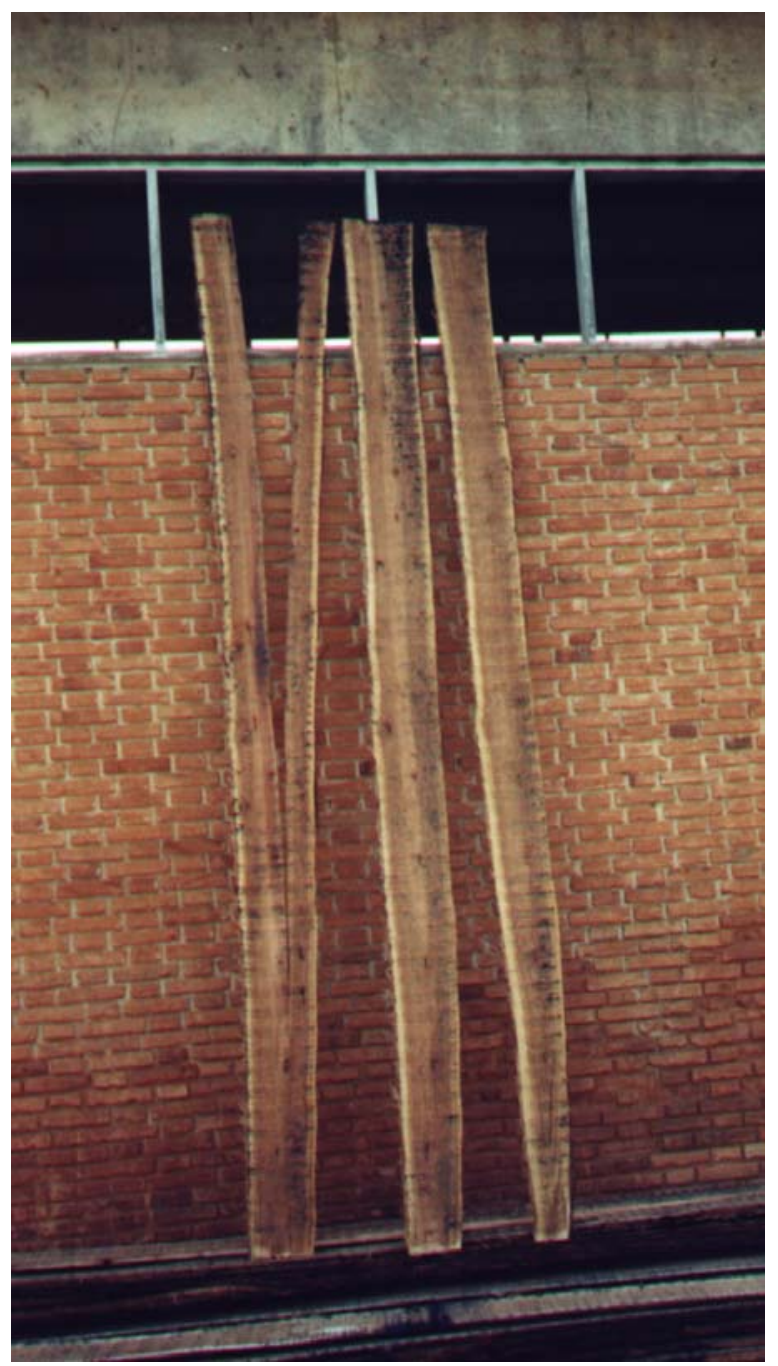

Figura 17 - Rachadura de extremidade de tábua. 


\subsubsection{Volume da tora}

As progênie selecionadas foram abatidas, cortando-se a árvore o mais próximo possível do solo, sendo que esta distância não ultrapassou $10 \mathrm{~cm}$. De cada progênie selecionada foi retirada uma tora de aproximadamente 4 metros a partir da base.

Os volumes das toras, com e sem casca foram calculados pela fórmula de Newton (Equação 5).

$\mathrm{O}$ volume de casca foi calculado pela diferença entre os volumes com e sem casca.

$$
\operatorname{Voltor}\left(m^{3}\right)=(\pi / 24) \times\left(D_{\text {base }}^{2}+4 D_{\text {médio }}+D_{\text {topo }}^{2}\right) \times h
$$

Em que:

Voltorcc $=$ Volume da tora com casca $\left(\mathrm{m}^{3}\right)$;

Voltorsc $=$ Volume da tora sem casca $\left(\mathrm{m}^{3}\right)$;

Volcasca $=$ Volume de casca $\left(\mathrm{m}^{3}\right)($ Voltorcc - Voltorsc $)$;

$\mathrm{D}_{\text {base }}=$ Diâmetro da base da tora com e sem casca $(\mathrm{m})$;

$\mathrm{D}_{\text {médio }}=$ Diâmetro do meio da tora com e sem casca $(\mathrm{m})$;

$\mathrm{D}_{\text {topo }}=$ Diâmetro do topo da tora com e sem casca $(\mathrm{m})$;

$\mathrm{h}=$ Altura (comprimento) da tora $(\mathrm{m})$.

\subsubsection{Volume das tábuas e perdas em rendimento}

$\mathrm{O}$ volume primário $=$ VOLPRI $=$ volume das tábuas e prancha central (largura * comprimento * espessura) $\left(\mathrm{m}^{3}\right)$.

$\mathrm{O}$ volume secundário $=$ VOLSEC $=$ volume das tábuas e da prancha central descontadas as rachaduras das duas extremidades das peças serradas $\left(\mathrm{m}^{3}\right)$ (tensões de crescimento longitudinal). 
$\mathrm{O}$ rendimento final baseou-se no volume das toras sem casca (Voltorsc) descontadas todas as perdas (desdobro e tensão de crescimento longitudinal) (Perdas 1 e 2).

A primeira perda aconteceu no desdobro das toras. Desta forma o VOLPRI refletiu o rendimento em madeira serrada sem levar em consideração as tensões de crescimento. As perdas causadas nestas transformações foram em função da conicidade, forma da troa, espessura da serra de corte e falhas operacionais de desdobro (Perdas 1).

O VOLSEC refletiu a influência da tensão de crescimento longitudinal no rendimento em madeira serrada, pois foram computadas as larguras e os comprimentos das peças livres de rachaduras, conseqüentes da tensão de crescimento longitudinal (Perdas 2).

As perdas foram avaliadas em porcentagem porque desta forma eliminaram-se as possíveis distorções em progênies que apresentavam toras com volumes maiores.

A tensão de crescimento longitudinal foi avaliada de forma indireta, isto é, através do rendimento em madeira serrada. VOLPRI - VOLSEC = Perda $2(\%)$.

Desta forma obtiveram-se 3 perdas a saber:

Perda 1 = Perda no desdobro da tora (Voltorsc - Volpri) (\%);

Perda 2 = Perda devido as tensões de crescimento (Volpri - Volsec) (\%);

Perda 3 = Perda total (Voltorsc - Volsec) (\%).

\subsubsection{Conicidade}

A conicidade $(\mathrm{cm} / \mathrm{m})$ foi determinada pela diferença entre o diâmetro da base e o diâmetro do topo da tora divido pelo comprimento da mesma. 
Os diâmetros foram mensurados com o auxílio de uma suta, tomando-se duas medidas em cada extremidade e fazendo-se a média destas medidas. Foram calculadas as conicidades com (Conic1) e sem casca (Conic2).

\subsubsection{Densidade básica (Db)}

As dimensões dos corpos de prova foram $2 \times 2 \times 3 \mathrm{~cm}$. Os corpos de prova foram secos em estufa a $102 \pm 3^{\circ} \mathrm{C}$ e pesados. As dimensões deste e de todos os outros corpos de provas foram mensuradas com auxílio de um paquímetro digital com $0,01 \mathrm{~mm}$ de precisão e todos os pesos foram tomados em balança eletrônica com $0,01 \mathrm{~g}$ de precisão.

A Db foi determinada pela equação 6 .

$$
\mathrm{Db}=\mathrm{Ms} / \mathrm{Vv}
$$

Em que:

$\mathrm{Db}=$ Densidade básica $\left(\mathrm{g} / \mathrm{cm}^{3}\right)$;

Ms = Massa seca $(\mathrm{g})$;

$\mathrm{Vv}=$ Volume saturado $\left(\mathrm{cm}^{3}\right)$.

\subsubsection{Retratibilidade (\%)}

A retratibilidade mede a estabilidade dimensional da madeira. Sendo esta um material ortótropo, o comportamento varia em função da orientação dos corpos de prova em relação as fibras. As dimensões dos corpos de prova foram de 2 x 2 × $3 \mathrm{~cm}$ nas direções radial, tangencial e longitudinal (axial), respectivamente.

Após a saturação dos corpos de prova em água, os mesmos foram mensurados e pesados. Em seguida, os corpos de prova foram colocados para secar em estufa à $103^{\circ} \mathrm{C} \pm 2^{\circ} \mathrm{C}$. Após a estabilização dos pesos, estes foram pesados e mensurados novamente. A retratibilidade foi mensurada em porcentagem. 


\subsubsection{Resistência ao Cisalhamento tangencial aos anéis de crescimento (Fs) (MPa)}

A resistência ao cisalhamento tangencial aos anéis de crescimento da madeira (fwv,0 ou fv0) é dada pela máxima tensão de cisalhamento que pode atuar na seção de um corpo de prova prismático, sendo dada pela equação 7 .

$\mathrm{Fv} 0=\mathrm{fv} 0, \max / \mathrm{Av} 0$.

Em que:

Fv0,max: máxima força cisalhante aplicada ao corpos de prova, em Newton $(\mathrm{N})$; Av0: área inicial da seção crítica do corpo de prova, num plano paralelo às fibras, $\left(\mathrm{m}^{2}\right)$.

As dimensões dos corpos de prova foram de 2 x $5 \times 3 \mathrm{~cm}$, com $10 \mathrm{~cm}^{2} \mathrm{na}$ área de cisalhamento (Figura 18). A força aplicada foi de aproximadamente $400 \mathrm{~kg} / \mathrm{min}$.

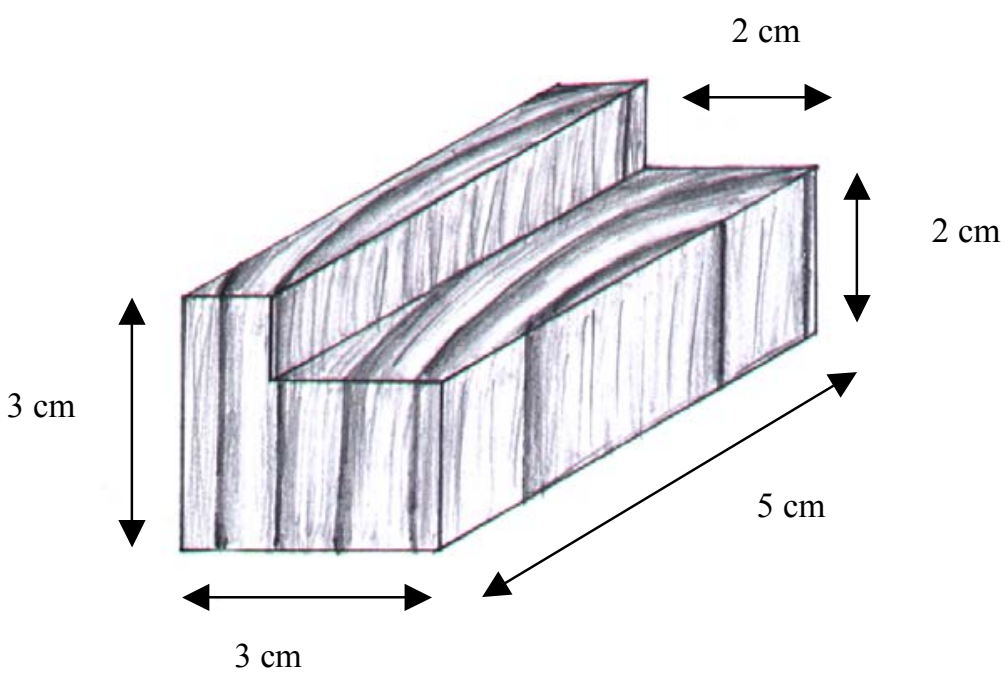

Figura 18 - Corpo de prova do ensaio de cisalhamento. 


\subsubsection{Resistência a Compressão paralela às fibras (Fc) (MPa)}

Este ensaio determina a resistência e a rigidez à compressão paralela às fibras da madeira, de um lote considerado homogêneo.

A resistência à compressão paralela às fibras da madeira (fwc,0 ou fc0) é dada pela máxima tensão de compressão que pode atuar em um corpos de prova com seção transversal quadrada de 2 × $2 \mathrm{~cm}$, sendo dada pela equação 8 .

$\mathrm{Fc} 0=\mathrm{fc} 0, \max / \mathrm{A}$

Em que:

Fc0,max: máxima força de compressão aplicada ao corpo de prova durante o ensaio $(\mathrm{N})$; A: área inicial da seção transversal comprimida $\left(\mathrm{m}^{2}\right)$.

As dimensões dos corpos de prova foram de $3 \times 2 \times 2 \mathrm{~cm}$, totalizando

$4 \mathrm{~cm}^{2}$ na área de compressão. Na determinação desta propriedade foi aplicada uma força de $400 \mathrm{~kg} / \mathrm{min}$.

\subsubsection{Resistência à flexão estática (Ff) (MPa) e módulo de elasticidade na flexão estática (Ef) (MPa)}

Este ensaio visa determinar a resistência e a rigidez da madeira à flexão, em um lote de madeira considerado homogêneo.

A resistência da madeira à flexão $\left(\mathrm{fw}_{\mathrm{M}}\right.$ ou $\left.\mathrm{f}_{\mathrm{M}}\right)$ é um valor convencional dado pela máxima tensão que pode atuar em um corpo de prova no ensaio de flexão simples, calculado com a hipótese da madeira ser um material elástico, sendo este valor calculado conforme a equação 9. 
$\mathrm{f}_{\mathrm{M}}=\mathrm{Mmax} / \mathrm{We}$

Em que:

Mmax: máximo momento aplicado ao corpos de prova (Nm);

We: módulo de resistência elástica da seção transversal do corpo de prova, dado por $\mathrm{bh}^{2} / 6$ expresso em metro cúbico $\left(\mathrm{m}^{3}\right)$.

A Resistência à flexão e o módulo de elasticidade à flexão foram obtidos simultaneamente de um mesmo corpo de prova cujas dimensões foram de 2 x 2 × $60 \mathrm{~cm}$ (base $\mathrm{x}$ altura $\mathrm{x}$ comprimento) usando a máquina universal de ensaios.

O ensaio consistiu em aplicar uma carga no meio do comprimento do corpo de prova, que estava apoiado nas duas extremidades da máquina universal e que apresentou $50 \mathrm{~cm}$ de vão livre, portanto estava sujeito à flexão. A carga foi aumentada gradativa e constantemente, permitindo a medição da flecha a cada aumento de $5 \mathrm{kgf}$ de carga até o rompimento do mesmo.

A carga foi aplicada tangencialmente aos anéis de crescimento do corpo de prova. A velocidade de aplicação da carga foi tal que a tensão aumentou em $100 \mathrm{kfg} / \mathrm{cm}^{2} / \mathrm{min}$. A flecha foi medida com auxílio de um relógio digital com precisão de $0,01 \mathrm{~mm}$.

Os resultados obtidos nesta medição permitiram fazer um gráfico, o trecho do gráfico que apresentou uma reta, isto é, sofreu deformação proporcional à carga $(\mathrm{x}=$ deformação e $\mathrm{y}=$ carga $)$ foi utilizado para determinar o módulo de elasticidade, através do coeficiente angular desta reta dada pela equação 10.

$\mathrm{P}=\mathrm{A}+\mathrm{Bf}$.

Em que:

$\mathrm{P}=$ Carga aplicada $(\mathrm{N})$;

$\mathrm{A}=$ Coeficiente linear da reta;

$\mathrm{B}=$ Coeficiente angular da reta $\left(\mathrm{R}^{2}=0,9223\right)$;

$\mathrm{f}=$ Valor da deformação da flecha (m). 
$\mathrm{O}$ módulo de ruptura à flexão estática $(\mathrm{Ff})$ é calculado através da equação 11.

$$
F f=\frac{3 \times P \times L}{2 \times b \times h^{2}}
$$

Em que:

$\mathrm{Ff}=$ Módulo de ruptura à flexão estática (MPa);

$\mathrm{P}=$ Carga aplicada no momento da ruptura $(\mathrm{N})$;

$\mathrm{L}=$ Vão livre da viga (no caso $0,50 \mathrm{~m}$ );

$\mathrm{b}=$ Base da seção transversal $(0,02 \mathrm{~m})$;

$\mathrm{h}=$ Altura da seção transversal $(0,02 \mathrm{~m})$.

O módulo da elasticidade à flexão estática (Ef) foi calculado pela equação

12.

$E f=\frac{B \times L^{3}}{4 \times b \times h^{2}}$

Em que:

$\mathrm{Ef}=$ Módulo de elasticidade à flexão estática (MPa);

$\mathrm{B}=$ Coeficiente angular da reta encontrada através da regressão linear da equação $\mathrm{P}=\mathrm{A}$

$+\mathrm{Bf}\left(\mathrm{R}^{2}=0,9992\right)(\mathrm{MPa})$;

$\mathrm{L}=$ vão livre da viga $(0,50 \mathrm{~m})$;

$\mathrm{b}=$ Base da seção transversal $(0,02 \mathrm{~m})$;

$\mathrm{h}=$ Altura da seção transversal $(0,02 \mathrm{~m})$. 


\section{RESULTADOS E DISCUSSÕES}

\subsection{Análise silvicultural do ensaio}

A Tabela 5 apresenta os resultados das análises estatísticas das características silviculturais. As Figuras 19 e 20 apresentam respectivamente, as freqüências dos tipos de casca e copa, no ensaio. As Tabelas 6 e 7, apresentam a produtividade do ensaio em função do tipo de casca e do tipo de copa, respectivamente.

Tabela 5. Resumo da análise de variância para a raiz quadrada do DAP ( $\sqrt{D A P})$, raiz quadrada da altura $(\sqrt{\text { Altura }})$ e raiz quadrada do Volume cilíndrico ( $\sqrt{\text { Volcil }})$.

\begin{tabular}{lllll}
\hline & & & \multicolumn{2}{c}{ QM } \\
FV & GL & $\sqrt{D A P}$ & $\sqrt{\text { Altura }}$ & $\sqrt{\text { Volcil }}$ \\
\hline Bloco & 2 & 0,000065 & 0,4218 & 0,0183 \\
Procedência & 12 & $0,004590 \mathrm{~ns}$ & $0,1810 \mathrm{~ns}$ & $0,2270 \mathrm{~ns}$ \\
Erro a & 23 & 0,003875 & 0,1048 & 0,1627 \\
Progênie & 54 & $0,003337 \mathrm{~ns}$ & $0,2019 \mathrm{~ns}$ & $0,1698 \mathrm{~ns}$ \\
Erro b & 602 & 0,002941 & 0,1504 & 0,1370 \\
CVe (\%) & & 10,26 & 6,60 & 24,96 \\
\hline ns = não significativo. & & &
\end{tabular}


A Tabela 5 mostra que pelo teste $\mathrm{F}$ não houveram diferenças estatísticas entre as procedências ou progênies para todas as características de crescimento. $\mathrm{O}$ coeficiente de variação experimental foi baixo para a altura e médio para o DAP e o volume cilíndrico, conforme classificação de Garcia (1989), mostrando que a altura sofreu menos influência ambiental que o DAP.

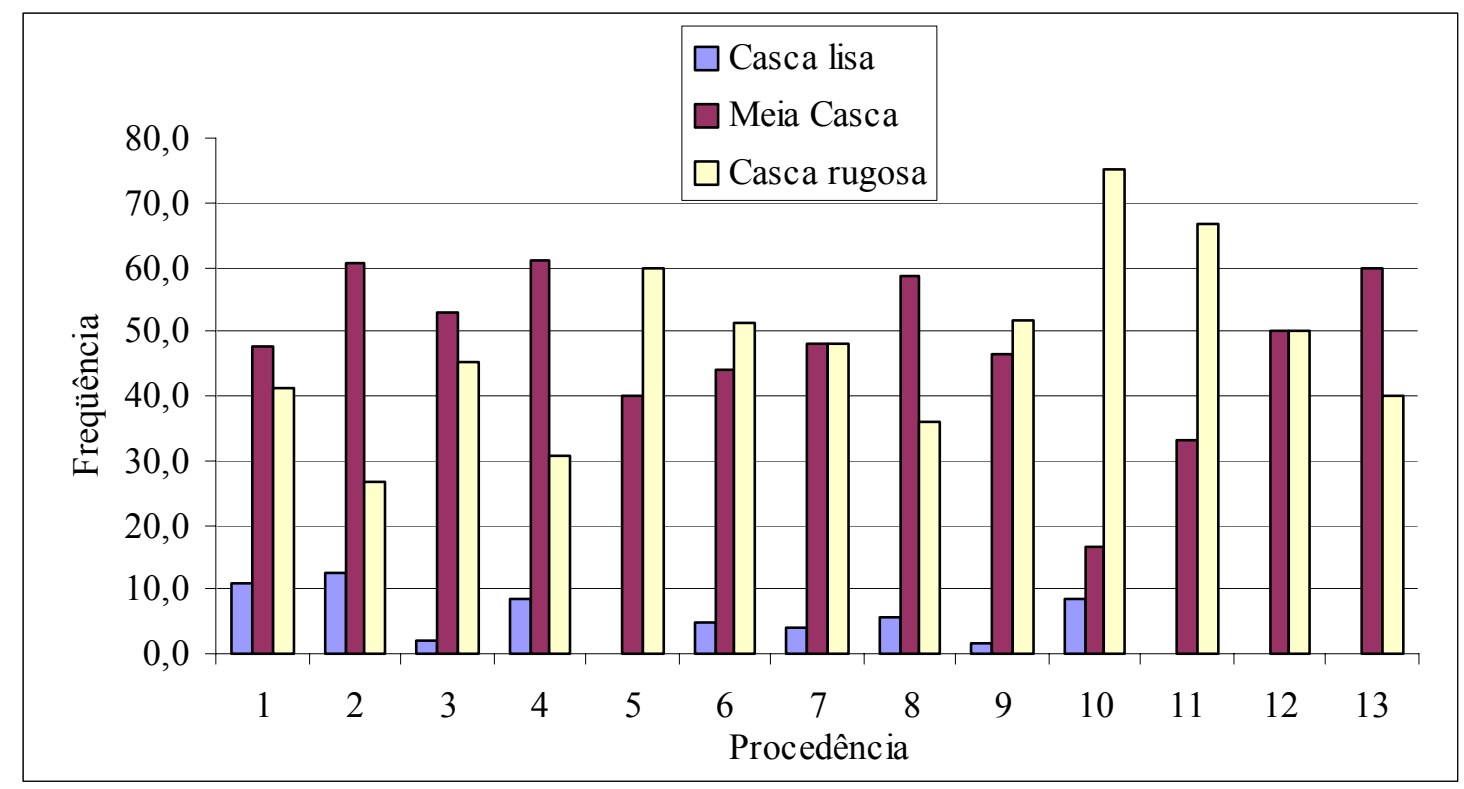

Figura 19 - Tipos de casca dentro de procedência.

A Figura 19 mostra que a freqüência de árvores com casca lisa foi muito baixa $(5,2 \%)$ e que não apareceram árvores com casca lisa nas procedências $5,11,12$ e 13.

A freqüência de árvores com casca rugosa até metade da altura do fuste, predominou no teste com $51,4 \%$ do total, sendo predominante nas procedências $1,2,3$, 4,8 e 13 .

As árvores com casca rugosa apresentaram 43,4\% de freqüência e predominaram nas procedências 5, 6, 9, 10 e 11 . As procedências 7 e 12 apresentaram freqüências iguais para os dois últimos tipos. 
As freqüências dos tipos de casca encontradas no presente experimento, estão de acordo com as descrições de Martin \& Cossalter (1975a) e Viera \& Bucsan (1980). Luz (1997) trabalhando com progênies de Lewotobi e Egon, também encontrou freqüências próximas a estas.

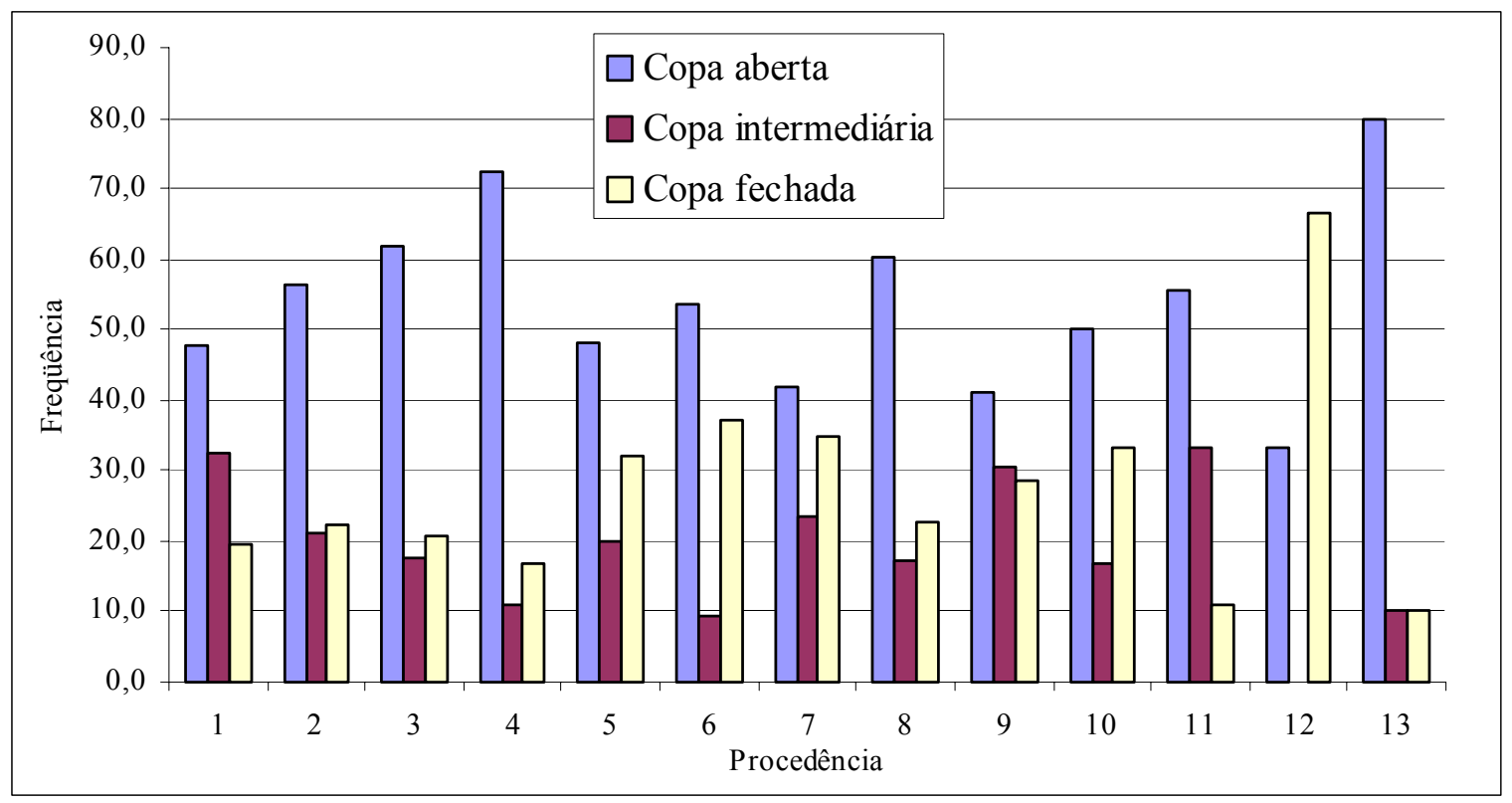

Figura 20 - Tipos de copa dentro de procedência.

A Figura 20 mostra que a freqüência de árvores de copa aberta predominou no teste com 53,3\% do total, predominando em todas as procedências, exceto na procedência 12 , onde predominou a copa fechada.

As freqüências de árvores de copa intermediária e de copa fechada foram de $20,3 \%$ e $26,4 \%$, respectivamente.

Tabela 6. Tipo de casca, número de observações em porcentagem (N\%), DAP (m), altura $(\mathrm{m})$ e volume cilíndrico $\left(\mathrm{m}^{3}\right)$, com os respectivos coeficientes de variação em porcentagem $(\mathrm{CV} \%)$. 


\begin{tabular}{llllllll}
\hline Tipo de casca & N\% & DAP & CV \% & Alt & CV \% & Volcil & CV \% \\
\hline Lisa & 5,2 & $0,2840 \mathrm{~A}$ & 20,43 & $34,99 \mathrm{~A}$ & 12,48 & $2,3814 \mathrm{~A}$ & 46,67 \\
Meia casca & 51,4 & $0,2875 \mathrm{~A}$ & 20,08 & $34,94 \mathrm{~A}$ & 12,35 & $2,4334 \mathrm{~A}$ & 48,32 \\
Rugosa & 43,4 & $0,2758 \mathrm{~A}$ & 21,51 & $34,26 \mathrm{~A}$ & 14,01 & $2,2297 \mathrm{~A}$ & 51,93 \\
Média & & 0,2822 & 20,77 & 34,65 & 13,11 & 2,3423 & 49,84 \\
\hline
\end{tabular}

A Tabela 6 mostra que o CV foi menor para a altura, seguido pelo DAP e maior para o volume cilíndrico. Mesmo não havendo diferença estatística para as características de produtividade em função do tipo de casca, houve uma ligeira superioridade no volume para o tipo meia casca seguido do tipo casca lisa e por último o tipo casca rugosa.

Luz (1997) estudou procedências de E. urophylla em função do tipo de casca (rugosa, meia casca e lisa) e encontrou uma tendência da produtividade (DAP, altura e volume) das árvores ser maior no tipo casca rugosa seguido pelo tipo meia casca, que por sua vez apresentou produtividade maior que o tipo casca lisa.

A Tabela 7 apresenta os parâmetros dendrométricos em função do tipo de copa. 
Tabela 7. Tipo de copa, número de observações em porcentagem (N\%), DAP (m), altura (m) e volume cilíndrico $\left(\mathrm{m}^{3}\right)$, com os respectivos coeficientes de variação em porcentagem $(\mathrm{CV} \%)$.

\begin{tabular}{llllllll}
\hline Tipo de copa & N\% & DAP & CV \% & Alt & CV \% & Volcil & CV \% \\
\hline Aberta & 53,3 & $0,2878 \mathrm{~A}$ & 20,65 & $34,78 \mathrm{~A}$ & 13,13 & $2,4431 \mathrm{~A}$ & 49,46 \\
Intermediária & 20,3 & $0,2773 \mathrm{AB}$ & 21,56 & $34,38 \mathrm{~A}$ & 13,59 & $2,2636 \mathrm{AB}$ & 52,57 \\
Fechada & 26,4 & $0,2748 \mathrm{~B}$ & 29,06 & $34,58 \mathrm{~A}$ & 12,72 & $2,1993 \mathrm{~B}$ & 47,55 \\
Média & & 0,2822 & 20,77 & 34,65 & 13,11 & 2,3423 & 49,84 \\
\hline
\end{tabular}

A Tabela 7 mostra que também para os tipos de copa, a altura sofreu menos influência ambiental que o DAP, desta forma os CV\% foram menores para a altura, DAP e volume cilíndrico, respectivamente. Não houve diferença estatística para a altura, mas para o DAP e o volume cilíndrico houve. Quanto mais aberta a copa da árvore, maior sua produtividade. Admitindo-se que a eficiência fotossintética seja a mesma em todas as folhas, a maior produtividade é o resultado da maior quantidade de folhas na árvore.

\subsection{Análise silvicultural das progênies selecionadas}

A Tabela 8 apresenta os resultados da análise estatística das características silviculturais e as Tabelas 9 e 10, a produtividade das progênies selecionadas em função do tipo de casca e do tipo de copa, respectivamente. 
Tabela 8. Resumo da análise de variância do DAP (m), altura (m) e volume cilíndrico $\left(\mathrm{m}^{3}\right)$ das progênies selecionadas.

\begin{tabular}{lllll}
\hline & & & \multicolumn{2}{c}{ QM } \\
FV & GL & DAP & Altura & Volume cilíndrico \\
\hline Bloco & 2 & 0,00070 & 1,2089 & 0,2334 \\
Progênie & 19 & $0,00201 \mathrm{~ns}$ & $18,9874 \mathrm{~ns}$ & $0,7017 \mathrm{~ns}$ \\
Erro & 98 & 0,00161 & 19,5640 & 0,6168 \\
CVe \% & & 15,36 & 12,82 & 40,42 \\
\hline
\end{tabular}

A Tabela 8 mostra que não houve diferença estatística entre progênies para a produtividade e que os coeficientes de variação experimental (CVe) foram altos para o DAP e o volume cilíndrico e médio para a altura (Garcia, 1989). A igualdade para a produtividade entre as progênie foi intencional uma vez que o objetivo era medir a influencia da tensão de crescimento longitudinal sobre o rendimento em madeira serrada. Deste modo, era desejável que não houvesse diferença estatística entre os volumes das toras para as progênies.

Tabela 9. Tipo de casca, número de observações em porcentagem (N\%), DAP (m), altura $(\mathrm{m})$ e volume cilíndrico $\left(\mathrm{m}^{3}\right)$, com os respectivos coeficientes de variação em porcentagem (CV \%).

\begin{tabular}{lllll}
\hline Tipo de casca & $\mathrm{N} \%$ & Alt & DAP & Volcil \\
\hline Lisa & 3,4 & $37,125 \mathrm{~A}$ & $0,3125 \mathrm{~A}$ & $2,8533 \mathrm{~A}$ \\
Meia casca & 60,8 & $33,957 \mathrm{AB}$ & $0,2695 \mathrm{~B}$ & $2,1033 \mathrm{~B}$ \\
Rugosa & 35,8 & $32,687 \mathrm{~B}$ & $0,2432 \mathrm{~B}$ & $1,5868 \mathrm{~B}$ \\
Média & & 34,51 & 0,2615 & 1,9432 \\
CV\% & & 12,12 & 14,50 & 37,94 \\
\hline
\end{tabular}


A Tabela 9 mostra que o CV foi baixo para as variáveis altura e DAP e médio para o volume cilíndrico (Garcia, 1989). Houve diferença estatística entre as progênies para a produtividade em função do tipo de casca. A produtividade foi maior para a casca lisa, seguido pelo tipo meia casca e por último o tipo casca rugosa. No ensaio, o tipo meia casca foi mais produtivo que o tipo casca lisa e o tipo casca rugosa teve o pior desempenho tanto no ensaio com nas árvores selecionadas.

Somente 4 árvores de casca lisa foram selecionadas, enquanto que no ensaio existiam 36 árvores, embora estes números representem freqüências semelhantes, é mais confiável se basear em 36 árvores. Deste modo produtividade foi considerada maior para os tipo meia casca, seguido pelo tipo casca lisa e finalmente o tipo casca rugosa.

Tabela 10. Tipo de copa, número de observações em porcentagem $(\mathrm{N} \%)$, DAP $(\mathrm{m})$, altura $(\mathrm{m})$ e volume cilíndrico $\left(\mathrm{m}^{3}\right)$, com os respectivos coeficientes de variação em porcentagem (CV \%).

\begin{tabular}{lllll}
\hline Tipo de copa & $\mathrm{N} \%$ & Alt & DAP & Volcil \\
\hline Aberta & 55,8 & $35,162 \mathrm{~A}$ & $0,2737 \mathrm{~A}$ & $2,1632 \mathrm{~A}$ \\
Intermediária & 19,2 & $33,957 \mathrm{~A}$ & $0,2561 \mathrm{AB}$ & $1,8277 \mathrm{AB}$ \\
Fechada & 25,0 & $33,470 \mathrm{~A}$ & $0,2383 \mathrm{~B}$ & $1,5404 \mathrm{~B}$ \\
Média & & 34,51 & 0,2615 & 1,9432 \\
CV\% & & 12,60 & 14,62 & 38,60 \\
\hline
\end{tabular}

A Tabela 10 mostra que o CV foi médio para o volume e baixo para a altura e DAP (Garcia, 1989). Não houve diferença estatística para a altura, mas houve para o DAP e o volume cilíndrico. Para todas as características analisadas, quanto mais aberta a copa maior a produtividade. 


\subsection{Análise da folha}

Os resultados da forma da folha (características qualitativa) e a razão entre o comprimento e a largura da folha (característica quantitativa) estão na Tabela 11. Nas Tabelas 12 e 13 temos os resultados das características quantitativas e as análises estatísticas das folhas estão nas Tabelas 14 e 15, descritos e discutidos a seguir. 
Tabela 11. Tratamento (Trat), freqüência da forma da folha (Letras de acordo com a Figura 9), razão entre o comprimento (L1) e a largura (W) da folha e sua amplitude de variação.

\begin{tabular}{|c|c|c|c|c|c|c|c|c|c|c|}
\hline \multirow[b]{2}{*}{ Trat } & \multicolumn{8}{|c|}{ Forma da folha } & \multicolumn{2}{|c|}{ Razão L1/W } \\
\hline & A & B & $\mathrm{C}$ & $\mathrm{D}$ & $\mathrm{E}$ & $\mathrm{F}$ & M & $\mathrm{N}$ & Média & Amplitude \\
\hline 1 & 6,7 & 6,7 & 31,7 & & 25 & & 20 & 10 & 5,24 & 3,01 a 9,13 \\
\hline 2 & & 18,3 & 63,3 & & 6,7 & & 11,7 & & 4,81 & 3,23 a 6,91 \\
\hline 3 & & 30 & 52 & & 10 & & 6 & 2 & 4,57 & 2,76 a 6,39 \\
\hline 4 & & 20 & 62 & & 4 & & 14 & & 4,60 & 2,83 a 8,66 \\
\hline 5 & & 35 & 38,3 & & 3,3 & & 20 & 3,3 & 4,95 & 3,17 a 7,43 \\
\hline 6 & & 11,7 & 66,7 & & 1,7 & & 15 & 5 & 4,51 & 3,08 a 6,54 \\
\hline 7 & & 38 & 30 & & 10 & & 22 & & 4,89 & 3,12 a 8,59 \\
\hline 8 & & 3,3 & 56,7 & & 21,7 & & 18,3 & & 4,35 & 2,65 a 7,20 \\
\hline 9 & 5 & 13,3 & 50 & & 10 & & 13,3 & 8,3 & 4,58 & 3,26 a 7,61 \\
\hline 10 & & & 58,3 & 1,7 & 30 & 3,3 & 5 & 1,7 & 3,83 & 2,15 a 5,29 \\
\hline 11 & & & 48,3 & & 20 & & 31,7 & & 3,98 & 2,72 a 5,86 \\
\hline 12 & & 23,3 & 51,7 & & 5 & & 16,7 & 3,3 & 5,40 & 3,21 a 8,19 \\
\hline 13 & & 8,3 & 55 & & 25 & 1,7 & 8,3 & 1,7 & 3,88 & 2,32 a 6,18 \\
\hline 14 & & 13,3 & 66,7 & & 11,7 & & 8,3 & & 4,14 & 2,31 a 7,05 \\
\hline 15 & & 6,7 & 55 & & 15 & & 23,3 & & 4,80 & 2,91 a 6,79 \\
\hline 16 & 1,7 & 13,3 & 33,3 & & 26,7 & & 16,7 & 8,3 & 4,36 & 2,97 a 6,24 \\
\hline 17 & & 26,7 & 35 & & 20 & & 16,7 & 1,7 & 4,76 & 3,06 a 7,21 \\
\hline 18 & & 1,7 & 65 & 3,3 & 23,3 & & 1,7 & 5 & 3,87 & 2,31 a 6,07 \\
\hline 19 & & 21,7 & 46,7 & & 16,7 & & 8,3 & 6,7 & 4,37 & 2,79 a 7,66 \\
\hline 20 & & 16,7 & 33,3 & & 40 & 1,7 & 1,7 & 6,7 & 3,86 & 2,50 a 6,56 \\
\hline Média & 0,7 & 14,7 & 48,8 & 0,3 & 16,1 & 0,3 & 13,6 & 3,2 & 4,48 & 2,15 a 9,13 \\
\hline
\end{tabular}


A forma da folha variou de linear a cordiforme, com predominância da forma lanceolada (48,8\%). Diversos trabalhos na literatura descrevem a folha da espécie, com maior freqüência, variando entre larga a estreitamente lanceolada e acuminada (Martin \& Cossalter, 1975a; Turnbull \& Brooker, 1978; FAO, 1979; Goes, 1985; Pryor et al., 1995; Ferreira \& Souza, 1997; Ferreira, 1999).

Martin \& Cossalter (1976a) afirmaram que a forma e as dimensões das folhas variavam não só com a altitude mas também com a idade da planta. Os autores encontraram folhas lanceoladas a estreitamente lanceoladas e acuminadas. Concluíram que em altitudes maiores as folhas são mais longas e maiores, resultando em uma silhueta geralmente menos lanceolada.

Não foi observada esta tendência no presente trabalho, sendo que a forma lanceolada predominou em todas os tratamentos, exceto no tratamento 7, onde predominou a forma estreita lanceolada e no tratamento 20 onde predominou a forma larga lanceolada. Porém a amplitude de altitude analisada neste trabalho foi menor que as analisadas por Martin \& Cossalter (1976a).

A razão L1/W variou de 2,15 a 9,13 com média de 4,48. Existem vários trabalhos na literatura que apresentam valores próximos a estes (López, 1992; Ferreira \& Souza, 1997 e Ferreira, 1999).

Vários pesquisadores relataram a grande heterogeneidade nas características das folhas e dos frutos, principalmente da Ilha Flores (Martin \& Cossalter, 1976a; Turnbull \& Brooker, 1978; Vieira \& Bucsan, 1980; Eldridge et al., 1994; Pinyopusarerk et al., 1993; Pryor et al., 1995). 
Tabela 12. Tratamento (Trat), média e amplitude de variação do comprimento do pecíolo (Comp pecíolo), comprimento da folha, largura da folha e comprimento da cauda (Comp cauda).

\begin{tabular}{|c|c|c|c|c|c|c|c|c|}
\hline \multirow[b]{2}{*}{ Trat } & \multicolumn{2}{|c|}{ Comp pecíolo } & \multicolumn{2}{|c|}{ Comprimento da folha } & \multicolumn{2}{|c|}{ Largura da folha } & \multicolumn{2}{|c|}{ Comp cauda } \\
\hline & Média & Amplitude & Média & & Média & & Média & \\
\hline 1 & 26,18 & $7,97-41,55$ & & & 36,56 & & 31,90 & \\
\hline 2 & 26,84 & $-37,36$ & 66,64 & & 35,05 & & 25,17 & $3,19-47,74$ \\
\hline 3 & 26,59 & $-36,63$ & 66,68 & 26,17 & 38,00 & $-57,79$ & 31,96 & 15,4 \\
\hline 4 & 25,38 & $15,55-32,28$ & 151,25 & $96,82-206,20$ & 34,48 & $18,82-49,62$ & 27,00 & $8,42-52,55$ \\
\hline 5 & 25,72 & $14,01-33,97$ & 171,73 & $141,43-211,27$ & 35,81 & & 29,71 & $12,30-45,30$ \\
\hline 6 & 25,56 & & 167,22 & $128,64-202,08$ & 38,40 & $23,01-53,09$ & 23,48 & $9,95-48,47$ \\
\hline 7 & 24,94 & & 154,47 & & 33,44 & & & \\
\hline 8 & 26,45 & $18,91-38,29$ & 171,39 & 124 & 40,49 & $-58,91$ & 30,29 & $-67,70$ \\
\hline 9 & 23,93 & $12,05-34,59$ & 163,21 & $130,28-195,38$ & 36,84 & & 24,54 & $12,01-42,52$ \\
\hline 10 & 22,62 & $13,25-30,07$ & 157,46 & $119,95-211,32$ & 41,88 & $28,00-59,37$ & 25,46 & $3,44-54,14$ \\
\hline 11 & 23,17 & $14,23-32,11$ & 148,62 & $109,41-192,96$ & 37,97 & $29,90-51,68$ & 26,79 & $12,36-44,53$ \\
\hline 12 & 26,80 & $17,05-39,55$ & 178,94 & $128,72-227,95$ & 34,53 & & 34,68 & $13,95-75,04$ \\
\hline 13 & 25,80 & & & & & & & \\
\hline 14 & 24,75 & & 162,83 & $107,44-208,09$ & 41,18 & & 27,07 & \\
\hline 15 & 29,18 & $17,54-39,74$ & 171,92 & $126,73-234,68$ & 36,90 & $23,94-57,75$ & 33,97 & $16,21-87,83$ \\
\hline 16 & 26,81 & $13,04-37,01$ & 154,68 & $115,07-203,08$ & 36,10 & $22,36-55,11$ & 22,25 & $5,01-44,44$ \\
\hline 17 & 24,63 & $16,17-38,64$ & 161,23 & $126,13-226,81$ & 35,58 & $20,91-65,99$ & 24,04 & $4,29-54,70$ \\
\hline 18 & 25,26 & $18,09-33,70$ & 159,21 & $105,66-214,95$ & 42,05 & $30,01-56,74$ & 24,92 & $2,51-53,19$ \\
\hline 19 & 29,29 & $20,88-41,45$ & 148,19 & $119,68-201,15$ & 35,69 & $18,29-63,25$ & 23,63 & $7,00-49,02$ \\
\hline 20 & 25,66 & $17,96-39,32$ & 152,25 & $116,57-203,50$ & 41,06 & $21,34-57,49$ & 18,86 & $4,16-44,64$ \\
\hline Média & 25,78 & $12,05-41,55$ & 162,31 & $96,82-261,48$ & 37,69 & $18,29-65,99$ & 26,56 & $2,51-87,83$ \\
\hline
\end{tabular}


O comprimento do pecíolo variou de 12,05 a 41,05 mm, com média de 25,78 mm, o que esta de acordo com vários pesquisadores (Martin \& Cossalter, 1975b; Goes, 1985; López, 1992; Pryor et al., 1995).

O comprimento da folha variou de 96,82 a $261,48 \mathrm{~mm}$, com média de $162,31 \mathrm{~mm}$, corroborando os resultados obtidos por vários pesquisadores (Martin \& Cossalter, 1975b; Turnbull \& Brooker, 1978; Goes, 1985; Pryor et al., 1995; Ferreira \& Souza, 1997).

A largura da folha variou de 18,29 a $65,99 \mathrm{~mm}$, com média de $37,69 \mathrm{~mm}$. Há vários trabalhos na literatura que apresentam valores próximos a estes (Martin \& Cossalter, 1975b; Turnbull \& Brooker, 1978; Goes, 1985; Pryor et al., 1995; Ferreira \& Souza, 1997).

O comprimento da cauda variou de 2,51 a $87,83 \mathrm{~mm}$, com média de 26,56 mm. Resultado semelhante foi encontrado por Pryor et al. (1995).

Tabela 13. Resumo da análise de variância para o comprimento do pecíolo (Comp pecíolo), logaritmo (base 10) do comprimento da folha (Log comp folha), raiz quadrada da largura da folha $(\sqrt{\text { Larfolha }})$, raiz quadrada do comprimento da cauda $(\sqrt{\text { Compcaulda }})$ e o inverso da raiz quadrada da razão $\mathrm{L} 1 / \mathrm{W}(1 / \sqrt{L 1 / w})$.

\begin{tabular}{lllllll}
\hline FV & GL & Comp pecíolo & Log comp folha & $\sqrt{\text { Larfolha }} \sqrt{\text { Compcaulda }}$ & $1 / \sqrt{L 1 / w}$ \\
& & & & & \\
\hline Bloco & 2 & 81,20 & 0,0043 & 3,09 & 14,93 & 0,0227 \\
Progênie & 19 & $163,36^{* * *}$ & $0,2166^{* * *}$ & $2,91^{* * *}$ & $10,70^{* * *}$ & $0,0361^{* * *}$ \\
Erro & 1148 & 21,75 & 0,0183 & 0,37 & 1,02 & 0,0026 \\
CVe \% & & 18,09 & 2,66 & 9,98 & 20,06 & 10,58 \\
\hline
\end{tabular}

$* * *=$ significativo a $0,01 \%$ 
A Tabela 13 mostra que pelo teste $\mathrm{F}$ houve diferença altamente significativas entre progênies para todas as características quantitativas da folha e que os coeficientes de variação experimental $(\mathrm{CVe})$ foram muito bons, demonstrando a boa amostragem feita. Esta grande diferença entre as progênies reflete a heterogeneidade entre elas, mas as amplitudes destas variações estão dentro dos padrões definidos para a espécie (Martin \& Cossalter, 1975b; Turnbull \& Brooker, 1978; Goes, 1985; López, 1992; Pryor et al., 1995 e Ferreira \& Souza, 1997).

$\mathrm{Na}$ Tabela 14 encontram-se os valores médios e a classificação pelo teste de Duncan a 5\% de probabilidade para estes parâmetros. 
Tabela 14. Média do tratamentos (Trat) para o comprimento do pecíolo (Comp pecíolo), logaritmo (base 10) do comprimento da folha ( $\log$ comp folha), raiz quadrada da largura da folha $(\sqrt{\text { Larfolha }})$ e raiz quadrada do comprimento da cauda $(\sqrt{\text { Compcaulda }})$.

\begin{tabular}{|c|c|c|c|c|c|c|c|}
\hline Trat & Comp pecíolo & Trat & Log comp folha & Trat & $\sqrt{\text { Larfolha }}$ & Trat & $\sqrt{\text { Compcaulda }}$ \\
\hline 19 & $29,29 \mathrm{~A}$ & 1 & $5,1907 \mathrm{~A}$ & 18 & $6,4693 \mathrm{~A}$ & 12 & $5,8166 \mathrm{~A}$ \\
\hline 15 & $29,18 \mathrm{~A}$ & 12 & $5,1818 \mathrm{AB}$ & 10 & $6,4539 \mathrm{~A}$ & 15 & $5,7474 \mathrm{AB}$ \\
\hline 2 & $26,84 \mathrm{~B}$ & 5 & $5,1418 \mathrm{ABC}$ & 14 & $6,3840 \mathrm{AB}$ & 3 & $5,5788 \mathrm{AB}$ \\
\hline 16 & $26,81 \mathrm{~B}$ & 8 & $5,1348 \mathrm{BCD}$ & 20 & $6,3681 \mathrm{ABC}$ & 1 & $5,4871 \mathrm{ABC}$ \\
\hline 12 & $26,80 \mathrm{~B}$ & 15 & $5,1337 \mathrm{BCD}$ & 13 & $6,3474 \mathrm{ABC}$ & 5 & $5,4184 \mathrm{ABC}$ \\
\hline 3 & $26,59 \mathrm{BC}$ & 6 & 5,1104 CDE & 8 & $6,3413 \mathrm{ABC}$ & 8 & $5,3700 \mathrm{BCD}$ \\
\hline 8 & $26,45 \mathrm{BC}$ & 2 & $5,1096 \mathrm{CDEF}$ & 6 & $6,1680 \mathrm{BCD}$ & 11 & $5,1300 \mathrm{CDE}$ \\
\hline 1 & $26,18 \mathrm{BC}$ & 3 & 5,1089 CDEF & 11 & $6,1484 \mathrm{BCD}$ & 14 & $5,0932 \mathrm{CDE}$ \\
\hline 13 & $25,80 \mathrm{BCD}$ & 9 & 5,0913 CDEFG & 3 & $6,1236 \mathrm{CD}$ & 4 & $5,0602 \mathrm{DE}$ \\
\hline 5 & $25,72 \mathrm{BCD}$ & 14 & $5,0802 \mathrm{DEFGH}$ & 9 & $6,0471 \mathrm{DE}$ & 2 & $4,9063 \mathrm{EF}$ \\
\hline 20 & $25,66 \mathrm{BCD}$ & 17 & 5,0731 EFGHI & 15 & $6,0314 \mathrm{DE}$ & 9 & $4,8969 \mathrm{EF}$ \\
\hline 6 & $25,56 \mathrm{BCD}$ & 18 & 5,0554 FGHI & 1 & $6,0060 \mathrm{DE}$ & 10 & 4,8969 EF \\
\hline 4 & $25,38 \mathrm{BCD}$ & 10 & 5,0514 GHIJ & 16 & $5,9886 \mathrm{DEF}$ & 7 & $4,8917 \mathrm{EF}$ \\
\hline 18 & $25,26 \mathrm{BCD}$ & 16 & 5,0333 HIJK & 5 & $5,9579 \mathrm{DEF}$ & 18 & $4,8581 \mathrm{EF}$ \\
\hline 7 & 24,94 BCDE & 7 & 5,0327 HIJK & 19 & $5,9257 \mathrm{DEF}$ & 17 & $4,8164 \mathrm{EF}$ \\
\hline 14 & 24,75 CDE & 13 & 5,0256 HIJK & 17 & $5,9126 \mathrm{DEF}$ & 19 & $4,7821 \mathrm{EFG}$ \\
\hline 17 & $24,63 \mathrm{CDE}$ & 20 & 5,0179 IJK & 2 & $5,9085 \mathrm{DEF}$ & 6 & 4,7809 EFG \\
\hline 9 & 23,93 DEF & 4 & 4,9966 JK & 12 & $5,8406 \mathrm{EF}$ & 16 & 4,6166 FG \\
\hline 11 & $23,17 \mathrm{EF}$ & 11 & $4,9940 \mathrm{~K}$ & 4 & $5,8285 \mathrm{EF}$ & 13 & $4,4056 \mathrm{GH}$ \\
\hline 10 & $22,62 \mathrm{~F}$ & 19 & $4,9920 \mathrm{~K}$ & 7 & $5,7444 \mathrm{~F}$ & 20 & 4,2291 H \\
\hline Média & 25,78 & Média & 5,0788 & Média & 6,1049 & Média & 5,0356 \\
\hline
\end{tabular}

Médias seguidas das mesmas letras não diferem estatisticamente entre si pelo teste de Duncan a 5\% de probabilidade. 
A Tabela 14 mostra que há alternância na classificação dos tratamentos dependendo da característica analisada. De fato as correlações entre estas características foram baixas, com exceção do comprimento da folha com o comprimento da cauda $(\mathrm{R}=$ $0,6780)$ e para o comprimento da folha com a razão entre o comprimento e a largura da folha $(\mathrm{R}=0,5032)$.

Ainda pelo teste Duncan, dependendo da característica analisada, existem de 6 a 11 grupos de progênies. Ferreira (1999) trabalhando com 108 progênies de $E$. urophylla, encontrou 5 grupos, com grande amplitude entre e dentro deles e com indivíduos que não se encaixavam em nenhum destes 5 grupos.

\subsection{Análise do fruto}

Os resultados das características qualitativas (Tabelas 15 a 17) e quantitativas (Tabela 18) e as análises estatísticas (Tabelas 19 e 20) do fruto são descritos e discutidos a seguir. 
Tabela 15. Número de frutos por infrutescência (\%).

\begin{tabular}{|c|c|c|c|c|c|c|}
\hline \multirow[b]{2}{*}{ Tratamento } & \multicolumn{6}{|c|}{ Número de frutos por infrutescência em \% } \\
\hline & 3 & 4 & 5 & 6 & 7 & 8 \\
\hline 1 & 1,8 & 3,5 & 7 & 26,3 & 59,6 & 1,8 \\
\hline 2 & & 6 & 18 & 40 & 36 & \\
\hline 3 & & 10 & 13,3 & 23,3 & 53,3 & \\
\hline 4 & & & & 23,3 & 76,7 & \\
\hline 5 & 4,2 & & 20,8 & 41,7 & 33,3 & \\
\hline 6 & & 5,4 & 16,2 & 40,5 & 37,8 & \\
\hline 7 & & & & 10 & 90 & \\
\hline 8 & & 20 & 23,3 & 20 & 36,7 & \\
\hline 9 & & & 11,1 & 27,8 & 58,3 & 2,8 \\
\hline 10 & & & 7,4 & 33,3 & 51,9 & 7,4 \\
\hline 11 & & 10 & 24 & 26 & 40 & \\
\hline 12 & & & 3,3 & 33,3 & 63,3 & \\
\hline 13 & & & & 13 & 87 & \\
\hline 14 & & 23,1 & 7,7 & 41 & 28,2 & \\
\hline 15 & 2,9 & 11,8 & 14,7 & 29,4 & 41,2 & \\
\hline 16 & & & 7,5 & 27,5 & 65 & \\
\hline 17 & & & 11,4 & 34,3 & 54,3 & \\
\hline 18 & 12 & 4 & 24 & 20 & 40 & \\
\hline 19 & & 26,8 & 26,8 & 26,8 & 19,5 & \\
\hline 20 & & & 10 & 32 & 56 & 2 \\
\hline Freqüência & 0,8 & 6,3 & 12,6 & 29,8 & 49,7 & 0,7 \\
\hline
\end{tabular}

A Tabela 15 mostra que o número de frutos por infrutescência variou de 3 a 8 , sendo que 7 frutos por infrutescência foi mais freqüente (49,7\%). Outros autores corroboram estes resultados (Martin \& Cossalter, 1975a; Ferreira \& Souza, 1997 e Ferreira, 1999). 
Tabela 16. Freqüência da posição do disco (\%) (A = Rasante ou nivelado; $\mathrm{B}=$ Saliente e $\mathrm{C}=$ Incluso), número de valvas por fruto (\%) e freqüência da posição da valva (\%) ( $\mathrm{A}=$ Incluso; $\mathrm{B}=$ Rasante ou nivelado e $\mathrm{C}=$ Saliente).

\begin{tabular}{|c|c|c|c|c|c|c|c|c|c|}
\hline \multirow[b]{2}{*}{ Tratamento } & \multicolumn{3}{|c|}{ Posição disco (\%) } & \multicolumn{3}{|c|}{$\mathrm{N}^{\mathrm{o}}$ valvas / fruto (\%) } & \multicolumn{3}{|c|}{ Posição da valva (\%) } \\
\hline & A & B & $\mathrm{C}$ & 3 & 4 & 5 & A & B & $\mathrm{C}$ \\
\hline 1 & & & 100 & 1,8 & 98,2 & & 5,3 & 56,1 & 38,6 \\
\hline 2 & & & 100 & & 100 & & 2 & 98 & \\
\hline 3 & 33,3 & & 66,7 & 21,7 & 78,3 & & 66,7 & & 33,3 \\
\hline 4 & & & 100 & 48,3 & 51,7 & & & 100 & \\
\hline 5 & & & 100 & & 100 & & 16,7 & 83,3 & \\
\hline 6 & & & 100 & 5,4 & 94,6 & & 35,1 & 62,2 & 2,7 \\
\hline 7 & & & 100 & & 100 & & & & 100 \\
\hline 8 & & & 100 & 6,7 & 93,3 & & 16,7 & 23,3 & 60 \\
\hline 9 & & & 100 & 15,3 & 84,7 & & 44,4 & 55,6 & \\
\hline 10 & & & 100 & 37 & 63 & & 63 & & 37 \\
\hline 11 & 2 & 18 & 80 & 18 & 82 & & 4 & 88 & 8 \\
\hline 12 & 18,3 & 1,7 & 80 & 15,9 & 75 & 9,1 & 61,7 & 28,3 & 10 \\
\hline 13 & & & 100 & & 100 & & 30,4 & 69,6 & \\
\hline 14 & & & 100 & 28,2 & 71,8 & & 23,1 & 56,4 & 20,5 \\
\hline 15 & & & 100 & 19,1 & 80,9 & & 55,9 & 44,1 & \\
\hline 16 & & & 100 & 12,5 & 87,5 & & & 50 & 50 \\
\hline 17 & & & 100 & 25,8 & 74,2 & & & 57,1 & 42,9 \\
\hline 18 & & & 100 & 12 & 88 & & 40 & 28 & 32 \\
\hline 19 & & & 100 & 17,1 & 82,9 & & & 75,6 & 24,4 \\
\hline 20 & & & 100 & 27 & 71 & 2 & 4 & 22 & 74 \\
\hline Freqüência & 3 & 1,4 & 95,6 & 15,8 & 83,4 & 0,8 & 22,7 & 52,7 & 24,6 \\
\hline
\end{tabular}


A posição do disco dos anéis estaminais variou de incluso a saliente, com predominância de incluso $(95,6 \%)$. Mesmo resultado foi encontrado por Martin \& Cossalter (1975a), Ferreira \& Souza (1997) e Ferreira (1999).

O número de valvas por fruto (receptáculo) variou de 3 a 5 , com predominância de 4 valvas $(83,4 \%$ ), o que está de acordo com vários autores (Martin \& Cossalter, 1975a; Turnbull \& Brooker, 1978; Ferreira \& Souza, 1997).

A posição da valva variou de inclusa a saliente, com predominância de rasante ou nivelada (52,7\%). Encontraram os mesmos resultados Martin \& Cossalter (1975a), Turnbull \& Brooker (1978), López (1992), Ferreira \& Souza (1997) e Ferreira (1999). 
Tabela 17. Freqüência da forma do fruto (\%).

\begin{tabular}{|c|c|c|c|}
\hline \multirow[b]{2}{*}{ Tratamento } & \multicolumn{3}{|c|}{ Forma do fruto $(\%)$} \\
\hline & Ovóide truncado & Amplamente cônico & Cônico \\
\hline 1 & 14 & 31,6 & 54,4 \\
\hline 2 & 36 & 24 & 40 \\
\hline 3 & 16,7 & 50 & 33,3 \\
\hline 4 & 33,3 & 30 & 36,7 \\
\hline 5 & 12,5 & 12,5 & 75 \\
\hline 6 & 43,2 & 45,9 & 10,8 \\
\hline 7 & & & 100 \\
\hline 8 & 26,7 & 36,7 & 36,7 \\
\hline 9 & 55,6 & 44,4 & \\
\hline 10 & 37 & 25,9 & 37 \\
\hline 11 & 24 & 56 & 20 \\
\hline 12 & 30 & 30 & 40 \\
\hline 13 & 56,5 & 34,8 & 8,7 \\
\hline 14 & 28,2 & 25,6 & 46,2 \\
\hline 15 & 17,6 & 29,4 & 52,9 \\
\hline 16 & 50 & & 50 \\
\hline 17 & & 37,1 & 62,9 \\
\hline 18 & 52 & 8 & 40 \\
\hline 19 & 65,9 & 34,1 & \\
\hline 20 & & 56 & 44 \\
\hline Freqüência & 29,9 & 32,8 & 37,2 \\
\hline
\end{tabular}

A Tabela 17 mostra que os frutos ocorreram em três formas distintas, ovóide truncado $(29,9 \%)$, amplamente cônico $(32,8 \%)$ e cônico $(37,2 \%)$, corroborando os resultados dos trabalhos de Martin \& Cossalter (1975b), Turnbull \& Brooker (1978), López (1992), Ferreira \& Souza (1997) e Ferreira (1999). 
Tabela 18. Médias e amplitudes de variação do diâmetro e comprimento do fruto (mm) e comprimento do pedicelo ( $\mathrm{mm}$ ).

\begin{tabular}{|c|c|c|c|c|c|c|}
\hline \multirow[b]{2}{*}{ Tratamento } & \multicolumn{2}{|c|}{$\begin{array}{l}\text { Diâmetro do } \\
\text { fruto }\end{array}$} & \multicolumn{2}{|c|}{ Comprimento do fruto } & \multicolumn{2}{|c|}{ Comp do pedicelo } \\
\hline & Média & Amplitude & Média & Amplitude & Média & Amplitude \\
\hline 1 & 8,34 & $6,79-10,06$ & 7,10 & $3,48-9,85$ & 5,49 & $1,86-8,89$ \\
\hline 2 & 8,63 & $7,41-10,27$ & 8,53 & $7,18-10,49$ & 5,72 & $3,21-8,88$ \\
\hline 3 & 8,63 & $7,23-10,66$ & 8,15 & $6,33-9,42$ & 8,61 & $2,39-10,01$ \\
\hline 4 & 8,10 & $6,42-9,40$ & 7,48 & $5,69-9,20$ & 4,89 & $2,96-6,53$ \\
\hline 5 & 8,85 & $7,84-9,92$ & 8,03 & $6,37-11,80$ & 4,27 & $2,06-7,96$ \\
\hline 6 & 7,94 & $6,76-9,13$ & 7,84 & $6,11-8,89$ & 5,29 & $2,19-8,26$ \\
\hline 7 & 9,06 & $8,53-9,83$ & 6,37 & $5,63-7,91$ & 4,64 & $3,75-5,84$ \\
\hline 8 & 8,88 & $7,51-10,39$ & 8,24 & $6,73-10,74$ & 4,70 & $2,41-7,37$ \\
\hline 9 & 7,80 & $5,24-9,90$ & 8,31 & $6,48-9,78$ & 5,81 & $3,86-9,15$ \\
\hline 10 & 8,70 & $6,75-10,88$ & 7,72 & $6,50-8,68$ & 5,41 & $2,87-8,83$ \\
\hline 11 & 8,28 & $6,41-10,44$ & 7,87 & $5,52-9,51$ & 6,01 & $2,54-8,75$ \\
\hline 12 & 8,71 & $7,07-11,07$ & 8,42 & $5,88-11,61$ & 4,95 & $2,58-10,08$ \\
\hline 13 & 8,81 & $7,25-10,33$ & 8,82 & $7,12-10,31$ & 5,47 & $3,59-6,71$ \\
\hline 14 & 8,33 & $7,08-9,66$ & 8,14 & $7,12-10,09$ & 6,15 & $3,10-10,60$ \\
\hline 15 & 8,71 & $6,30-10,52$ & 8,11 & $6,28-9,29$ & 4,24 & $1,30-7,48$ \\
\hline 16 & 8,72 & $7,31-10,01$ & 8,30 & $7,38-9,54$ & 5,39 & $1,53-9,98$ \\
\hline 17 & 8,42 & $6,78-11,85$ & 6,81 & $5,19-9,32$ & 5,22 & $2,84-8,09$ \\
\hline 18 & 8,31 & $6,96-9,72$ & 8,09 & $5,80-10,89$ & 3,13 & $1,75-4,45$ \\
\hline 19 & 8,09 & $6,74-9,17$ & 7,86 & $5,70-10,50$ & 5,87 & $2,92-10,49$ \\
\hline 20 & 8,89 & $6,63-10,29$ & 7,76 & $5,94-9,26$ & 5,91 & $1,92-8,97$ \\
\hline Média & 8,48 & $5,24-11,85$ & 7,94 & $3,48-11,80$ & 5,36 & $1,30-10,60$ \\
\hline
\end{tabular}


O diâmetro do fruto variou de 5,24 a 11,85 mm, com média de 8,48 mm. Valores próximos a esta média foram encontrados por Martin \& Cossalter (1975a), López (1992) e Pryor et al. (1995). Com relação à amplitude, os trabalhos de Turnbull \& Brooker (1978), Goes (1985) e Ferreira \& Souza (1997), apresentam valores semelhantes a estes.

O comprimento do fruto variou de 3,48 a $11,80 \mathrm{~mm}$, com média de 7,94mm, corroborando os resultados dos trabalhos de López (1992), Pryor et al. (1995) e Ferreira \& Souza (1997).

O comprimento do pedicelo variou de 1,30 a 10,60 mm, com média de 5,36 mm. López (1992) e Ferreira \& Souza (1997) encontraram valores médios e amplitudes menores que estes, enquanto que, Martin \& Cossalter (1975b) e Pryor et al. (1995) encontraram valores médios e amplitudes maiores que estes.

Tabela 19. Resumo da análise de variância do diâmetro e comprimento do fruto (mm) e raiz quadrada do comprimento do pedicelo $(\mathrm{mm})(\sqrt{\text { Comppedicelo }})$.

\begin{tabular}{lllll}
\hline & & & & \multicolumn{2}{c}{ QM } \\
FV & GL & Diâmetro fruto & Comprimento fruto & $\sqrt{\text { Comppedicelo }}$ \\
\hline Bloco & 2 & 6,29 & 11,19 & 0,83 \\
Progênie & 19 & $3,67 * * *$ & $10,70^{* * *}$ & $0,96 * * *$ \\
Erro & 706 & 0,87 & 1,01 & 0,12 \\
CVe \% & & 10,97 & 12,67 & 15,35 \\
\hline$* * *=$ significativo a $0,01 \%$. & &
\end{tabular}

Observa-se na Tabela 19, que houve diferença altamente significativa entre as progênies para todas as características quantitativas do fruto e que os coeficientes de variação experimental $(\mathrm{CVe})$ foram baixos para todas as características analisadas. 
A Tabela 20 apresenta os valores médios e a classificação dos tratamentos pelo teste Duncan a 5\% de probabilidade para os parâmetros quantitativos do fruto.

Tabela 20. Média dos tratamentos (Trat) para o diâmetro do fruto (mm), comprimento do fruto $(\mathrm{mm})$ e raiz quadrada do comprimento do pedicelo $(\mathrm{mm})$.

\begin{tabular}{|c|c|c|c|c|c|}
\hline Trat & Diâmetro do fruto & Trat & Comp do fruto & Trat & Comp do pedicelo \\
\hline 7 & $9,0580 \mathrm{~A}$ & 13 & $8,8257 \mathrm{~A}$ & 3 & $2,5312 \mathrm{~A}$ \\
\hline 20 & $8,8908 \mathrm{AB}$ & 2 & $8,5250 \mathrm{AB}$ & 14 & $2,4440 \mathrm{AB}$ \\
\hline 8 & $8,8770 \mathrm{ABC}$ & 12 & $8,4150 \mathrm{ABC}$ & 11 & $2,4311 \mathrm{AB}$ \\
\hline 5 & 8,8513 ABCD & 9 & $8,3125 \mathrm{ABCD}$ & 9 & $2,3990 \mathrm{ABC}$ \\
\hline 13 & 8,8061 ABCDE & 16 & $8,3008 \mathrm{ABCD}$ & 20 & $2,3942 \mathrm{ABC}$ \\
\hline 16 & 8,7187 ABCDE & 8 & $8,2410 \mathrm{BCD}$ & 19 & $2,3884 \mathrm{ABC}$ \\
\hline 12 & 8,7075 ABCDE & 3 & $8,1527 \mathrm{BCD}$ & 2 & $2,3800 \mathrm{ABC}$ \\
\hline 15 & $8,7050 \mathrm{ABCDE}$ & 14 & $8,1413 \mathrm{BCD}$ & 13 & $2,3316 \mathrm{ABCD}$ \\
\hline 10 & 8,6981 ABCDE & 15 & 8,1053 BCD & 1 & 2,3104 BCD \\
\hline 3 & 8,6347 ABCDEF & 18 & $8,0880 \mathrm{BCD}$ & 10 & $2,2978 \mathrm{BCD}$ \\
\hline 2 & 8,6340 ABCDEF & 5 & 8,0329 BCDE & 16 & 2,2791 BCD \\
\hline 17 & $8,4200 \mathrm{BCDEFG}$ & 11 & 7,8668 CDE & 6 & 2,2736 BCD \\
\hline 1 & 8,3447 BCDEFG & 19 & 7,8583 CDE & 17 & $2,2638 \mathrm{BCD}$ \\
\hline 14 & 8,3274 CDEFGH & 6 & 7,8381 CDE & 4 & 2,2007 CDE \\
\hline 18 & 8,3140 DEFGH & 20 & $7,7552 \mathrm{DE}$ & 12 & 2,1967 CDE \\
\hline 11 & 8,2840 EFGH & 10 & $7,7181 \mathrm{DE}$ & 7 & $2,1485 \mathrm{DE}$ \\
\hline 4 & 8,0967 FGH & 4 & 7,4847 EF & 8 & $2,1444 \mathrm{DE}$ \\
\hline 19 & 8,0929 FGH & 1 & 7,0993 FG & 5 & $2,0372 \mathrm{E}$ \\
\hline 6 & 7,9354 GH & 17 & $6,8071 \mathrm{GH}$ & 15 & $2,0201 \mathrm{E}$ \\
\hline 9 & $7,8011 \mathrm{H}$ & 7 & $6,3720 \mathrm{H}$ & 18 & $1,7547 \mathrm{~F}$ \\
\hline Média & 8,4828 & Média & 7,9370 & Média & 2,2840 \\
\hline
\end{tabular}


Médias seguidas das mesmas letras não diferem estatisticamente entre si pelo teste Duncan a $5 \%$ de probabilidade.

Observa-se na Tabela 20 que há alternância na classificação das progênies, dependendo da característica analisada, confirmando a baixa correlação entre estas características. Existem 6 a 8 grupos dependendo da característica analisada e estes grupos independem das características das folhas. Ferreira (1999) também não achou correlação entre as características das folhas com as características dos frutos.

\subsection{Rachaduras de extremidades de tora e conicidade}

Na Tabela 21 encontram-se os resultados das análises estatísticas das rachaduras de extremidades de tora e da conicidade.

Tabela 21. Resumo da análise de variância do inverso da raiz quadrada da porcentagem estimada de rachadura de extremidade de tora com 1 dia $(1 / \sqrt{P E R 1})$ e 7 dias

( $1 / \sqrt{\operatorname{PER} 7})$, raiz quadrada da porcentagem estimada de rachadura de extremidade de tora 60 dias após o abate das árvores $(\sqrt{P E R 60})$, raiz quadrada da conicidade da tora com casca $(\sqrt{\text { Conicl }})$ e sem casca $(\sqrt{\text { Conic } 2})$.

\begin{tabular}{ccccccc}
\hline & & \multicolumn{5}{c}{ QM } \\
FV & GL & $1 / \sqrt{\text { PER1 }}$ & $1 / \sqrt{\text { PER7 }}$ & $\sqrt{\text { PER60 }}$ & $\sqrt{\text { Conic } 1}$ & $\sqrt{\text { Conic } 2}$ \\
\hline Bloco & 2 & 0,1832 & 0,4199 & 0,0141 & 0,000046 & 0,000128 \\
Progênie & 19 & $0,7107 \mathrm{~ns}$ & $0,4110 \mathrm{~ns}$ & $0,0269 \mathrm{~ns}$ & $0,001036 \mathrm{~ns}$ & $0,000829 \mathrm{~ns}$ \\
Erro & 98 & 0,7072 & 0,6211 & 0,0341 & 0,000886 & 0,000940 \\
CVe \% & & 29,67 & 31,06 & 3,88 & 22,54 & 25,29 \\
\hline
\end{tabular}

ns $=$ não significativo. 
A conicidade média com casca foi de $0,0182 \mathrm{~cm} / \mathrm{m}$ com amplitude de 0 a $0,0449 \mathrm{~cm} / \mathrm{m}$ e sem casca foi de $0,0156 \mathrm{~cm} / \mathrm{m}$ com amplitude de 0 a $0,0428 \mathrm{~cm} / \mathrm{m}$. Não houve diferença estatística entre as progênies para a conicidade.

As plantas quando jovens têm a forma de cone e com o passar dos anos tornam-se cilíndricas, isto é, a conicidade diminui com a idade. Grosser (1980) afirma que a conicidade influencia o rendimento em madeira serrada somente quando apresentar valores superiores a $1 \mathrm{~cm} / \mathrm{m}$ para o diâmetro ou $3 \mathrm{~cm} / \mathrm{m}$ para a circunferência da tora. Estas progênies estavam com 19 anos quando foram analisadas e nesta idade a conicidade das plantas não apresentou importância econômica, isto é, não influenciou no rendimento em madeira serrada.

A porcentagem estimada de rachadura com 1 dia (PER1) foi 0,0686 $\mathrm{m}^{2}$ para a média e amplitude de 0 a $0,6161 \mathrm{~m}^{2}$. Com 7 dias (PER7) a média foi de $0,1158 \mathrm{~m}^{2}$ com a mesma amplitude da PER1. A PER60 teve média de 0,3715 $\mathrm{m}^{2}$ e amplitude de 0,0862 a $1,0610 \mathrm{~m}^{2}$. Não houve diferença estatística entre as progênies para as rachaduras de extremidades de tora.

As rachaduras de extremidades de tora foram usadas como critério de seleção em árvores para serraria na África do Sul (Villiers, 1973 e Hillis, 1978), mas há divergências de quando se deve fazer a avaliação das rachaduras.

Purnell (1988) estudou a variação das rachaduras de extremidades de tora em procedências de E. nitens e mensurou estas rachaduras com 2 e 45 dias após o abate das árvores, não encontrando diferença estatística entre as procedências para as rachaduras das toras. As rachaduras com 45 dias foram significativamente maiores que as rachaduras com 2 dias. $\mathrm{O}$ autor não correlacionou estas rachaduras com as rachaduras das tábuas. Quanto à conicidade da tora, encontrou diferença entre a primeira e as demais toras (6 toras por árvore), mas não encontrou diferença estatística entre as procedências. 
Malan (1979) trabalhou com E. grandis e afirmou que as rachaduras de extremidades de tora se manifestavam em até 3 dias após o abate das árvores. Para Bariska (1990) esta manifestação se dá em até 5 dias e para Hillis (1978) acontece em até 7 dias após o abate das árvores. Hillis (1978) afirmou que as rachaduras que ocorrem depois deste período (7dias) podem ser manifestação de outras tensões como o colapso ou as tensões de secagem.

Não houve correlação entre as rachaduras de extremidades de tora com as rachaduras de extremidades de peça serrada, a não ser das rachaduras mensuradas com 60 dias (antes do desdobro) com a abertura das rachaduras na base da tora, mas esta correlação foi muito fraca. Outros pesquisadores encontraram resultados semelhantes (Crespo, 2000; Lopes, 2000; Lima, 2000 e Malan, 2000).

\subsection{Rachaduras de extremidades de tábua}

Nas Tabelas 22 e 23 encontram-se os resultados das análises estatísticas das características das tábuas. 
Tabela 22. Resumo da análise de variância para a raiz quadrada da abertura da rachadura na base da tábua $(\sqrt{\text { Aberbas }})$, raiz quadrada do comprimento da rachadura na base da tábua $(\sqrt{\text { Compbas }})$, raiz quadrada da abertura da rachadura no topo da tábua $(\sqrt{\text { Abertop }})$, raiz quadrada dos comprimento da rachadura no topo da tábua $(\sqrt{\text { Comptop }})$, raiz quadrada do número de peças por tora (tábuas e prancha central) $(\sqrt{\text { Npeças }})$ e comprimento da rachadura (base + topo) (Comprach).

\begin{tabular}{cccccccc}
\hline \multirow{2}{*}{ FV } & GL & $\sqrt{\text { Aberbas }}$ & $\sqrt{\text { Compbas }}$ & $\sqrt{\text { Abertop }}$ & $\sqrt{\text { Comptop }}$ & $\sqrt{\text { Npeças }}$ & Comprach \\
\hline Bloco & 2 & 0,000040 & 0,0086 & 0,00048 & 0,0487 & 0,0280 & 0,0024 \\
Progênie & 19 & $0,000027 \mathrm{~ns}$ & $0,0075 \mathrm{~ns}$ & $0,00024 \mathrm{~ns}$ & $0,0206 \mathrm{~ns}$ & $0,0152 \mathrm{~ns}$ & $0,0020 \mathrm{~ns}$ \\
Erro & 98 & 0,000032 & 0,0080 & 0,00028 & 0,0283 & 0,0854 & 0,0017 \\
CVe \% & & 0,56 & 8,15 & 1,64 & 13,93 & 12,08 & 1,03 \\
\hline
\end{tabular}

ns $=$ não significativo.

Tabela 23. Resumo da análise de variância da espessura média da tábua (Espess), largura média da tábua (Larg), comprimento da tora (Comptor) e comprimento útil da tora (livre das rachaduras) (Computil).

\begin{tabular}{cccccc}
\hline & & \multicolumn{4}{c}{ QM } \\
FV & GL & Espess & Larg & Comptor & Computil \\
\hline Bloco & 2 & 0,000017 & 0,000093 & 0,0024 & 0,7586 \\
Progênie & 19 & $0,000021^{*}$ & $0,001620 \mathrm{~ns}$ & $0,0020 \mathrm{~ns}$ & $0,2359 \mathrm{~ns}$ \\
Erro & 98 & 0,000010 & 0,001645 & 0,0017 & 0,3180 \\
CVe \% & 10,38 & 23,57 & 1,03 & 16,92 \\
\hline * = significativo à 5\% de probabilidade e ns = não significativo.
\end{tabular}


A abertura média da rachadura na base da tábua foi de $7,5 \mathrm{~mm}$ com amplitude de 0 a $60 \mathrm{~mm}$. O comprimento médio da rachadura na base da tábua foi de $22,98 \mathrm{~cm}$ com amplitude de 1,30 a 122,10 cm. A abertura média da rachadura no topo da tábua foi de $23 \mathrm{~mm}$ com amplitude de 0 a $233 \mathrm{~mm}$. O comprimento médio da rachadura no topo da tábua foi de 50,82 $\mathrm{cm}$ com amplitude de 0,80 a $257,60 \mathrm{~cm}$. O número de peças serradas por tora variou de 3 a 9 com média de 5,94. O comprimento médio da rachadura (base + topo) na tábua foi de 70,38 cm com amplitude de 7,00 a $287,00 \mathrm{~cm}$. A espessura média da tábua foi de 30,83 $\mathrm{mm}$ com amplitude de 26 a $49 \mathrm{~mm}$. A largura média da tábua foi de $17,21 \mathrm{~cm}$ com amplitude de 6,30 a $24,50 \mathrm{~cm}$. O comprimento médio da tora foi de $4,04 \mathrm{~m}$ com amplitude de 3,98 a $4,40 \mathrm{~m}$. O comprimento útil da tora foi de 3,33 m com amplitude de 1,15 a 4,00 m.

Não houve diferença estatística entre as progênies para nenhuma destas características, exceto para a espessura das tábuas, isto aconteceu devido a um problema na serra de fita durante o desdobro de uma tora. As rachaduras foram significativamente maiores no topo do que na base da tora, conforme a Tabela 24.

Tabela 24. Teste t pareado para a rachadura da tábua.

\begin{tabular}{ccccc}
\hline Característica & Base & Topo & Siferença mínima \\
& & & & \\
Abertura da rachadura $(\mathrm{mm})$ & 7,4832 & 22,9756 & 6,40 & 0,0001 \\
Comprimento rachadura $(\mathrm{cm})$ & 23,9456 & 50,8203 & 3,49 & 0,0001 \\
\hline
\end{tabular}

As Figuras 21 e 22 mostram as variações radiais das rachaduras de extremidades de tábua. 


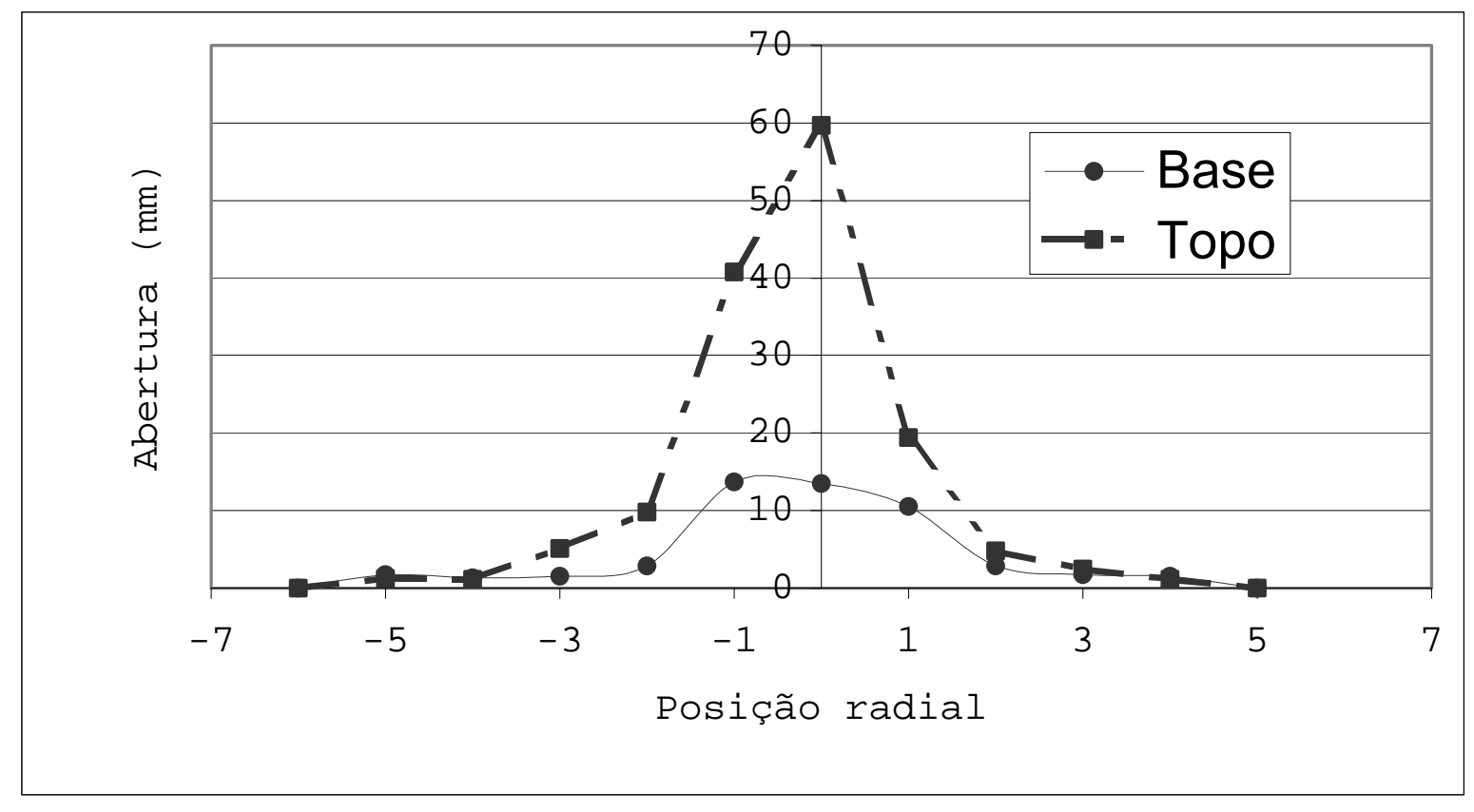

Figura 21 - Variação radial da abertura da rachadura de extremidade de tábua.

Na figura 21 observa-se que a abertura da rachadura foi maior no topo do que na base da tábua. A abertura da rachadura foi máxima na região da medula e desprezível nas proximidades da casca. 


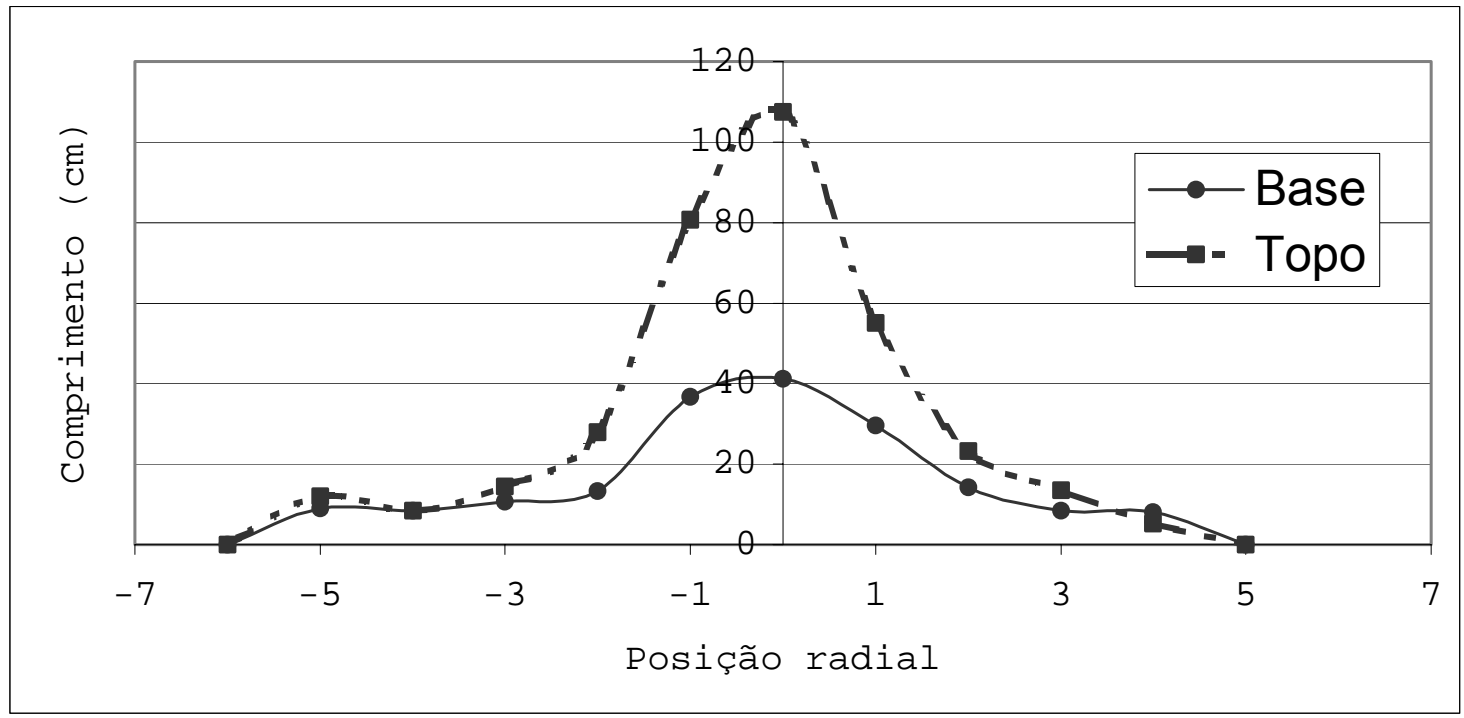

Figura 22 - Variação radial do comprimento da rachadura de extremidade de tábua.

Nota-se na Figura 22 que o comprimento da rachadura foi maior no topo do que na base da tábua e que próximo à casca as tábuas não racharam, enquanto que, próximo à medula o comprimento da rachadura foi máximo, o que está de acordo com a teoria do Boyd (1950b). Resultados parecidos foram encontrados por vários pesquisadores (Kubler, 1959; Fernandes, 1982; Schacht, 1998).

\subsection{Perdas e volumes}

Nas Tabelas 25 e 26 temos as análises estatísticas das perdas e dos volumes, respectivamente. 
Tabela 25. Resumo da análise de variância da perda no desdobro (Perda1) (\%), raiz quadrada das perdas devido as tensão de crescimento longitudinal $(\sqrt{\text { Perda2 }})(\%)$ e perdas totais (desdobro e tensão de crescimento longitudinal) (Perda3) (\%).

\begin{tabular}{ccccc}
\hline & & \multicolumn{3}{c}{ QM } \\
FV & GL & Perda1 & $\sqrt{\text { Perda2 }}$ & Perda3 \\
\hline Bloco & 2 & 61,1275 & 4,4082 & 354,3081 \\
Progênie & 19 & $72,1876 \mathrm{~ns}$ & $2,7181 \mathrm{~ns}$ & $85,1859 \mathrm{~ns}$ \\
Erro & 98 & 143,2227 & 3,6492 & 152,2921 \\
CVe \% & & 27,79 & 41,84 & 21,48 \\
\hline ns = não significativo. & &
\end{tabular}

A perda média no desdobro (Perda 1) foi de 43,06 \% com amplitude de 9,62 a 69,17 \%. A perda média com a tensão de crescimento longitudinal (Perda 2) foi de $24,33 \%$ com amplitude de 1,99 a 76,44 \%. A perda total média (Perda 3 ) foi de 57,47 $\%$ com amplitude de 16,47 a 87,36 \%. Não houve diferença estatística entre as progênies para nenhuma destas perdas. 
Tabela 26. Resumo da análise de variância do inverso da raiz quadrada do volume da tora com casca $(1 / \sqrt{\text { Voltorcc }})$ e sem casca $(1 / \sqrt{\text { Voltorsc }})$, raiz quadrada do volume da casca $(\sqrt{\text { Volcasc }})$, raiz quadrada do volume das tábuas ( $\sqrt{\text { Volpri }})$, raiz quadrada do volume das tábuas livre da tensão de crescimento longitudinal $(\sqrt{V o l \mathrm{sec}})$ e raiz quadrada do volume final $(\sqrt{\operatorname{Re} n d f i n})$.

\begin{tabular}{cccccccc}
\hline & & \multicolumn{5}{c}{ QM } & \\
FV & GL & $1 / \sqrt{\text { Voltorcc }}$ & $1 / \sqrt{\text { Voltorsc }}$ & $\sqrt{\text { Volcasc }}$ & $\sqrt{\text { Volpri }}$ & $\sqrt{\text { Vol sec }}$ & $\sqrt{\text { Rendfin }}$ \\
& & & & & & \\
\hline Bloco & 2 & 0,01165 & 0,0066 & 0,0014 & 0,000048 & 0,0048 & 2,2615 \\
Progênie & 19 & $0,09904 \mathrm{~ns}$ & $0,1118 \mathrm{~ns}$ & $0,0021 \mathrm{~ns}$ & $0,005043 \mathrm{~ns}$ & $0,0034 \mathrm{~ns}$ & $0,5823 \mathrm{~ns}$ \\
Erro & 98 & 0,11462 & 0,1361 & 0,0018 & 0,005738 & 0,0033 & 0,9668 \\
CVe \% & & 17,01 & 17,36 & 24,12 & 20,82 & 18,66 & 15,24 \\
\hline
\end{tabular}

ns = não significativo.

O volume médio da tora com casca (Voltorcc) foi de $0,2744 \mathrm{~m}^{3}$ com amplitude de 0,0889 a $0,7272 \mathrm{~m}^{3}$, o volume médio da tora sem casca (Voltorsc) foi de $0,2416 \mathrm{~m}^{3}$ com amplitude de 0,0811 a $0,6441 \mathrm{~m}^{3}$ e o volume médio de casca (Volcasc) foi de $0,0328 \mathrm{~m}^{3}(11,95 \%)$ com amplitude de 0,0078 a $0,0939 \mathrm{~m}^{3}$. O volume primário médio, isto é, aquele obtido pela transformação da tora em tábuas (Volpri) foi de $0,1378 \mathrm{~m}^{3}$ com amplitude de 0,0340 a $0,4540 \mathrm{~m}^{3}$, o volume secundário médio [Volume das tábuas descontadas as perdas devido as rachaduras (tensão de crescimento longitudinal) (Volsec)] foi de $0,0992 \mathrm{~m}^{3}$ com amplitude de 0,0240 a $0,1990 \mathrm{~m}^{3}$ e o rendimento final médio (descontadas as perda do desdobro e das tensões de crescimento longitudinal) (Rendfin) foi de 42,53 \% com amplitude de 12,64 a 83,53 \%. Não houve diferença estatística entre as progênies para nenhum dos volumes. 
O rendimento em madeira serrada encontrado no presente trabalho, está de acordo com vários trabalhos publicados (Villiers, 1973; Freitas \& Brito Neto, 1993; Sanches Acosta, 1995; Miranda, 1997; Carvalho, 2000; Rocha, 2000). Porém, estes trabalhos não detalharam as porcentagem de cada perda, além disso o rendimento em madeira serrada vária muito em função do tipo de serra, reaproveitamento de aparas e costaneiras e da metodologia utilizada na avaliação do rendimento em madeira serrada.

A idade da planta pode exercer um efeito considerável sobre as propriedades físicas, químicas e anatômicas da madeira, podendo ser decisiva para sua utilização econômica. Com o aumento da idade, aumentam o comprimento e a espessura da parede da fibra, a porcentagem da madeira madura (cerne), a porcentagem de extrativos e a densidade básica (Giordano, 1961; Boyd, 1967 e Harris, 1969). Nicholson (1973) estudou as tensões de crescimento em árvores de E. regnans e E. obliqua com 31 e 70 anos respectivamente. As tensões foram menores nas árvores mais velhas, levando o autor concluir que as tensões de crescimento diminuem com a idade da planta.

\subsection{Propriedades físicas da madeira}

As Tabelas 27 a 29 apresentam os resultados das análises estatísticas das propriedades físicas da madeira. 
Tabela 27. Resumo da análise de variância para a densidade básica $(\mathrm{Db})\left(\mathrm{g} / \mathrm{cm}^{3}\right)$, umidade (\%), raiz quadrada da retração longitudinal ( $\sqrt{R L})(\%)$, retração radial (RR) (\%), retração tangencial (RT) (\%), retração volumétrica (RV) (\%) e índice de retração anisotrópico (IRA) (\%).

\begin{tabular}{lllllllll}
\hline & & & & \multicolumn{2}{c}{ QM } & & RV & IRA \\
\hline Bloco & 2 & 0,0067 & 0,2427 & 0,0103 & 0,2202 & 0,8859 & 0,2744 & 0,1100 \\
Progênie & 19 & $0,0042 \mathrm{~ns}$ & $0,7169 \mathrm{~ns}$ & $0,0100 \mathrm{~ns}$ & $1,0516 \mathrm{~ns}$ & $2,5737 \mathrm{~ns}$ & $5,4742^{*}$ & $0,0544 \mathrm{~ns}$ \\
Erro & 38 & 0,0063 & 1,0407 & 0,0091 & 0,7479 & 1,5154 & 2,8254 & 0,0660 \\
Dentro & 58 & 0,0040 & 0,6860 & 0,0056 & 0,7953 & 1,2367 & 2,5434 & 0,0690 \\
CVe \% & 9,66 & 10,41 & 23,47 & 12,47 & 8,91 & 8,08 & 14,85 \\
\hline
\end{tabular}

* = significativos à $5 \%$ e ns = não significativo.

$\mathrm{O}$ valor médio encontrado para a retração longitudinal (RL) foi de $0,109 \%$ com amplitude de 0,030 a $0,243 \%$. O valor encontrado para a retração radial (RR) foi $7,178 \%$ para a média e amplitude de 4,780 a $9,760 \%$. Para a retração tangencial (RT) o valor encontrado para a média foi de $12,488 \%$ e amplitude de 9,770 a $15,475 \%$. Para a retração volumétrica (RV) o valor encontrado para a média foi de $19,774 \%$ e amplitude de 14,587 a 23,335\%. Para o índice de retração anisotrópico (IRA = RT/RR) o valor encontrado foi de 1,759 para a média e 1,292 a 2,477 para os limites da amplitude. Valores próximos a estes para o E. urophylla, foram encontrados por diversos pesquisadores (Oliveira, 1997; Vital e Trugilho, 1997 e Watai, 1990). Com estes valores a espécie foi classificada como de alta retratibilidade (Monteiro, 1996).

Não houve diferença estatística entre as progênies para as propriedade físicas da madeira, com exceção da Retração Volumétrica (RV), (Tabela 28). A grande similaridade entre as propriedades físicas pode ter sido reflexo da maturidade das árvores. 
Tabela 28. Teste Duncan para a retração volumétrica (RV) (\%) dos tratamentos.

\begin{tabular}{|c|c|}
\hline Tratamento & RV \\
\hline 7 & $22,00 \mathrm{~A}$ \\
\hline 4 & $20,92 \mathrm{AB}$ \\
\hline 5 & $20,90 \mathrm{AB}$ \\
\hline 11 & $20,83 \mathrm{ABC}$ \\
\hline 9 & $20,45 \mathrm{ABCD}$ \\
\hline 1 & $20,43 \mathrm{ABCD}$ \\
\hline 18 & $20,25 \mathrm{ABCD}$ \\
\hline 17 & $20,18 \mathrm{ABCD}$ \\
\hline 6 & $20,17 \mathrm{ABCD}$ \\
\hline 2 & $19,65 \mathrm{ABCDE}$ \\
\hline 3 & 19,63 ABCDE \\
\hline 10 & $19,54 \mathrm{ABCDE}$ \\
\hline 8 & 19,51 ABCDE \\
\hline 20 & $19,26 \mathrm{ABCDE}$ \\
\hline 12 & 19,06 BCDE \\
\hline 16 & $18,99 \mathrm{BCDE}$ \\
\hline 19 & $18,97 \mathrm{BCDE}$ \\
\hline 13 & $18,62 \mathrm{CDE}$ \\
\hline 15 & $18,29 \mathrm{DE}$ \\
\hline 14 & $17,88 \mathrm{E}$ \\
\hline Média & 19,749 \\
\hline
\end{tabular}

Médias seguidas das mesmas letras não diferem estatisticamente entre si pelo teste Duncan a $5 \%$ de probabilidade.

Quanto menor a retratibilidade volumétrica melhor é a madeira para marcenaria, em função da menor movimentação dimensional da mesma. Deste modo, destacaram-se as progênies 14,15 e 13 , respectivamente. 
Madeira com retratibilidade volumétrica entre 12,33 e 19,39\% são consideradas de média retratibilidade (Progênies 14 a 20). Retratibilidade volumétrica acima de 19,40\% são consideradas altas (Progênies 7 a 8) (Monteiro, 1996).

Na Tabela 29 encontram-se os parâmetros genéticos estimados para a retratibilidade volumétrica, de acordo com Vencovsky \& Barriga (1992).

Tabela 29. Estimativas das variâncias, coeficientes de variação, herdabilidades e estimativas dos erros destas estimativas para a retração volumétrica (RV).

\begin{tabular}{|c|c|}
\hline Parâmetros & RV \\
\hline$\sigma_{p}^{2}$ & 0,5531 \\
\hline$\sigma_{\mathrm{e}}^{2}$ & 0,1807 \\
\hline$\sigma_{d}^{2}$ & 2,5129 \\
\hline$\sigma_{F}^{2}$ & 3,2467 \\
\hline$\sigma_{\mathrm{A}}^{2}$ & 2,2124 \\
\hline $\mathrm{CVd}$ & 8,02 \\
\hline $\mathrm{CVg}$ & 3,76 \\
\hline Cve & 2,15 \\
\hline Cva & 7,47 \\
\hline CVf & 9,11 \\
\hline$\hat{\mathrm{h}}_{\mathrm{d}}^{2}$ & 0,6603 \\
\hline$\hat{\mathrm{h}}^{2}{ }_{\mathrm{i}}$ & 0,1704 \\
\hline$\hat{\mathrm{h}}_{\mathrm{m}}^{2}$ & 0,5559 \\
\hline $\mathrm{Gs}_{\mathrm{d}} \%\left(\mathrm{i} \hat{\mathrm{h}}_{\mathrm{d}}^{2}\right)$ & 0,9540 \\
\hline$\hat{b}$ & 1,7488 \\
\hline Vâr $\left(\sigma_{p}^{2}\right)$ & 0,1099 \\
\hline Vâr $\left(\sigma_{\mathrm{e}}^{2}\right)$ & 0,1554 \\
\hline Vâr $\left(\sigma_{d}^{2}\right)$ & 0,2105 \\
\hline Vâr $\left(\mathrm{h}_{\mathrm{m}}{ }^{2}\right)$ & 0,0674 \\
\hline Vâr $\left(\hat{\mathrm{h}}_{\mathrm{i}}^{2}\right)$ & 0,1404 \\
\hline
\end{tabular}


Observa-se na Tabela 29 que os coeficientes de variação (CV) foram baixos, o que reflete o bom planejamento experimental. Em termos de melhoramento genético é desejável que o CVg seja alto, indicando que a característica sofre bastante influência genética. O coeficiente $\hat{b} \quad(\mathrm{CVg} / \mathrm{CVe})$ reflete isto, pois quanto maior esta razão maior a influência genética e só quando o resultado desta razão for igual ou maior que um, a seleção para a característica será efetiva, como ocorreu neste caso (Vencovsky \& Barriga, 1992).

A variância entre as progênies foi alta, consequentemente os ganhos com a seleção também serão altos, o que favorece a seleção e um programa de melhoramento.

Como os coeficientes de variação foram baixos, as estimativas dos erro destes parâmetros bem como das variâncias também foram baixos.

\subsection{Propriedades mecânicas da madeira}

$\mathrm{Na}$ Tabela 30 encontram-se os resultados das análises estatísticas das propriedades mecânicas da madeira.

Tabela 30. Resumo da análise de variância para o módulo da ruptura à flexão estática (Ff) (MPa), do módulo da elasticidade (Ef) (MPa), cisalhamento paralelo às fibras $(\mathrm{Fs})(\mathrm{MPa})$ e compressão paralela às fibras $(\mathrm{Fc})(\mathrm{MPa})$.

\begin{tabular}{lllllll}
\hline \multirow{2}{*}{ FV } & GL & \multicolumn{1}{c}{ Ff } & \multicolumn{1}{c}{ Ef } & GL & Fs & Fc \\
\hline Bloco & 2 & 674,54 & 21910823,8 & 2 & 2,29 & 113,87 \\
Progênie & 19 & $364,61 \mathrm{~ns}$ & $8760948,6 \mathrm{~ns}$ & 19 & $3,25 \mathrm{~ns}$ & $36,36 \mathrm{~ns}$ \\
Erro & 93 & 316,48 & 7965367,8 & 94 & 3,12 & 53,79 \\
CVe \% & & 14,05 & 15,91 & & 9,48 & 11,40 \\
\hline ns = não significativo. & & & &
\end{tabular}


O cisalhamento apresentou média de 18,64 MPa e amplitude de 14,79 a 22,43 MPa, a compressão apresentou média de 64,43 MPa e amplitude de 42,11 a 84,14 $\mathrm{MPa}$, a resistência à flexão estática (Ff ) apresentou média de 126,65 MPa e amplitude de 69,13 a 170,08 MPa, e o módulo da elasticidade na flexão estática (Ef ) apresentou média de 17738,11 MPa e amplitude de 9493,83 a 25340,47 MPa.

Com estes valores todas as progênies foram classificadas como de alta resistência ao cisalhamento, à flexão estática e ao módulo de elasticidade à flexão. Para a compressão a progênie 1 (Wukok) foi classificada como de alta resistência $(68,69$ $\mathrm{MPa}$ ) e as demais foram classificadas como de média resistência (Monteiro, 1996).

Não houve diferença estatística entre as progênies para todas as propriedades mecânicas da madeira. A possível explicação para esta grande homogeneidade das propriedades mecânicas é a maturidade das árvores.

\subsection{Correlações entre as características quantitativas analisadas}

Foram testadas todas as correlações possíveis, os resultados encontrados são descritos e discutidos a seguir.

As variáveis de produtividade (DAP, altura e volume cilíndrico) correlacionaram entre si e com os volumes. Com as demais características (características da folha, fruto, conicidade, rachaduras de tora e tábua, propriedades físicas e mecânicas da madeira) não houveram correlações ou as correlações foram muito fracas.

As características da folha (comprimento do pecíolo, comprimento e largura da folha e comprimento da cauda) apresentaram fraca correlação entre si, com exceção do comprimento da folha com o comprimento da cauda (Coeficiente de correlação $\mathrm{R}=0,6780$ com $0,01 \%$ de probabilidade) e comprimento da folha com razão entre o comprimento e a largura da folha $(\mathrm{R}=0,5032 \mathrm{com} 0,01 \%$ de probabilidade). Com as demais características (características de produtividade, fruto, conicidade, rachaduras 
de tora e tábua, propriedades físicas e mecânicas da madeira) as correlações foram muito fracas ou não existiram.

As características do fruto (diâmetro e comprimento do fruto e comprimento do pedicelo) apresentaram fraca correlação entre si e não se correlacionaram com as demais características (produtividade, características da folha, conicidade, rachaduras de tora e tábua, propriedades físicas e mecânicas da madeira).

As características climatológicas correlacionam-se de maneira fraca com as características do fruto e não se correlacionaram com as características da folha.

Os índices de rachaduras de extremidades de tora (PER 1, PER 7 e PER60) apresentaram fracas correlações entre si, com exceção da PER 1 com a PER7 ( $R=0,7537$ com $0,01 \%$ de probabilidade). Não houve correlação desses índices com as demais características.

Não houveram correlações das rachaduras de extremidades de tora ou das rachaduras de extremidades de tábua com o diâmetro. Mesmo resultado foi encontrado por outros pesquisadores (Nicholson, 1973; Villiers, 1973; Fernandes, 1982; Mc Kimm, 1985; Combes et al., 1997; Schacht, 1998; Lopes, 2000).

A conicidade de tora com casca só se correlacionou com a conicidade de tora sem casca ( $\mathrm{R}=0,9323$ com $0,01 \%$ de probabilidade). Não houve correlação com as demais características.

Alguns autores também não encontraram correlação entre a conicidade e o volume da tora (Grosser, 1980; Miranda, 1997 e Del Menezzi, 1999).

Não houve correlação da conicidade (com e sem casca) com a tensão de crescimento longitudinal. O mesmo resultado foi encontrado por Malan (1984) e Purnell (1988).

Os resultados das correlações entre as rachaduras de extremidades de tábua [abertura da rachadura na base da tábua (Aberbas), comprimento da rachadura na base da tábua (Compbas), abertura da rachadura no topo da tábua (Abertop), comprimento da rachadura no topo da tábua (Comptop)] estão na Tabela 31. 
Tabela 31. Correlações ente as variáveis das rachaduras de extremidades de tábua

\begin{tabular}{|c|c|c|c|c|}
\hline Características & Aberbas & Compbas & Abertop & Comptop \\
\hline Compbas & $0,9503(* * *)$ & ----- & & \\
\hline Abertop & $0,1748(*)$ & $0,2266(*)$ & ----- & \\
\hline Comptop & $0,2982(* * *)$ & $0,3664(* * *)$ & $0,9219(* * *)$ & ----- \\
\hline Largura & $0,4428(* * *)$ & $0,5087(* * *)$ & ns & $0,3233(* * *)$ \\
\hline Computil & $-0,5881(* * *)$ & $-0,6687(* * *)$ & $-0,8145(* * *)$ & $-0,9333(* * *)$ \\
\hline $\mathrm{N}^{\mathrm{o}}$ peças & $0,3398(* * *)$ & $0,3969(* * *)$ & ns & $0,2253(*)$ \\
\hline Comprach & $0,6024(* * *)$ & $0,6755(* * *)$ & $0,8179(* * *)$ & $0,9336(* * *)$ \\
\hline Perda2 & $0,5736(* * *)$ & $0,6663(* * *)$ & $0,7625(* * *)$ & $0,8805(* * *)$ \\
\hline Perda3 & $0,3477(* * *)$ & $0,4217(* * *)$ & $0,6014(* * *)$ & $0,6636(* * *)$ \\
\hline Rendfin & $-0,3477(* * *)$ & $-0,4217(* * *)$ & $-0,6014(* * *)$ & $-0,6636(* * *)$ \\
\hline Voltorcc & $0,3537(* * *)$ & $0,4120(* * *)$ & ns & $0,2584(* *)$ \\
\hline Voltorsc & $0,3611(* * *)$ & $0,4176(* * *)$ & ns & $0,2913(* *)$ \\
\hline Volcasc & $0,1802(*)$ & $0,2262(*)$ & ns & ns \\
\hline Volpri & $0,4510(* * *)$ & $0,5100(* * *)$ & ns & $0,2704(* *)$ \\
\hline Volsec & ns & ns & $-0,3635(* * *)$ & $-0,3131(* * *)$ \\
\hline Volcilt & $0,1904(*)$ & $0,2255(*)$ & ns & ns \\
\hline PER1 & ns & ns & $0,2259(*)$ & $0,2209(*)$ \\
\hline PER7 & ns & ns & $0,2622(* *)$ & $0,2449(* *)$ \\
\hline PER60 & $0,2044(*)$ & $0,2456(*)$ & $0,2604(* *)$ & $0,2420(* *)$ \\
\hline $\mathrm{Db}$ & ns & $0,1962(*)$ & $0,2346(*)$ & $0,2955(* *)$ \\
\hline Módulo & $\mathrm{ns}$ & ns & $0,2223(* *)$ & $0,2787(* *)$ \\
\hline RR & ns & ns & ns & $0,2228(*)$ \\
\hline Compressão & ns & ns & Ns & $0,1924(*)$ \\
\hline
\end{tabular}

$*, * *, * * *$ significativo a $5 \%, 1 \%$ e $0,1 \%$ respectivamente, e ns $=$ não significativo. 
Observa-se na Tabela 31 que a abertura das rachaduras se correlacionou bem com o seu respectivo comprimento, base com base e topo com topo. A correlação da base com o topo foi fraca. O comprimento da rachadura apresentou correlação melhor que a abertura, com o comprimento útil da tábua. As correlações nos topos foram melhores do que as correlações das bases das tábuas.

A abertura e o comprimento das rachaduras tiveram boas correlações com a perda 2, que expressaram a tensão de crescimento longitudinal, correlação um pouco mais fraca com a perda 3 (tensão de crescimento longitudinal e desdobro) e não se correlacionaram ou correlacionaram de maneira fraca com a perda 1 (desdobro).

A correlação da abertura e do comprimento das rachaduras com as características de produtividade, com as características das folhas e dos frutos, com a conicidade, rachaduras de extremidades de tora e com as propriedades físicas e mecânicas da madeira não existiram ou foram muito fracas.

As perdas (Perda1, Perda2 e Perda3) tiveram correlações boas e negativas com os volumes. Com as demais características (produtividade, folhas, frutos, conicidade, rachaduras de extremidades de tora e tábua e com as propriedades físicas e mecânicas da madeira) as correlações foram fracas ou não existiram.

Os volumes (Voltorcc, Voltorsc, Volcasc, Volpri, Volsec e o Rendfin) tiveram boas correlações entre si, correlações razoáveis e negativas com as perdas e positivas com as características de crescimento, principalmente com o DAP, e não se correlacionaram com as demais características.

Os resultados das correlações entre as propriedades físicas e mecânicas da madeira [umidade (U), Db, RL, RR, RT, RV, IRA, resistência ao cisalhamento (Fs), resistência a compressão $(\mathrm{Fc})$, resistência à flexão $(\mathrm{Ff})$ e módulo da elasticidade à flexão (Ef)] estão na Tabela 32. 
Tabela 32. Correlações entre as propriedades físicas e mecânicas da madeira.

\begin{tabular}{cccccc}
\hline Característica & Db & Fc & Fs & Ef & Ff \\
\hline Db & --------- & & & & \\
Fc & $0,5672(* * *)$ & -------- & & & \\
Fs & $0,5181(* * *)$ & $0,5316(* * *)$ & ------ & & \\
Ef & $0,5216(* * *)$ & $0,6694(* * *)$ & $0,5142(* * *)$ & ------ & \\
Ff & $0,6690(* * *)$ & $0,6771(* * *)$ & $0,5586(* * *)$ & $0,7984(* * *)$ & -------- \\
U & $-0,9392(* * *)$ & $-0,3660(* * *)$ & $-0,3069(* * *)$ & $-0,3868(* * *)$ & $-0,3959(* * *)$ \\
RL & $\mathrm{ns}$ & $0,2036(*)$ & $\mathrm{ns}$ & $\mathrm{ns}$ & $\mathrm{ns}$ \\
RR & $0,3407(* * *)$ & $0,3845(* * *)$ & $0,3616(* * *)$ & $0,4614(* * *)$ & $0,3011(* * *)$ \\
RT & $-0,0405(\mathrm{~ns})$ & $\mathrm{ns}$ & $\mathrm{ns}$ & $\mathrm{ns}$ & $\mathrm{ns}$ \\
RV & $0,1403(\mathrm{~ns})$ & $\mathrm{ns}$ & $0,2082(*)$ & $0,2084(*)$ & $\mathrm{ns}$ \\
$\mathrm{IRA}$ & $-0,3735(* * *)$ & $-0,3963(* * *)$ & $-0,3244(* * *)$ & $-0,4645(* * *)$ & $-0,3460(* * *)$ \\
\hline
\end{tabular}

*,*** significativo a 5 e $0,1 \%$ respectivamente e ns = não significativo.

A umidade apresentou correlação negativa com todas as propriedades físicas e mecânicas da madeira. Com as retratibilidades as correlações foram fracas, com as propriedades mecânicas foram razoáveis e com a densidade básica foi muito boa. Resultados semelhantes foram encontrados por vários pesquisadores (Brotero, 1945; Hillis, 1978; Garcia \& Lima, 1990; Della Lucia \& Vital, 1980; Lopes, 2000).

A retratibilidade longitudinal não se correlacionou com nenhuma característica, com exceção da resistência à compressão, porém esta correlação foi fraca. As retratibilidades radial e tangencial apresentaram boas correlações apenas com a retratibilidade volumétrica, e esta por sua vez, também só se correlacionou com aquelas. O índice de retração anisotrópico apresentou correlação boa e negativa apenas com a retratibilidade radial. Não houve correlação de nenhuma destas retratibilidades bem com o índice de retração anisotrópico com as demais características ou as correlações foram fracas. 
A densidade básica (Db) não se correlacionou ou a correlação foi muito fraca com as características de crescimento, características da folha, do fruto, rachaduras de extremidades de tora, rachaduras de extremidades de peça serrada, com os volumes e com as retratibilidades.

A densidade básica apresentou correlação fraca e negativamente com a retração radial e consequentemente com o índice de retração anisotrópico. Esta fraca correlação da densidade básica com a retratibilidade está de acordo com Chafe (1986; 1987), que afirmou que isso ocorria em função da elevada quantidade de extrativos.

Malan \& Verryn (1996) trabalhando com E. grandis e híbridos desta com outras 3 espécies, também não encontraram correlações entre a densidade básica e as retrações da madeira.

Houve boa correlação entre a densidade básica e todas as propriedades mecânicas, sendo melhor para o módulo de ruptura à flexão estática. Isto é conveniente porque a densidade básica é uma propriedade de fácil determinação e através dela será possível estimarem-se as demais propriedades mecânicas de resistência da madeira.

Como regra geral, quanto maior a densidade básica, maiores serão as propriedades mecânicas de resistência da madeira. Corroboram com isto os trabalhos de Brotero (1945), Hillis (1978), Mendes (1984), Sales (1991) e Nascimento (1993).

A Tabela 33 mostra os coeficientes de regressão linear da equação 13 para a densidade básica com as propriedade mecânicas da madeira, segundo o modelo:

$\mathrm{Y}=\mathrm{A}+\mathrm{B} \mathrm{Db}$

Em que:

$\mathrm{Y}=$ variável dependente (propriedade mecânica);

$\mathrm{A}=$ Coeficiente linear da reta;

$\mathrm{B}=$ Coeficiente angular da reta;

$\mathrm{Db}=$ Densidade básica (variável independente). 
Tabela 33. Valores de A e B obtidos através da equação 13 para as estimativas das propriedades mecânicas da madeira em função da densidade básica com os respectivos coeficientes de determinação $\left(\mathrm{R}^{2}\right)$.

\begin{tabular}{lccc}
\hline Propriedade & A & B & $\mathrm{R}^{2}$ \\
\hline Compressão (Fc) & 64,8997 & 849,8936 & 0,5263 \\
Cisalhamento (Fs) & 42,0314 & 212,7880 & 0,4978 \\
Módulo elasticidade (Ef) & -27242 & 303184 & 0,4613 \\
Módulo ruptura (Ff) & $-340,2529$ & 2400,5366 & 0,7126 \\
\hline
\end{tabular}

Na Tabela 33 observa-se que o módulo de ruptura à flexão teve bom ajuste $\left(\mathrm{R}^{2}=0,7126\right)$, portanto, será possível predizer esta propriedade através da densidade básica. 


\section{CONCLULSÕES}

Com base nos resultados obtidos pode-se concluir que:

- Não existem diferenças estatísticas entre procedências ou progênies para a produtividade (DAP, altura e volume cilíndrico).

- Houve uma tendência das árvores de copa mais aberta serem mais produtivas que as árvores de copa fechada.

- Houve uma tendência das árvores de casca rugosa até a metade do fuste serem mais produtivas que as árvores de a casca totalmente lisa, que por sua vez foram mais produtivas que as árvores de casca totalmente rugosa.

- Apesar da grande amplitude de variação, as características da folha e do fruto estão dentro dos padrões definidos para a espécie.

- Não houve correlação de nenhuma característica da folha ou do fruto com as características climatológicas, com as características de produtividade, volumes, perdas, tensão de crescimento, conicidade ou com as propriedades tecnológicos da madeira.

- Não houve diferença estatística entre as progênies para as rachaduras de extremidades de tora, rachaduras de extremidades de tábua, conicidade, volume da tora ou volume de madeira serrada.

- Não houve correlação entre a conicidade e a tensão de crescimento longitudinal.

- A conicidade não influenciou no rendimento em madeira serrada. 
- Não houve correlação entre o diâmetro da tora com as rachaduras de extremidades de tora ou com as rachaduras de extremidades de tábua. Portanto não houve correlação do diâmetro com a tensão de crescimento longitudinal.

- Não houve correlação entre as rachaduras de extremidades de tora com as rachaduras de extremidades de tábua.

- A tensão de crescimento foi maior no topo que na base da tora.

- O rendimento em madeira serrada médio foi de 42,54 \% com amplitude de 12,64 a $83,53 \%$.

- A umidade correlaciona-se negativamente com as propriedades física e mecânicas da madeira.

- A espécie apresentou alta densidade básica.

- Não houve diferença estatística entre as progênies para as propriedades físicas e mecânicas da madeira, exceto para a retratibilidade volumétrica.

- A retratibilidade da madeira foi alta e não se correlacionou com a densidade básica.

- As propriedades mecânicas da madeira apresentaram boas correlações com a densidade básica.

- A espécie apresentou alta resistência mecânica para todas as propriedades exceto para a compressão que foi considerada média.

- Foi possível predizer o módulo de ruptura à flexão estática através da densidade básica. 
ANEXOS 
ANEXO A - Média e amplitude de variação das características das folhas e dos frutos.

\begin{tabular}{|c|c|c|c|c|c|c|c|c|c|c|}
\hline \multirow[t]{2}{*}{ Características } & \multicolumn{10}{|c|}{ Fonte } \\
\hline & 1 & 2 & 3 & 4 & 5 & 6 & 7 & 8 & 9 & 10 \\
\hline Forma da Folha & $1 d$ & & & & & $1 \mathrm{f}$ & & 1f & 1f & $1 \mathrm{~b}$ \\
\hline Amplitude & & $1 b$ & $1 \mathrm{e}$ & $1 \mathrm{c}$ & & & & 1f & $1 \mathrm{e}$ & $1 \mathrm{~g}$ \\
\hline Comp do pecíolo (mm) & & 22,35 & & 25 & 23,5 & 25,06 & 25,49 & & & \\
\hline Amplitude & & $19,4-27,0$ & & $20-30$ & $15,0-30,0$ & $20,2-31,0$ & $24,27-29,08$ & & & \\
\hline Comp da Folha $(\mathrm{cm})$ & & 15,29 & 16 & 12,5 & & 14,43 & 14,44 & 14,51 & 16,56 & \\
\hline Amplitude & & $12,75-17,80$ & $12-20$ & $11-14$ & & $12,27-15,45$ & $13,67-16,45$ & $13,14-16,87$ & $14,72-18,84$ & \\
\hline Largura da Folha $(\mathrm{cm})$ & & 4,95 & 3,5 & 4,5 & & 3,89 & 3,80 & 4,97 & 3,71 & \\
\hline Amplitude & & $3,8-6,8$ & 2 a 5 & 3 a 6 & & $3,10-4,53$ & $3,34-4,01$ & $4,20-5,59$ & $3,13-4,54$ & \\
\hline Comp cauda folha $(\mathrm{cm})$ & & & & & & 2,12 & 2,15 & & & 4,43 \\
\hline Amplitude & & & & & & $1,36-3,00$ & $1,73-3,00$ & & & $2,2-6,6$ \\
\hline Relação C/L folha & & 3,19 & 5 & 3 & 4,50 & 3,71 & 3,80 & 2,98 & 4,60 & 4,43 \\
\hline Amplitude & & $2,32-3,56$ & 4 a 6 & $2,3-3,7$ & $3,09-6,83$ & $2,71-4,98$ & $3,41-4,73$ & $2,55-3,69$ & $3,24-5,59$ & $2,2-6,6$ \\
\hline Forma da Fruto & & $2 \mathrm{~h}$ & & & & & & & & $2 \mathrm{i}$ \\
\hline Amplitude & & $2 d$ & $2 \mathrm{a}$ & $2 b$ & $2 d$ & $2 \mathrm{c}$ & $2 \mathrm{c}$ & $2 f$ & $2 \mathrm{~g}$ & $2 d$ \\
\hline Comp do pedicelo (mm) & & 12,5 & & & 4,70 & 6,97 & 6,88 & 2,81 & 2,09 & \\
\hline Amplitude & & $9-16$ & & & $2,0-9,3$ & $4,40-9,08$ & $6,00-7,58$ & $1,62-3,54$ & $1,48-2,79$ & \\
\hline Comp do Fruto (mm) & & 12 & 12 & 8,5 & 7,6 & 6,81 & 6,43 & 7,63 & 7,91 & \\
\hline Amplitude & & $6-18$ & $8-18$ & $7-10$ & $6,5-9,7$ & $5,80-9,76$ & $5,97-7,02$ & $6,32-8,16$ & $7,27-8,24$ & \\
\hline
\end{tabular}


ANEXO A - Média e amplitude de variação das características das folhas e dos frutos.

\begin{tabular}{|c|c|c|c|c|c|c|c|c|c|c|}
\hline \multirow[t]{2}{*}{ Características } & \multicolumn{10}{|c|}{ Fonte } \\
\hline & 1 & 2 & 3 & 4 & 5 & 6 & 7 & 8 & 9 & 10 \\
\hline Diâmetro do fruto $(\mathrm{mm})$ & & 8 & 10 & 7,5 & 8,0 & 9,22 & 8,81 & 7,64 & 7,41 & \\
\hline Amplitude & & $6-10$ & 6-14 & 6-9 & $6,0-10,7$ & $8,03-11,63$ & $8,23-9,16$ & $6,78-8,21$ & $6,95-7,68$ & \\
\hline Posição do disco & & $3 \mathrm{c}$ & & & & & & $3 \mathrm{~d}$ & $3 d$ & $3 d$ \\
\hline Amplitude & & $3 \mathrm{a}$ & $3 b$ & & $3 b$ & & & $3 \mathrm{~d}$ & $3 d$ & $3 \mathrm{a}$ \\
\hline Número de valvas & & 4 & & & & 4,27 & 4,27 & 3,98 & 4,14 & \\
\hline Amplitude & & 3 a 5 & 3 a 5 & & & $4,00-4,75$ & $4,00-4,45$ & $3,9-4,1$ & $4,0-4,2$ & \\
\hline Posição das valvas & & $4 \mathrm{a}$ & $4 \mathrm{c}$ & $4 \mathrm{a}$ & & & & $4 a$ & $4 \mathrm{a}$ & $4 \mathrm{e}$ \\
\hline Amplitude & & $4 \mathrm{~b}$ & & & $4 \mathrm{~b}$ & & & $4 d$ & $4 \mathrm{a}$ & $4 \mathrm{~b}$ \\
\hline $\mathrm{N}^{\mathrm{o}}$ de furtos/infrutescência & & 7 & & & & & & 6,96 & 6,96 & 7 \\
\hline Amplitude & & $4-11$ & & $3-7$ & & & & $6,8-7,0$ & $6,8-7,0$ & $7-9$ \\
\hline
\end{tabular}

$1 \mathrm{a}=$ Lanceolada estreita; $1 \mathrm{~b}=$ Lanceolada a lanceolada estreita; $1 \mathrm{c}=$ Larga a estreita lanceolada; $1 \mathrm{~d}=$ Lanceolada; $1 \mathrm{e}=$ Lanceolada larga $\mathrm{a}$ lanceolada; 1f = Lanceolada larga; $1 \mathrm{~g}=$ Larga a estreita lanceolada e ovóide lanceolada. $2 \mathrm{a}=$ Cônico; $2 \mathrm{~b}=$ Amplamente cônico e cônico; $2 \mathrm{c}=$ Cônico, campanulado e hemisférico; $2 \mathrm{~d}=$ Globular truncado, campanulado, amplamente cônico e cônico; $2 \mathrm{e}=$ Campanulado, amplamente cônico e ovóide truncado; $2 \mathrm{f}=$ Campanulado e barril; $2 \mathrm{~g}=$ Campanulado e hemisférico (taciformes); $2 \mathrm{~h}=$ hemisférico. $3 \mathrm{a}=$ Saliente a incluso; $3 \mathrm{~b}=$ Rasante a incluso; $3 \mathrm{c}=$ Rasante; $3 \mathrm{~d}=$ incluso. $4 \mathrm{a}=$ Saliente; $4 \mathrm{~b}=$ Saliente a inclusa; $\quad 4 \mathrm{c}=$ Nivelada; $4 \mathrm{~d}=$ Rasante a saliente; $4 \mathrm{e}=$ Inclusa a rasante.

Fonte: 1 =FAO, 1979; 2 = Martin e Cossalter, 1975A,B; 3 = Turnbull e Brooker, 1978; 4 = Goes, 1985; 5 = López, 1992 E. urophylla ilha Flores; $6=$ Pryor et al., 1995 E. urophylla todas as ilhas; $7=$ Pryor et al., 1995 E. urophylla ilha Flores; $8=$ Ferreira e Souza, 1997, E. urophylla de casca fibrosa, $9=$ Ferreira e Souza, 1997, E. urophylla de casca lisa; $10=$ Ferreira, 1999, E. urophylla de casca lisa. 
ANEXO B - Características das folhas e dos frutos (Pryor et al., 1995).

\begin{tabular}{|c|c|c|c|c|c|}
\hline \multirow[b]{2}{*}{ Característica } & \multicolumn{2}{|c|}{ E. urophylla } & \multicolumn{2}{|c|}{ E. wetarensis } & \multirow{2}{*}{$\begin{array}{l}\text { E. orophila } \\
\text { Média }\end{array}$} \\
\hline & Média & Amplitude & Média & Amplitude & \\
\hline Teor de óleo $\%$ & 1,1 & & 0,5 & & 0,3 \\
\hline Comprimento da folha ( $\mathrm{mm})$ & 144,28 & $122,70-154,50$ & 130,40 & $127,80-139,10$ & 97,80 \\
\hline Largura da folha $(\mathrm{mm})$ & 38,88 & $31,00-45,33$ & 32,20 & $27,90-35,81$ & 40,11 \\
\hline Comprimento pecíolo (mm) & 25,06 & $20,20-31,00$ & 21,36 & $20,40-22,86$ & 24,00 \\
\hline Comprimento da calda (mm) & 21,15 & $13,58-30,00$ & 16,35 & $13,60-19,70$ & 9,28 \\
\hline Ângulo da folha (graus) & 47,8 & $41,17-55,86$ & 41,15 & $36,57-45,40$ & 60,33 \\
\hline Comprimento pedicelo ( $\mathrm{mm})$ & 6,97 & $4,40-9,08$ & 6,74 & $5,50-8,33$ & 4,65 \\
\hline Comprimento do fruto (mm) & 6,81 & $5,80-9,76$ & 10,49 & $8,44-11,60$ & 8,28 \\
\hline Largura do fruto $(\mathrm{mm})$ & 9,22 & $8,03-11,63$ & 13,36 & $12,11-14,50$ & 10,07 \\
\hline Número de valvas & 4,27 & $4,00-4,75$ & 4,68 & $4,50-4,89$ & 4,00 \\
\hline Comp. Pedúnculo (mm) & 14,61 & $12,05-19,25$ & 14,38 & $13,43-16,90$ & 15,09 \\
\hline № lóculos por fruto & & 3 a 5 & & 5 a 6 & 4 \\
\hline Altura da árvore & & $20-55$ & & $10-17$ & 14,5 \\
\hline Casca & & & & $1 \mathrm{a}$ & $1 \mathrm{~b}$ \\
\hline Folha de plântulas & & & & $2 \mathrm{a}$ & $2 \mathrm{e}$ \\
\hline Folha juvenis & & & & $2 b$ & \\
\hline Folha adulta & & $2 f$ & & $2 c$ & $2 \mathrm{~d}$ \\
\hline Comp. Botão foral (mm) & & & & $10-15$ & $8-12$ \\
\hline Largura botão foral (mm) & & & & $5-7$ & $7-8$ \\
\hline Forma do fruto & & & & $3 \mathrm{a}$ & $3 \mathrm{a}$ \\
\hline Posição do disco & & & & $4 \mathrm{a}$ & $4 \mathrm{a}$ \\
\hline Posição das valvas & & & & $5 b$ & $5 \mathrm{a}$ \\
\hline Nervura & & & & Saliência dorsal & \\
\hline
\end{tabular}

$1 \mathrm{a}=$ Casca fibrosa a rugosa marrom até a metade dos galhos; $1 \mathrm{~b}=$ Casca rugosa até 4 ou $5 \mathrm{~m}$, depois casca lisa e esverdeada. $2 \mathrm{a}=$ Opostas com 5 a 6 pares, depois isoladas, curto pecíolo, forma elíptica a ovada, cor distinta nas duas faces; $2 \mathrm{~b}=$ Ovada a lanceolada, glabosa, de 90 a $115 \mathrm{~mm}$ de comprimento por 40 a $65 \mathrm{~mm}$ de largura, cor distinta nas duas faces; $2 \mathrm{c}=$ Lanceolada estreita tendendo a linear, de 120 a $140 \mathrm{~mm}$ de comprimento por 25 a $35 \mathrm{~mm}$ de largura, cor distinta nas duas faces, pecíolo de 20 a 23mm; $2 \mathrm{~d}=$ Ovada a lanceolada, com cauda curta ou as vezes sem cauda; 2e = Opostas com 5 pares depois isoladas, glabosa, ovadas, curto pecíolo, forma elíptica a ovada, cor distinta nas duas faces; 2f $=$ Lanceolada larga. $3 \mathrm{a}=$ Capanulado a barril. $4 \mathrm{a}=$ Incluso ( $2 \mathrm{a} 3 \mathrm{~mm}) .5 \mathrm{a}=$ Incluso a nivelada $(2 \mathrm{~mm}) ; 5 \mathrm{~b}=$ Saliente. 
ANEXO C - Local do ensaio, idade (anos), parâmetro avaliado, fonte e classificação das 5 melhores procedências em ordem decrescente.

\begin{tabular}{|c|c|c|c|c|}
\hline Local & Idade & Parâmetro & Fonte & Procedências \\
\hline \multirow[t]{5}{*}{ Anhembi-SP } & 0,5 & Alturas(m) & 2 & Wukoh, Ilegele, Saler Wukoh, Londangwuang e Egon \\
\hline & 1 & Altura (m) & 2 & Ilegele, Egon, Ara Detung, Wukoh e Londangwuang. \\
\hline & 2 & DAP $(\mathrm{cm})$ & 2 & Ilegele, Egon, Ara Detung, // Lewotobi e Saler Wukoh \\
\hline & 3 & $\mathrm{DAP}(\mathrm{cm})$ & 2 & Egon, Londangwuang, Ilegele, Ara Detung e / Lewotobi \\
\hline & 10 & $\mathrm{DAP}(\mathrm{cm})$ & 5 & Egon II, Ara Detung, Lewotobi, Ilimandiri e Wukoh \\
\hline \multirow[t]{4}{*}{ Aracruz-ES } & 1 & Altura (m) & 2 & Ilegele, Lewotobi, Londangwuang, Ara Detung e Ilimandiri. \\
\hline & 2 & $\mathrm{DAP}(\mathrm{cm})$ & 2 & Ilegele, Lewotobi, Egon II, Saler Wukoh e Ara Detung \\
\hline & 3 & $\mathrm{DAP}(\mathrm{cm})$ & 2 & Lewotobi, Ilegele, Egon, Londangwuang e Ara Detung \\
\hline & 7 & Volcil $\left(\mathrm{m}^{3}\right)$ & 4 & Lewotobi, Ilegele, Londangwuang, Ilimandiri e Egon II/Ara Detung \\
\hline \multirow[t]{6}{*}{ Belo Oriente-MG } & 1,58 & Volcil $\left(\mathrm{m}^{3}\right)$ & 3 & Egon, Ilegele, Lewotobi, Ilimandiri e Londangwuang. \\
\hline & 2,25 & Volcil $\left(\mathrm{m}^{3}\right)$ & 3 & Egon, Ilegele, Lewotobi, Londangwuang e Ilimandiri. \\
\hline & 3,5 & Volcil $\left(\mathrm{m}^{3}\right)$ & 3 & Egon, Ilegele, Lewotobi, Ilimandiri e Londangwuang. \\
\hline & 4 & Volcil $\left(\mathrm{m}^{3}\right)$ & 1 & Egon, Ilegele, Lewotobi, Londangwuang e Ilimandiri. \\
\hline & 4,25 & Volcil $\left(\mathrm{m}^{3}\right)$ & 3 & Egon, // Ilegele, Lewotobi, Ilimandiri e Londangwuang. \\
\hline & 7 & Volcil $\left(\mathrm{m}^{3}\right)$ & 4 & Ilegele, Egon, Lewotobi, Ilimandiri e Egon II/Ara Detung. \\
\hline Bom Despacho-MG & 1 & Altura (m) & 2 & Ilegele, Egon, Lewotobi, Ara Detung e Saler Wukoh. \\
\hline
\end{tabular}


ANEXO C - Local do ensaio, idade (anos), parâmetro avaliado, fonte e classificação das 5 melhores procedências em ordem decrescente.

\begin{tabular}{ccccc}
\hline Local & Idade & Parâmetro & Fonte & Procedências \\
\hline Bom Despacho-MG & 2 & DAP $(\mathrm{cm})$ & 2 & Ilegele, Egon, Ara Detung, Saler Wukoh e Lewotobi. \\
& 3 & DAP $(\mathrm{cm})$ & 2 & Ilegele, Egon, Ara Detung, Lewotobi e Wukoh. \\
& 7 & Volcil $\left(\mathrm{m}^{3}\right)$ & 4 & Ilegele, Egon, Lewotobi, Ilimandiri e Wukoh. \\
Grão Mogol-MG & 7 & Volcil $\left(\mathrm{m}^{3}\right)$ & 4 & Londangwuang, Ilegele, Egon, Saler Wukoh e Lewotobi \\
& 8 & Volcil $\left(\mathrm{m}^{3}\right)$ & 6 & Ende, Ara Detung, Londangwuang, Saler Wukoh e Ilegele. \\
Linhares-ES & 4 & Volcil $\left(\mathrm{m}^{3}\right)$ & 1 & Egon, // Ilegele, Lewotobi, Saler Wukoh e Egon II \\
& 8 & Volcil $\left(\mathrm{m}^{3}\right)$ & 6 & // Lewotobi, Ilegele, Wukoh, Londangwuang e Egon II \\
Planaltina-DF & 1 & Altura $(\mathrm{m})$ & 2 & Egon, Ilegele, Lewotobi, Ilimandiri e Londangwuang. \\
& 2 & DAP $(\mathrm{cm})$ & 2 & Egon, Ilegele, Saler Wukoh, Lewotobi e Londangwuang \\
& 3 & DAP $(\mathrm{cm})$ & 2 & Egon, Ilegele, Saler Wukoh, Ilimandiri e Londangwuang. \\
\hline
\end{tabular}

Obs: Procedências posteriores à // significa produtividade inferior destas procedências em relação à testemunha para o parâmetro analisado.

1 = Brasil, (1983); 2 = Pinto Junior, (1984); 3 = Capitani et al. (1987); 4 = Mori et al. (1988); 5 = IPEF, (1990); $6=$ Santos et al., (1990). 
ANEXO D - Espécie, fonte, idade (anos), área de cada planta $\left(\mathrm{m}^{2}\right)$, tora da árvore (sendo a primeira da base, a segunda a subsequente e assim por diante) e conicidade $(\mathrm{cm} / \mathrm{m})$.

\begin{tabular}{|c|c|c|c|c|c|}
\hline Espécie & Fonte & Idade & Área & Tora & Conicidade \\
\hline E. citriodora & 1 & 17 & 6 & Árvore & 1,12 \\
\hline E. cloeziana & 3 & 17 & 6 & $1^{\mathrm{o}}$ & 0,96 \\
\hline E. cloeziana & 3 & 17 & 6 & $2^{\circ}$ & 0,66 \\
\hline E. cloeziana & 3 & 17 & 6 & Média & 0,80 \\
\hline E. cloeziana & 1 & 19 & 9 & Árvore & 1,13 \\
\hline E. grandis & 9 & 8,75 & & & 0,58 \\
\hline E. grandis & 3 & 21 & 6 & $1^{\mathrm{o}}$ & 1,10 \\
\hline E. grandis & 3 & 21 & 6 & $2^{\circ}$ & 0,48 \\
\hline E. grandis & 3 & 21 & 6 & Média & 0,79 \\
\hline E. grandis & 4 & 21 & 90,91 & & 0,66 \\
\hline E. grandis & 5 & 20 & & & 0,54 \\
\hline E. maculata & 1 & 17 & 9 & Árvore & 0,98 \\
\hline E. microcorys & 1 & 17 & 9 & Árvore & 0,97 \\
\hline E. nitens & 7 & 11 & & 1 & 1,47 \\
\hline E. nitens & 7 & 11 & & 2 & 0,65 \\
\hline E. nitens & 7 & 11 & & 3 & 0,71 \\
\hline E. nitens & 7 & 11 & & 4 & 0,71 \\
\hline E. nitens & 7 & 11 & & 5 & 0,80 \\
\hline E. nitens & 7 & 11 & & 6 & 0,89 \\
\hline E. paniculata & 1 & 20 & 6 & Árvore & 1,19 \\
\hline E. pellita & 1 & 17 & 9 & Árvore & 1,01 \\
\hline E. phaeotricha & 1 & 17 & 9 & Árvore & 1,30 \\
\hline E. pilularis & 1 & 17 & 9 & Árvore & 1,04 \\
\hline E. proprinqua & 1 & 21 & 6 & Árvore & 1,25 \\
\hline E. pyrocarpa & 1 & 17 & 9 & Árvore & 1,11 \\
\hline E. resinifera & 1 & 12 & 9 & Árvore & 1,07 \\
\hline
\end{tabular}


ANEXO D - Espécie, fonte, idade (anos), área de cada planta $\left(\mathrm{m}^{2}\right)$, tora da árvore (sendo a primeira da base, a segunda a subsequente e assim por diante) e conicidade $(\mathrm{cm} / \mathrm{m})$.

\begin{tabular}{cccccc}
\hline Espécie & Fonte & Idade & Área & Tora & Conicidade \\
\hline E. saligna & 6 & 9 & 9 & & 0,73 \\
E. saligna & 6 & 9 & 12 & & 0,73 \\
E. saligna & 6 & 9 & 16 & & 0,83 \\
E. saligna & 6 & 9 & Média & & 0,76 \\
E. saligna & 1 & 23 & 6 & Árvore & 1,18 \\
E. tereticornis & 1 & 19 & 6 & Árvore & 1,11 \\
E. torelliana & 1 & 20 & 6 & Árvore & 1,34 \\
E. urophylla & 8 & 9 & 9 & & 1,61 \\
E. urophylla & 1 & 20 & 6 & Árvore & 0,96 \\
E. urophyllaxE. grandis & 2 & 4,83 & & & 2,0 \\
E. urophyllax E. pellita & 2 & 4,83 & & & 2,3 \\
\hline
\end{tabular}

Fonte: 1 = Berchat, 2002; 2 Combes et al., 1997; 3 = Del Menezzi, 1999; 4 = Malan, 1988; 5 = Malan, 1984; 6 = Miranda, 1997; 7 = Purnell, 1988; $8=$ Schacht, 1998; $9=$ Van Wyk, 1990. 
ANEXO E - Espécie, fonte, idade (anos), diâmetro da ponta mais fina da tora $(\mathrm{cm})$, tipo de corte e rendimento em madeira serrada (\%).

\begin{tabular}{|c|c|c|c|c|c|}
\hline Espécie & Fonte & Idade & Diâmetro & Tipo de corte & Rendimento \\
\hline E. cloeziana & 3 & 17 & $1^{\mathrm{o}}$ tora & Paralelo & 54,6 \\
\hline E. cloeziana & 3 & 17 & $2^{\underline{o}}$ tora & Paralelo & 48,7 \\
\hline E. cloeziana & 3 & 17 & Média & Paralelo & 51,7 \\
\hline E. diversicolor & 12 & $15-25$ & & & 42 \\
\hline E. dunnii & 9 & 16,5 & 21,5 & Tangencial & 36,8 \\
\hline E. dunnii & 9 & 16,5 & 27,5 & Tangencial & 37,1 \\
\hline E. dunnii & 9 & 16,5 & 21,5 & Radial & 37,3 \\
\hline E. dunnii & 9 & 16,5 & 27,5 & Radial & 38 \\
\hline E. globoidea & 12 & $15-25$ & & & 46 \\
\hline E. globulus & 6 & 20 & 24 & Paralelo & 51,5 \\
\hline E. globulus & 6 & 20 & 32 & Paralelo & 56 \\
\hline E. globulus & 6 & 20 & 33 & Paralelo & 58 \\
\hline E. grandis & 10 & & $15-20$ & Paralelo & 47 \\
\hline E. grandis & 10 & & $20-25$ & Paralelo & 53 \\
\hline E. grandis & 10 & & $25-30$ & Paralelo & 57 \\
\hline E. grandis & 10 & & $30-35$ & Paralelo & 59 \\
\hline E. grandis & 10 & & $35-40$ & Paralelo & 60 \\
\hline E. grandis & 9 & 12 & 21,5 & Tangencial & 40 \\
\hline E. grandis & 9 & 12 & 27,5 & Tangencial & 45 \\
\hline E. grandis & 9 & 12 & 21,5 & Radial & 49,7 \\
\hline E. grandis & 9 & 12 & 27,5 & Radial & 52 \\
\hline E. grandis & 3 & 21 & 30,3 & Paralelo & 51,8 \\
\hline E. grandis & 5 & 19 & 37,5 & Paralelo & 46,8 \\
\hline E. grandis & 12 & 20 & & & 43 \\
\hline E. grandis & 11 & & & & 41,5 \\
\hline E. grandisxE. urophylla & 2 & 7 & $12-20$ & Paralelo & 39,7 \\
\hline E. maculata & 12 & 20 & & & 60 \\
\hline E. maculata & 12 & 20 & & & 70 \\
\hline E. microcorys & 12 & 20 & & & 50 \\
\hline E. quadrangulata & 12 & 20 & & & 71 \\
\hline E. resinifera & 12 & 20 & & & 31 \\
\hline E. saligna & 8 & 9 & 14,75 & Paralelo & 19,6 \\
\hline E. saligna & 8 & 9 & 20,88 & Paralelo & 41,3 \\
\hline E. saligna & 8 & 9 & 29 & Paralelo & 59,1 \\
\hline E. saligna Média & 8 & 9 & 20,9 & Paralelo & 41 \\
\hline E. saligna & 12 & 20 & & & 48 \\
\hline E. saligna & 1 & 34 & 12,9 & Radial & 60,4 \\
\hline E. saligna & 1 & 34 & 19,7 & Radial & 69,2 \\
\hline E. saligna & 1 & 34 & 17,9 & Paralelo & 60,8 \\
\hline E. saligna & 1 & 34 & 28,1 & Paralelo & 67,6 \\
\hline Eucalyptus spp. & 7 & & & & $45-55$ \\
\hline
\end{tabular}


ANEXO E - Espécie, fonte, idade (anos), diâmetro da ponta mais fina da tora $(\mathrm{cm})$, tipo de corte e rendimento em madeira serrada (\%).

\begin{tabular}{cccccc}
\hline Espécie & Fonte & Idade & Diâmetro & Tipo de corte & Rendimento \\
\hline Eucalyptus $\mathrm{spp}$. & 4 & & $15-30$ & & $42-50$ \\
Eucalyptus $\mathrm{spp}$. & 4 & & & & 55,6 \\
Eucalyptus $\mathrm{spp}$. & 10 & $14-17$ & Paralelo & 35,7 \\
Eucalyptus $\mathrm{spp}$. & 10 & $18-21$ & Paralelo & 47,3 \\
Eucalyptus $\mathrm{spp}$. & 10 & $22-25$ & Paralelo & 50,8 \\
Eucalyptus $\mathrm{spp}$. & 10 & $26-29$ & Paralelo & 56,3 \\
Eucalyptus $\mathrm{spp}$. & 10 & $30-33$ & Paralelo & 57,1 \\
Eucalyptus $\mathrm{spp}$. & 10 & $34-37$ & Paralelo & 57,3 \\
Eucalyptus $\mathrm{spp}$. & 10 & $38-40$ & Paralelo & 59,9 \\
Eucalyptus $\mathrm{spp}$. & 10 & $14-40$ & Paralelo & 52,1 \\
\hline
\end{tabular}

Fonte: 1 = Berengut et al., 1973; 2 = Carvalho, 2000; 3 = Del Menezzi, 1999; $4=$ Freitas \& Brito Neto, 1993; 5 = Jara et al., 1997; 6 = Luengo Mendoza, 1996; 7 = Mello, 1978; 8 = Miranda, 1997; 9 = Rocha, 2000; $10=$ Sanches Acosta, 1998; $11=$ Sanches Acosta, 1995; 12 = Villiers, 1973 . 


\section{REFERÊNCIAS BIBLIOGRÁFICAS}

ARGANBRIGHT, D. G. Influence of extractives on bending strenght of redwood (Sequoia semprevirens). Wood and Fiber, v. 2, n. 4, p.367-372, 1971.

BARCHET, V. G. Potencialidade de espécies de Eucalyptus para produção de madeira serrada. Piracicaba, 2001. 166p. Dissertação (Mestrado) - Escola Superior de Agricultura “Luiz de Queiroz”, Universidade de São Paulo.

BARISKA, M. A method for predicting timber quality in eucalypts. In: MANEGEMENT OF Eucalyptus grandis IN SOUTH AFRICA. Stellenbosh, 1990. Proceedings. Stellenbosh: Southern African Institute of Forestry, 1990. p.215-228.

BERENGUT, G.; PONCE, R. H.; FREITAS, A. R. Ensaio de desdobro de Eucalyptus saligna Smith. Silvicultura em São Paulo, v.8, p.81-98, 1973.

BOYD, J. D. Tree growth stresses. I - Growth stresses evaluation. Australian Journal Science Research, v. 3, p.270-293, 1950a.

BOYD, J. D. Tree growth stresses. II - The development of shakes and other visual failures in timber. Australian Journal of Applied Science, v.1, p.296-312, 1950 b.

BOYD, J. D. Effect of plantation conditions on wood properties and utilization. In: FAO WORLD SYMPOSIUM ON MAN-MADE FORESTS AND THEIR INDUSTRIAL IMPORTANCE, Canberra, 1967. Documents. Rome: FAO, 1967. v. 1, p.789-821. 
BOYD, J. D. Relation between fibre morphology, growth strain and physical properties of wood. Australia Forest Research, v. 10, n. 4, p.337-360, 1980.

BRASIL, M. A. M. Variação da densidade básica da madeira entre e dentro de procedências de Eucalyptus urophylla S. T. BLAKE. Botucatu, 1983. 89 p. Tese (Livre Docência) - Universidade Estadual Paulista.

BROOKER, M. I. H.; KLENIG, D. A. Field guide to Eucalypts: Southeastem Australia. Melbourne: Inkata Press, 1983.288p.

BROTERO, F. A. Métodos de ensaios adotados no I. P. T. para o estudo de madeiras nacionais. Boletim Instituto Florestal, v.31, p.7-28, 1945.

CAPITANI, L. R.; VIEIRA, F. S.; MENDES, F. S. Eucalyptus urophylla da Indonésia no vale do Rio Doce. Revista CVRD, v. 8, n. 27, p.37-52, 1987.

CARVALHO, A. M. Valorização da madeira do híbrido Eucalyptus grandis x Eucalyptus urophylla através da produção conjunta de madeira serrada em pequenas dimensões, celulose e lenha. Piracicaba, 2000. 129p. Dissertação (Mestrado) - Escola Superior de Agricultura “Luiz de Queiroz”, Universidade de São Paulo.

CHAFE, S. C. Collapse, volumetric shrinkage, specific gravity and extratives in Eucalyptus and others species. Part 1: The shrinkage/specific gravity ratio. Wood Science and Technology, v. 20, n. 4, p.293-307, 1986.

CHAFE, S. C. Collapse, volumetric shrinkage, specific gravity and extratives in Eucalyptus and others species. Part 2: The influence of wood extratives. Wood Science and Technology, v. 21, n. 1, p.27-41, 1987. 
COMBES, J. G.; BOUVET, J. M.; BAILLERES, H. Analyses of growth, morphological and wood properties traits in ortet populations of Eucalyptus in the Congo. In: CONFERÊNCIA IUFRO SOBRE SILVICULTURA E MELHORAMENTO DE EUCALIPTOS, Salvador, 1997. Anais. Colombo: EMBRAPA/CNPF, 1997. v.3, p.37-42.

CORBASSON, M.; COSSALTER, C. Essais de provenances d' Eucalyptus urophylla Blake realises a partir des provenances recoltees par le Centre Technique Forestier Tropical. Silvicultura, v. 8, n. 31, p.424-426, 1983.

CRÊSPO, É. A. Tensão de crescimento e suas conseqüências, controláveis e não controláveis, no desdobro e secagem do Eucalyptus grandis e Eucalyptus saligna. Piracicaba, 2000. 119p. Dissertação (Mestrado) - Escola Superior de Agricultura “Luiz de Queiroz”, Universidade de São Paulo.

DELLA LUCIA, R. M.; VITAL, B. R. Características físicas e mecânicas da madeira de Eucalyptus grandis W. Hill ex Maiden. Revista Árvore, v. 4, n. 1, p.70-74, 1980.

DARROW, K.; ROEDER, K. R. Provenance trials of Eucalyptus urophylla and Eucalyptus alba in South Africa: seven-year results. South African Forestry Journal, v. 125, p.20-28, 1983.

DEL MENEZZI, C. H. S. Utilização de um método combinado de desdobro e secagem para a produção de madeira serrada de Eucalyptus grandis Hill ex Maiden e E. cloeziana F. Muell. Piracicaba, 1999. 87p. Dissertação (Mestrado) - Escola Superior de Agricultura "Luiz de Queiroz”, Universidade de São Paulo.

DORAN, J. C.; WILLIANS, E. R.; BROPHY, J. J. Patterns of variation in the seedling leaf oils of Eucalyptus urophylla, E. pellita and E. scias. Australian Journal of Botany, v. 43, n. 3, p.327-336, 1995. 
ELDRIDGE, K.; DAVIDSON, J.; HARWOOD, C.; VAN WYK, G. Eucalyptus urophylla. In: ELDRIDGE, K.; DAVIDSON, J.; HARWOOD, C.; VAN WYK, G. Eucalypts domestication and breeding. Oxford: Clarendon Press, 1994. cap.16, p.144-153.

ESTADOS UNIDOS. Forest Products Laboratory. Wood handbook: wood as an engeneering material. Madison: FLP, 1974. 1v.

FAO. Eucalypts for planting. Rome, 1979. 677p.

FERNANDES, P. S. Variação da densidade básica da madeira e suas relações com as tensões de crescimento em progênies de Eucalyptus urophylla S. T. Blake. Piracicaba, 1982. 85p. Dissertação (Mestrado) - Escola Superior de Agricultura "Luiz de Queiroz”, Universidade de São Paulo.

FERREIRA, M. Melhoramento e a silvicultura intensiva clonal. IPEF, n. 45, p.22-30, 1992.

FERREIRA, M. Melhoramento genético do Eucalyptus urophylla S. T. Blake direcionado para a formação de populações base tipo casca lisa ("gum"). Piracicaba: FAPESP, 1999. 106 p.

FERREIRA, M.; SOUZA, I. C. G. Caracterização e identificação dos clones de Eucalyptus da Bahia Sul Celulose S. A. Piracicaba: IPEF, 1997. 227p.

FLYNN, B.; SHIELD, E. Eucalyptus progress in higer value utilization: a global review. Tacoma: Robert Flynn \& Associates, 1999. 212p. 
FREITAS, A. R.; BRITO NETO, O. Os avanços tecnológicos no processamento e uso de produtos florestais: produção de madeira serrada de eucalipto. In: CONGRESSO FLORESTAL PANAMERICANO, 1, CONGRESSO FLORESTAL BRASILEIRO, 7., Curitiba, 1993. Anais. São Paulo: SBS/SBEF, 1993. v. 3, p.293-295.

GARCIA, C. H. Tabelas para classificação do coeficiente de variação. Circular Técnica IPEF, n. 171, p.1-11, nov. 1989.

GARCIA, J. N.; LIMA, I. L. Propriedades físicas e mecânicas como indicadores de seleção. In: CONGRESSO FLROESTAL BRASILEIRO, 6., Campos do Jordão, 1990. Anais. São Paulo: SBS/SBEF, 1990. v. 3, p.685-689.

GIORDANO, G. Aptude au travail du bois d' Eucalyptus. In: CONFERÊNCIA MUNDIAL DO EUCALIPTO, 2, São Paulo, 1961. Relatórios e Documentos. São Paulo: FAO, 1961. v. 2, p.1138-1146.

GOES, E. Os eucaliptos: Identificação e monografia de 121 espécies existentes em Portugal. Lisboa: Portucel, 1985. 372p.

GOUMA, R. Adaptation des provenances de Eucalyptus urophylla au Congo. Cahiers Agricultures, v.7, n. 5, p.403-406, 1998.

GROSSER, D. Defeitos da madeira. Série Técnica FUPEF, v. 2, p.1-62, 1980.

HARRIS, J. M. Mejoramiento genético de arboles para elevar la calidade de la madeira: oputunidades y ventajas practicas. In: WORLD CONSULTATION ON FOREST TREE BREEDING, 2., Washington, 1969. Proceedings. Rome: FAO, 1969. v. 1, cap. $4 / 1,22 \mathrm{p}$. 
HILLIS, W. E. Wood quality and utilization. In: HILLIS, , W. E.; BROWN, A. G. Eucalypts for wood production. Adelaide: CSIRO, Division of Forest Research, 1978. cap.12, p.259-289.

HOUSE, A. P. N.; BELL, J. C. Isozyme variation and mating system in Eucalyptus urophylla S. T. Blake. Silvae Genetica, v.43, n.2/3, p.167-176, 1994.

INSTITUTO DE PESQUISAS E ESTUDOS FLORESTAIS (IPEF). Reunião técnica sobre população base em Eucalyptus. Piracicaba, 1990. 53p.

JARA, E. R. P.; MIRANDA, M. J.; HUMPHERYS, R. D. Influência do tratamento térmico na redução das tensões internas de crescimento em toras de Eucalyptus grandis. In: CONFERÊNCIA IUFRO SOBRE SILVICULTURA E MELHORAMENTO DE EUCALIPTOS, Salvador, 1997. Anais. Colombo: EMBRAPA/CNPF, 1997. v. 3, p.276-281.

KOLlMAN, F. F. P.; CÔTÉ, W. A. Principles of wood science and technology. I Solid wood. New York: Springer-Verlag, 1968. 592p.

KUBLER, H. Studies on growth stresses in trees- Part 1: The origin of growth stresses and the stresses in transverse direction. Holz als Roh-und Wekstoff, v.17, n. 1, p.1-9, 1959.

LIMA, I. L. Variação de propriedades indicativas da tensão crescimento em função da posição na árvore e da intensidade de desbaste. Piracicaba, 2000. 90p. Dissertação (Mestrado) - Escola Superior de Agricultura "Luiz de Queiroz", Universidade de São Paulo. 
LOPES, G. A. Qualidade da madeira de Eucalyptus saligna Smith, de Itatinga, associada aos padrões de casca apresentados pela população. Piracicaba, 2000. 74p. Dissertação (Mestrado) - Escola Superior de Agricultura "Luiz de Queiroz", Universidade de São Paulo.

LÓPEZ, C. R. Variação fenotípica e genética em clones de Eucalyptus urophylla S. T. Blake da ilha Flores. Piracicaba, 1992. 101p. Dissertação (Mestrado) - Escola Superior de Agricultura “Luiz de Queiroz”, Universidade de São Paulo.

LUENGO MENDONZA, I. E. Industrialización de eucalipto y pino en Chile. In: SEMINÁRIO SOBRE PROCESSAMENTO E UTILIZAÇÃO DE MADEIRAS DE REFLORESTAMENTO, 4., Curitiba, 1996. Anais. Curitiba: ABPM, 1996. p.59-69

LUZ, H. F. Comparação de progênies de populações naturais e raças locais de Eucalyptus urophylla S. T. Blake. Piracicaba, 1997. 191p. Dissertação (Mestrado) Escola Superior de Agricultura “Luiz de Queiroz”, Universidade de São Paulo.

MALAN, F. S. The control of end splitting in saw logs: A short literature review. South African Forestry Journal, v. 109, p.14-18, 1979.

MALAN, F. S. Studies on the phenotypic variation in growth stresses intensity and its association with tree and wood properties of South African grown Eucalyptus grandis. Stellenbosch, 1984. 272p. Thesis (Doctor) - University of Stellenbosch.

MALAN, F. S. Relatoinships between growth stress and some tree characteristics in South African grown Eucalypts hybrids. South African Forestry Journal, v. 144, p.43-46, 1988.

MALAN, F. S. The wood properties and sawn board quality of the Eucalyptus grandis $\mathrm{X}$ E. urophylla hybrid. South African Forestry Journal, v. 188, p.29-35, 2000. 
MALAN, F. S.; VERRYN, S. D. Effect of genotype-by-environment interaction on the wood properties and qualities of four-year-old E. grandis hybrids. South African Forestry Journal, v. 176, p.47-53, 1996.

MARTIN, B.; COSSALTER, C. Les Eucalyptus des Iles de la Sonde. Bois et Forêts des Tropiques, n. 163, p.3-25, Set/Out. 1975a.

MARTIN, B.; COSSALTER, C. Les Eucalyptus des Iles de la Sonde. Bois et Forêts des Tropiques, n. 164, p.3-14, Nov/Dez. 1975b.

MARTIN, B.; COSSALTER, C. Les Eucalyptus des Iles de la Sonde. Bois et Forêts des Tropiques, n. 165, p.3-20, Jan/Fev. 1976a.

MARTIN, B.; COSSALTER, C. Les Eucalyptus des Iles de la Sonde. Bois et Forêts des Tropiques, n. 166, p.3-22, Mar/Fev. 1976b.

Mc KIMM, R. J. Characteristics of the wood of young fast-grown trees of Eucalyptus nitens Maiden with special reference to provenance variation. I Variation in growth, strain and density associated with provenance. Australia Forest Research, v. 15, n. 2, p.207-218, 1985 .

MELLO, G. R. Processamento mecânico da madeira. Piracicaba: ESALQ/DS, 1978. $88 \mathrm{p}$.

MENDES, A. P. Resistência da madeira ao cisalhamento. São Carlos, 1984. 122p. Dissertação (Mestrado) - Escola de Engenharia de São Carlos, Universidade de São Paulo. 
MIRANDA, M. J. A. C. Estudo da influência do espaçamento de plantio de Eucalyptus saligna Smith no rendimento em madeira serrada, nas condições verde e seca. Piracicaba, 1997. 177p. Dissertação (Mestrado) - Escola Superior de Agricultura "Luiz de Queiroz", Universidade de São Paulo.

MONTEIRO, L. V. Anatomia, identificação e usos de trinta e uma espécies de madeiras comercializadas no estado do Maranhão, Brasil. Piracicaba, 1996. 200p. Dissertação (Mestrado) - Escola Superior de Agricultura "Luiz de Queiroz", Universidade de São Paulo.

MORA, A. L.; GARCIA, C. H. A cultura do eucalipto no Brasil. São Paulo: SBS, 2000. 111p.

MORI, E. S.; KAGEYAMA, P. Y.; FERREIRA, M. Variação genética e interação progênies x locais em Eucalyptus urophylla. IPEF, n. 39, p.53-63, 1988.

MOURA, V. P. G. Resultado de pesquisa com várias procedências de Eucalyptus urophylla $\mathrm{S} \mathrm{T}$. Blake, no centro-leste do Brasil. Boletim de Pesquisa EMBRAPA/CPAC, n. 3, p.1-22, 1981.

NASCIMENTO, C. C. Variabilidade da densidade básica e de propriedades mecânicas de madeiras da Amazônia. Piracicaba, 1993. 119p. Dissertação (Mestrado) - Escola Superior de Agricultura "Luiz de Queiroz", Universidade de São Paulo.

NICHOLSON, J. E. Growth stresses differences in Eucalyptus. Forest Science, v. 19, n. 3, p.169-174, 1973.

NICHOLSON, J. E.; HILLIS, W. E.; DIRCHBURNE, N. Some tree growth - wood property relationships of eucalypts. Canadian Journal of Forest Research, v. 5, n. 3, p.424-432, 1975. 
OLIVEIRA, J. T. S. Caracterização da madeira de eucalipto para a construção civil. São Paulo, 1997. 447 p. 2V. Tese (Doutorado) - Escola de Engenharia de São Paulo, Universidade de São Paulo.

PANSHIN, A. J.; ZEEUW, C. Textbook of wood technology. 3.ed. New York: Mc Graw-Hill Book, 1970. 705p. v.1.

PASZTOR, Y. P. C.; ETTORI, L. C.; ZANATO, A. C. S.; MORAIS, E. Teste internacional de procedências de Eucalyptus urophylla $\mathrm{S}$. T. Blake. In: CONGRESSO FLORESTAL BRASILEIRO, 6., Campos do Jordão, 1990. Anais. São Paulo: SBS/SBEF, 1990. v. 3, p.421-425.

PENFOLD, A. R.; WILLIS, J. L. The Eucalypts. Londres: Leonard Hill, 1961. 550p.

PINTO JUNIOR, J. E. Variabilidade genética em progênies de uma população de Eucalyptus urophylla S T. Blake da Ilha de Flores - Indonésia. Piracicaba, 1984. 166p. Dissertação (Mestrado) - Escola Superior de Agricultura "Luiz de Queiroz", Universidade de São Paulo.

PINYOPUSARERK, K.; GUNN B. V.; WILLIANS, E. R.; PRYOR, L. D. Comparative geographical variation in seedling morphology of three closely related red mahoganies, Eucalyptus urophylla, E. pellita and E. scias. Australian Journal of Botany, v. 41, n. 1, p.23-34, 1993.

PRYOR, L. D.; JOHNSON, L. A. S. A classification of the Eucalyptus. Canberra: The Australian National University. 1971. 112 p.

PRYOR, L. D.; WILLIAMS, E. R.; GUNN, B. V. A morphometric analysis of Eucalyptus urophylla and related taxa with descriptions of two new species. Australian Systematic Botany, v. 8, p.57-70, 1995. 
PURNELL, R. C. Variation in wood properties of Eucalyptus nitens in a Provenance trial on the Eastern Transvaal Highveld in South Africa. South African Forestry Journal, v. 144, p.10-22, 1988.

ROCHA, M. P. Eucalyptus grandis Hill ex Maiden e Eucalyptus dunnii Maiden como fontes de matéria prima para serrarias. Curitiba, 2000. 184p. Tese (Doutorado) Universidade Federal do Paraná.

SALES, A. Característica de resistência mecânica de espécies de eucalipto do Estado de São Paulo. São Carlos, 1991. 204p. Dissertação (Mestrado) - Escola de Engenharia de São Carlos, Universidade de São Paulo.

SANCHES ACOSTA, M. Experiência argentina en el uso de la madera de eucalipto. In: SEMINÁRIO INTERNACIONAL DE UTILIZAÇÃO DA MADEIRA DE EUCALIPTO PARA SERRARIA, São Paulo, 1995. Anais. Piracicaba: IPEF/IPT, 1995. p.74-91.

SANCHES ACOSTA, M. Estado de la tecnologia en usos no tradicionales de la madera de eucalipto en el mercosur y otros paises. In: SEMINÁRIO INTERNACIONAL SOBRE PRODUTOS SÓLIDOS DA MADEIRA DE ALTA TECNOLOGIA, 1, E ENCONTRO SOBRE TECNOLOGIAS APROPRIADAS DE DESDOBRO, SECAGEM E UTILIZAÇÃO DA MADEIRA DE EUCALIPTO, 1., Viçosa, 1998. Anais. Viçosa: SIF/UFV/DEF, 1998. p.82-105.

SAS Institute. SAS / STAT user's guide: version 6. 4.ed., Cary, NC: SAS Institute Inc., 1990. 1022p. 
SANTOS, P. E. T.; MORI, E. S.; MORAES, M. L. T. Potencial para programas de melhoramento, estimativas de parâmetros genéticos e interação progênies x locais em populações de Eucalyptus urophylla S .T. Blake. IPEF, v. 43/44, p.11-19, 1990.

SCANAVACA JUNIOR, L.; GARCIA, C. H.; GOMES, F. S. Comportamento de procedências/progênies de Eucalyptus urophylla S. T. Blake na região do Jari. In: CONGRESSO FLORESTAL PANAMERICANO, 1, CONGRESSO FLORESTAL BRASILEIRO, 7., Curitiba, 1993. Anais. São Paulo: SBS/SBEF, 1993. v. 3. p.104-106.

SCHACHT, L. Variação de caracteres e suas implicações para o melhoramento genético da madeira serrada em Eucalyptus urophylla. Piracicaba, 1998. 61p. Dissertação (Mestrado) - Escola Superior de Agricultura "Luiz de Queiroz", Universidade de São Paulo.

STEELE, P. H. Factors determining lumber recovery in sawmilling USDA. Forest Service FPL General Technical Report, n. 34, p.1-8, 1984.

TURBULL, J.; BROOKER, I. Eucalyptus urophylla S. T. Blake Timor Mountain Gum. SCIRO Division of Forest Research. Forest Tree Series, n. 214. 1978. 4p.

VAN WYK, G. Genetic improvement of timber yield and wood quality in Eucalyptus grandis (Hill) Maiden. South African Forestry Journal, v. 153, p.1-11, 1990.

VENCOVSKY, R.; BARRIGA, P. Genética biométrica no fitomelhoramento. Ribeirão Preto: Sociedade Brasileira de Genética, 1992. 496 p.

VIEIRA, F. S.; BUCSAN, B. Ocorrências naturais de Eucalyptus urophylla na Indonésia. Silvicultura, n. 14, p. 359-361, 1980. 
VILLIERS, A. M. Utilization problems with some eucalypts in South Africa. In: IINTENATIONAL UNION OF FORESTRY RESEARCH ORGANIZATIONS, 5., Pretoria, 1973. Proceedings. Pretoria: IUFRO, 1973. v.2, p.238-255.

VITAL, B. R.; TRUGILHO, P. F. Variação dimensional e uso da madeira de Eucalyptus. Informe Agropecuário, v. 18, n. 186, p.57-61, 1997.

WADE, M. W.; BUllard, S. H.; STEELE, P. H.; ARAMAN, P. A. Estimating hardwood sawmill conversion efficiency based on sawing machine and log characteristics. Forestry Products Journal, v. 42, n. 11/12, p.21-26, 1992.

WATAI, L. T. Substituição de espécies de madeiras nativas por madeiras de reflorestamento. In: CONGRESSO FLORESTAL BRASILEIRO, 6., Campos do Jordão, 1990. Anais. São Paulo: SBS/SBEF, 1990. v. 1, p.131-133.

WENCELIUS, F. Eucalyptus urophylla na Costa do Marfim. Silvicultura, v. 8, n. 31, p.515-518, 1983.

WILKINS, A. P. Nature and origin of growth stresses in trees. Australian Forestry, v. 49, n. 1, p.56-62, 1986.

WILSON, P. J. Splitting studies on logs of Eucalyptus macarthurii, E. elata, and E. radiata. Annual Report Institute for Commercial Forestry Research, p.135-142, 1985. 